\author{
UNIVERSIDADE DE SÃO PAULO \\ ESCOLA DE ENFERMAGEM DE RIBEIRÃO PRETO
}

SOBRECARGA VIVENCIADA POR CUIDADORES DE IDOSOS NA COMUNIDADE

Aline Cristina Martins Gratão

Ribeirão Preto 


\section{SOBRECARGA VIVENCIADA POR CUIDADORES DE IDOSOS NA COMUNIDADE}

Tese apresentada à Escola de Enfermagem de Ribeirão Preto da Universidade de São Paulo para obtenção do título de Doutor em Ciências.

Área de Concentração: Enfermagem Fundamental. Linha de pesquisa: Saúde do idoso.

Orientadora: Profa. Dra. Rosalina Ap. Partezani Rodrigues

Ribeirão Preto 


\section{FICHA CATALOGRÁFICA}

AUTORIZO A REPRODUÇÃO E DIVULGAÇÃO TOTAL OU PARCIAL DESTE TRABALHO, POR QUALQUER MEIO CONVENCIONAL OU ELETRÔNICO, PARA FINS DE ESTUDO E PESQUISA, DESDE QUE CITADA A FONTE.

Catalogação da Publicação

Serviço de Documentação da Enfermagem

Escola de Enfermagem de Ribeirão Preto da Universidade de São Paulo

Gratão, Aline Cristina Martins

Sobrecarga vivenciada por cuidadores de idosos na comunidade. Ribeirão Preto, 2010.

160 p.: il.; $30 \mathrm{~cm}$

Tese de Doutorado, apresentada à Escola de Enfermagem de Ribeirão Preto/USP. Área de concentração: Enfermagem Fundamental.

Orientador: Rodrigues, Rosalina Aparecida Partezani

1. Cuidador familiar. 2. Sobrecarga. 3. Idosos.

4. Escala de sobrecarga de Zarit. 


\section{FOLHA DE APROVAÇÃO}

Aline Cristina Martins Gratão

Sobrecarga vivenciada por cuidadores de idosos na comunidade

Tese apresentada à Escola de Enfermagem de Ribeirão Preto da Universidade de São Paulo para obtenção do título de Doutor em Ciências.

Área de Concentração: Enfermagem Fundamental.

Aprovado em:

\section{BANCA EXAMINADORA}

Prof. Dr.:

Instituição: Assinatura:

Prof. Dr.:

Instituição: Assinatura:

Prof. Dr.:

Instituição: Assinatura:

Prof. Dr.:

Instituição: Assinatura:

Prof. Dr.: Instituição: Assinatura: 


\section{AGRADECMMENTOS}

Agradeça.

Em primeira lugar, a Deus, por ter me dada a vida e oportunidade para sequir cam sacide enfrentanda as abstáculas e desafias encontrados em men caminho.

Aos mens pais. Joãa Alberta e Maria Cristina, e a men noiva Leandra. que faram a alicerce desta conquista, pelas araçäs. pela apoia integral, e incondicional cam muita amor e carinho. supartanda por muitas vezes as momentos de ausência, cansaça e impaciência aa longa desta trajetória de estuda.

À professara Dra. Rasalina Aparecida Partezani Radrigues, pela dedicaçäa, arientaçãa e amizade, par confiar em meu patencial, mastrando sempre cam carinha sua competencia, respansabilidade e profissionalisma.

Aos idosos e seus cuidadores que me receberam em suas casas dispostos a colaborar com esta pesquisa.

À minha sogra Rita e a meu sogra Nenê. que com amor, carinha e respeita me proparcionaram apoia. confianca e me dispanibilizaram a seu lar para que en finalizasse este trabalho.

Aa professor Dr. Vanderlei José Haas, pela sua competência. profissionalisma, atençãa e paciência na tratamenta dos dados.

Aa professar Dr. Francisca de Assis Carvalha da Vale, pela auxilia. aprendizado e incentiva os quais muito contribuiram para a meu trabalho. 
À professora Dra. Sueli Marques, pela auxilia, atençãa, dedicaçãa e profissionalisma.

À Edma, pela paciência, carinho, compreensãa, pela disponibilidade em sempre querer ajudar.

Aos meus irmãas Alberta e Adriana, pela amor e alegria que sempre me depasitaram.

As amigas Luana e Carina, uma canvivencia impartante, que sempre estiveram aa meu lado torcenda. incentivanda meu trabalho e colaboranda para men crescimenta pessoal e profissional.

As pessoas que colaboraram, cada um a sua maneira, para a realizaçãa deste trabalha, nas sugestoes, coleta dos dados, na digitaçãa da banca de dados. Thais. Cibele. Clarice, Talita. Bärbara. Fäbia, Elizandra. Suzele, Idiane. Cheila e Ana Eugenia.

Agradeç an CMP q pela passibilidade de realizar a presente pesquisa, cam a concessãa da balsa de estuda.

Enfim, a cada um que, de alguma farma, contribuiu incentiuanda meu trabalho e que faz parte da minha vida em momentos distintos, cada um a seu moda, tanta direta coma indiretamente, ofereceu auxilia para a construçãa desta pesquisa, muita obrigada. 
... Zuera pader ter a liberdade de dizer a que sinto a uma pessoa, de pader dizer a alguém a quanto ela é especial e impartante pra mim. sem ter de me preacupar com terceiros... Sem carrer a risca de ferir uma an mais pessoas cam esse sentimenta.

2uera, um dia, pader dizer às pessoas que nada fai em vãa... Zue a amor existe, que vale a pena se doar às amizades a as pessoas, que a vida é bela sim. e que eu sempre dei a melhor de mim... e que ualeu a pena... 


\section{RESUMO}

GRATÃO, A. C. M. Sobrecarga vivenciada por cuidadores de idosos na comunidade. 2010. 160f. Tese (Doutorado) - Escola de Enfermagem de Ribeirão Preto, Universidade de São Paulo, Ribeirão Preto, 2010.

O envelhecimento populacional é um dos maiores triunfos da humanidade, porém um dos grandes desafios para os gestores de saúde. Associado ao processo do envelhecimento, o declínio da capacidade física e cognitiva pode ocorrer, levando o idoso à perda progressiva da autonomia e independência. Assim, a família é quem, geralmente, assume a responsabilidade do cuidado de forma despreparada, contribuindo para quadros depressivos, de ansiedade e de sobrecarga no cuidador. A falta de conhecimento sobre o idoso, na comunidade de Ribeirão Preto, bem como da sobrecarga da atividade de prestar cuidado no domicílio perfazem a relevância deste estudo. Os objetivos foram identificar e caracterizar idosos na comunidade de Ribeirão Preto, avaliar a função cognitiva e a independência funcional dos idosos e a sua relação com sexo, idade, estado civil e escolaridade e caracterizar os cuidadores familiares bem como descrever a sobrecarga e o desconforto emocional dos mesmos em relação à atividade do cuidar. Este representa um estudo epidemiológico, descritivo e transversal com idosos de 65 anos ou mais de idade e seus respectivos cuidadores, ambos os sexos, residentes na área urbana de Ribeirão Preto, São Paulo. Foram utilizados os seguintes instrumentos: Caracterização do idoso; Miniexame do Estado Mental (MEEM); Medida da Independência Funcional (MIF); Instrumento para Caracterização do Cuidador; Escala de Sobrecarga de Zarit; Self Reporting Questionnaire (SRQ-20). Do total de 574 idosos, que se caracterizaram pela média de 76,6 anos de idade, $67,8 \%$ do sexo feminino, 54,7\% com baixa escolaridade, $19,7 \%$ com deficit cognitivo e $15,7 \%$ com algum grau de dependência funcional, $21,6 \%$ possuíam cuidadores. Dentre os 124 cuidadores estudados, $85,6 \%$ eram do sexo feminino, com média de 56,5 anos de idade, $37,9 \%$ com baixa escolaridade, $90,3 \%$ eram familiares (filhas e esposas principalmente), $79,8 \%$ residiam com o idoso, utilizando, em média, 12,4 horas diárias para o cuidar. Os resultados evidenciaram que os cuidadores apresentam leve a moderada sobrecarga. Após a regressão linear múltipla, a dependência funcional do idoso e as características dos cuidadores como sexo feminino e tempo em horas semanais para o cuidado diário foram os preditores da sobrecarga $(p<0,05)$. Encontrou-se, também, que a sobrecarga é fator de risco para desconforto emocional $(p<0,05)$. Sugerem-se outros estudos na área e intervenções com os cuidadores que residem na comunidade, utilizando instrumentos de avaliação, validados para a população brasileira. As pesquisas realizadas nessa área enfocam, na maioria das vezes, o cuidador de idoso com demência, o que trará não só resultados para os cuidadores como também para os pacientes, pois sem sobrecarga e desconfortos o cuidador estará renovado para cuidar.

Palavras-chave: Cuidadores. Familiares. Sobrecarga. Idoso. 


\begin{abstract}
GRATÃO, A. C. M. Burden of family caregivers of elderly people in the community. 2010. 160h. Dissertation (Doctoral) - University of São Paulo at Ribeirão Preto, College of Nursing, Ribeirão Preto, 2010.

Population aging represents one of the major advancements of humanity but it is also a great challenge to health managers. Decreased physical and cognitive abilities are associated to the aging process and lead to elderly individuals' progressive loss of autonomy and independence. As a consequence, family members assume the responsibility to provide care with no previous preparedness, which leads caregivers to develop depressive conditions such as anxiety and burden. The lack of knowledge concerning elderly individuals in the community of Ribeirão Preto, SP, Brazil and burden that results from delivering care at home are the topic of this study. It identifies and characterizes elderly individuals in the community of Ribeirão Preto, evaluates their cognitive function and functional independence and relates these variables with gender, age, marital status, and schooling. Family caregivers are also characterized, while burden and emotional discomfort is evaluated in relation to the care activity. This epidemiological, descriptive and transversal study was carried out with 65 years old or older individuals and their respective caregivers, both genders, residents in the urban area of Ribeirão Preto, SP, Brazil. The following instruments were used: instrument to characterize the elderly individuals; Mini-mental State Examination (MMSE); Functional Independence Measure (FIM); instrument to characterize caregivers; Zarit Burden Scale; Self-Reporting Questionnaire (SRQ-20). The total of 574 elderly individuals were 76.6 years old in average, $67.8 \%$ were female, $54.7 \%$ had low levels of schooling, $19.7 \%$ had low cognitive performance and $15.7 \%$ some degree of functional dependence, while only $21.6 \%$ had caregivers. Among the 124 caregivers, $85.6 \%$ were female and 56.5 years old in average, $37.9 \%$ had low levels of schooling, $90.3 \%$ were family members (mainly daughters and wives), $79.8 \%$ lived with the elderly individual and spent in average 12.4 hours daily. The results evidenced that the caregivers present low to moderate burden. Multiple linear regression revealed that functional dependence of elderly individuals and caregivers' characteristics such as being females and time of weekly hours spent in daily care were predictors of burden $(p<0.05)$. Burden is also a risk factor for psychiatric morbidity $(p<0.05)$. We suggest further studies in the field and investigations with caregivers in the community using evaluation instruments validated for the Brazilian population since research in the field usually focuses on caregivers of elderly individuals with dementia. These actions are expected to help caregivers and patients, since with no burden and discomfort, caregivers will be renovated to provide care.
\end{abstract}

Key words: Family. Caregivers. Burden. Elderly. 


\section{RESUMEN}

GRATÃO, A. C. M. Sobrecarga del cuidador familiar de ancianos en la comunidad. 2010. 160h. Tesis (Doctorado) - Escuela de Enfermería de Ribeirão Preto, Universidad de São Paulo, Ribeirão Preto, 2010.

El envejecimiento poblacional representa uno de los mayores triunfos de la humanidad, pero es uno de los grandes retos para los gestores de salud. Asociados al proceso de envejecimiento pueden estar los deterioros en la capacidad física y cognitiva, llevando el anciano a la pérdida progresiva de autonomía e independencia. Así, la familia es quién generalmente asume la responsabilidad del cuidado de forma no preparada, contribuyendo a cuadros depresivos, ansiedad y sobrecarga en el cuidador. La falta de conocimiento sobre el cuidado en ancianos en la comunidad de Ribeirão Preto, además de la sobrecarga de la actividad de prestar cuidado en domicilio fundamenta la relevancia de este estudio. Los objetivos fueron identificar y caracterizar ancianos en la comunidad de Ribeirão Preto, evaluar la función cognitiva y la independencia funcional de los ancianos y su relación con sexo, edad, estado civil y escolaridad; caracterizar a los cuidadores familiares y describir su sobrecarga e incomodidad emocional respecto a la actividad de cuidar. Este representa un estudio epidemiológico, descriptivo y transversal con ancianos de 65 años de edad o más y sus respectivos cuidadores, de ambos sexos, residentes en el área urbana de Ribeirão Preto, São Paulo. Fueron utilizados los instrumentos de: instrumento para caracterización del anciano; Mini-Examen del Estado Mental (MEEM); Medida da Independencia Funcional (MIF); Instrumento para Caracterización del Cuidador; Escala de Sobrecarga de Zarit; Self Reporting Questionnaire (SRQ-20). Del total de 574 ancianos, caracterizados con la edad promedia de 76,6 años, $67,8 \%$ del sexo femenino, $54,7 \%$ con escolaridad baja, $19,7 \%$ con desempeño cognitivo bajo y $15,7 \%$ con algún grado de dependencia funcional, sólo el $21,6 \%$ tenía cuidador. Entre los 124 cuidadores, el $85,6 \%$ era del sexo femenino, con edad promedia de 56,5 años, $37,9 \%$ con escolaridad baja, $90,3 \%$ era familiar (principalmente hijas y esposas), $79,8 \%$ vivía con el anciano, utilizando en promedio 12,4 horas diaria para el cuidar. Los resultados evidenciaron que los cuidadores presentan sobrecarga leve a moderada. Tras la regresión linear múltiple, la dependencia funcional del anciano y características de los cuidadores, como sexo femenino y tiempo en horas semanales para el cuidado diario fueron los factores predictivos de la sobrecarga $(p<0,05)$. También fue encontrado que la sobrecarga es factor de riesgo para morbilidad psiquiátrica $(p<0,05)$. Más estudios en el área son sugeridos, además de trabajos con los cuidadores que residen en la comunidad utilizando instrumentos de evaluación validados para la población brasileña, ya que las investigaciones realizadas en esa área enfocan, en la mayoría de las veces, al cuidador del anciano con demencia, lo que traerá resultados no sólo para los cuidadores si no también para los pacientes, pues sin sobrecarga e incomodidades el cuidador estará renovado para cuidar.

Palabras-clave: Cuidadores. Familiares. Sobrecarga. Anciano 


\section{LISTA DE TABELAS}

Tabela 1 População de idosos do município de Ribeirão Preto, estado de São Paulo, por idade e sexo, 2004. Ribeirão Preto, 2008.

Tabela 2 Distribuição da amostra, segundo sexo e faixa etária dos idosos (acima de 65 anos) em Ribeirão Preto, no ano de 2004. Ribeirão Preto, 2008.

Tabela 3 Distribuição dos idosos que vivem na comunidade de Ribeirão Preto, segundo faixa etária, sexo, estado conjugal, escolaridade, renda, com quem mora e desempenho cognitivo, relacionados ao fator sem/com cuidador. Ribeirão Preto, 2010.

Tabela 4 Distribuição das médias do MEEM, segundo grau de escolaridade dos idosos que vivem na comunidade de Ribeirão Preto e os pontos de corte do MEEM segundo Bertolucci et al. (1994) e Brucki et al. (2003). Ribeirão Preto, 2010

Tabela 5 Distribuição dos idosos, segundo a escolaridade, relacionada ao desempenho no MEEM e sexo do idoso. Ribeirão Preto, 2010.

Tabela 6 Características dos idosos, segundo faixa etária, categorias da MIF, situação conjugal e "com quem mora" relacionadas ao desempenho cognitivo. Ribeirão Preto, 2010.

Tabela 7 Distribuição das médias da MIF Global, MIF Motora e MIF Cognitiva relacionada ao sexo dos idosos. Ribeirão Preto, 2010.

Tabela 8 Coeficientes de correlação da MIF com variáveis sociodemográficas, idade, escolaridade, renda familiar dos idosos.

Ribeirão Preto, 2010. 73

Tabela 9 Distribuição dos idosos, segundo categorias da MIF, relacionada ao desempenho cognitivo e ao sexo dos idosos. Ribeirão Preto, 2010...73

Tabela 10 Distribuição da média e desvio-padrão dos domínios da MIF relacionada ao desempenho cognitivo. Ribeirão Preto, 2010.

Tabela 11 Distribuição da média, desvio-padrão da MIF e do MEEM, relacionada ao fator sem/com cuidador. Ribeirão Preto, 2010.

Tabela 12 Distribuição dos cuidadores dos idosos, segundo faixa etária, estado conjugal, escolaridade, parentesco, se vive com o idoso, conhecimento sobre o cuidar relacionado ao sexo do cuidador. 
Tabela 13 Distribuição das respostas da Escala de Sobrecarga de Zarit dos cuidadores que vivem na comunidade de Ribeirão Preto, Ribeirão Preto, 2010.

Tabela 14 Distribuição das respostas da Escala SRQ dos cuidadores que vivem na comunidade de Ribeirão Preto. Ribeirão Preto, 2010.

Tabela 15 Distribuição das características de idosos, segundo as médias de sobrecarga e de desconforto emocional. Ribeirão Preto, 2010.

Tabela 16 Correlação de Pearson referente à sobrecarga e ao desconforto emocional relacionado à idade, às horas e aos dias de cuidado. Ribeirão Preto, 2010.

Tabela 17 Distribuição das médias da idade do cuidador e de valores do SRQ relacionada às categorias ordinais de sobrecarga. Ribeirão Preto, 2010

Tabela 18 Resultado da análise de regressão múltipla, tendo como desfecho a Escala de Sobrecarga de Zarit com as variáveis explicativas do cuidador consideradas. Ribeirão Preto, 2010.

Tabela 19 Distribuição das características sociodemográficas dos idosos relacionada às médias de sobrecarga e de desconforto emocional do cuidador. Ribeirão Preto, 2010.

Tabela 20 Distribuição da correlação de Pearson entre sobrecarga e desconforto emocional do cuidador relacionada à idade, aos anos de escolaridade, ao escore total da MIF e MEEM dos idosos que vivem na comunidade de Ribeirão Preto. Ribeirão Preto, 2010.

Tabela 21 Distribuição das médias da idade do idoso, MEEM, MIF Global, MIF Motora e MIF Cognitiva relacionada às categorias ordinais da Escala de Sobrecarga de Zarit. Ribeirão Preto, 2010

Tabela 22 Resultado da análise de regressão linear, tendo como desfecho a Escala de Sobrecarga de Zarit e a SRQ com as variáveis explicativas do idoso consideradas. Ribeirão Preto, 2010 .

Tabela 23 Valores médios das dimensões da Escala de Sobrecarga de Zarit, segundo os domínios da MIF. Ribeirão Preto, 2010

Tabela 24 Distribuição das médias das respostas dos cuidadores, segundo a ajuda que recebem para auxílio nas atividades da vida diária do idoso. Ribeirão Preto, 2010. 


\section{LISTA DE SIGLAS}

\begin{tabular}{ll} 
AVDS & Atividades da Vida Diária \\
AVE & Acidente Vascular Encefálico \\
AAVDs & Atividades Avançadas da Vida Diária \\
ABVDs & Atividades Básicas da Vida Diária \\
AIVDs & Atividades Instrumentais da Vida Diária \\
CBI & Caregiver Burden Inventory \\
CBS & Caregiver Burden Scale \\
CCL & Comprometimento Cognitivo Leve \\
CID & Classificação Internacional de Doenças \\
CRA & Caregiver Reaction Assessment \\
CSI & Caregiver Strain Index \\
DA & Doença de Alzheimer \\
DCNT & Doenças Crônicas Não Transmissíveis \\
DM & Diabetes Mellitus \\
EUA & Estados Unidos da América \\
FBIS & Family Burden Interview Schedule \\
HAS & Hipertensão Arterial Sistêmica \\
HCFMRP & Hospital das Clínicas da Faculdade de Medicina de Ribeirão \\
IBGE & Preto \\
MEEM & Instituto Brasileiro de Geografia e Estatística \\
MIF & Miniexame do Estado Mental \\
MPAS & Medida de Independência Funcional \\
OMS & Ministério da Previdência e Assistência Social \\
OPAS & Organização Mundial da Saúde \\
PNAD & Organização Pan-Americana de Saúde \\
SM & Pesquisa Nacional por Amostra de Domicílio \\
SPSS & Salário Mínimo \\
SRQ & Statistical Package for the Social Sciences \\
SUS & Self Reporting Questionnaire \\
WHO & Sistema Único de Saúde \\
& World Organization \\
\hline
\end{tabular}




\section{SUMÁRIO}

1. INTRODUÇÃO

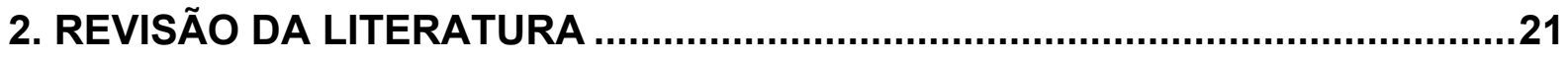

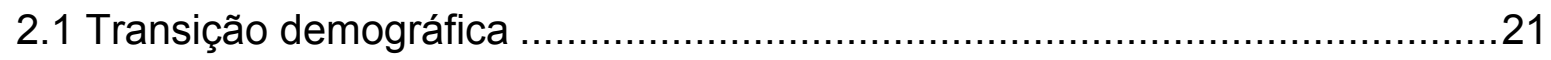

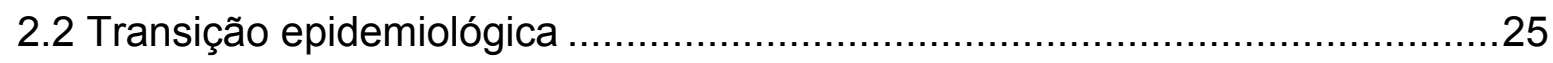

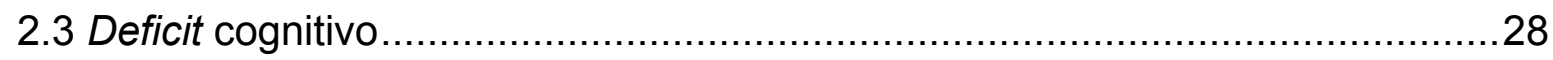

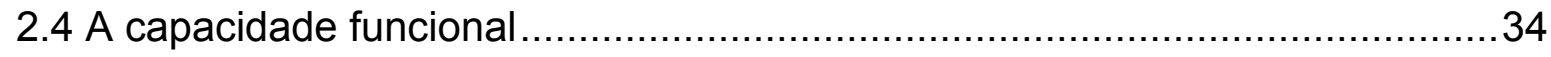

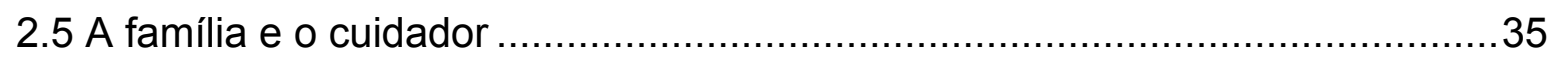

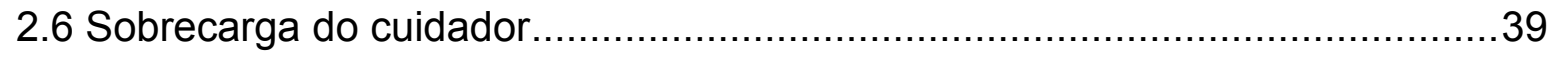

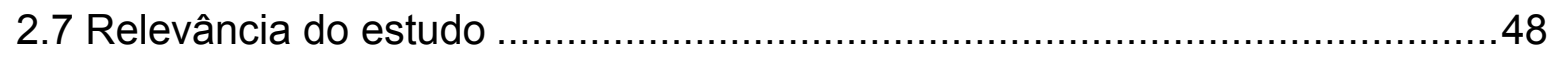

3. OBJETIVOS

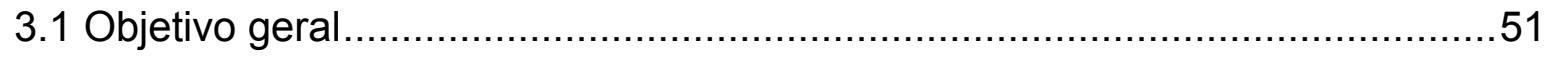

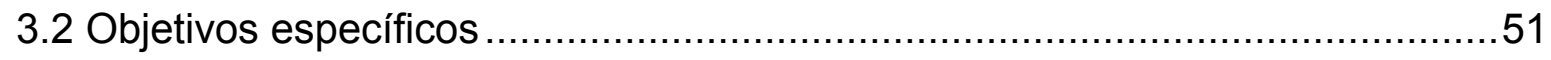

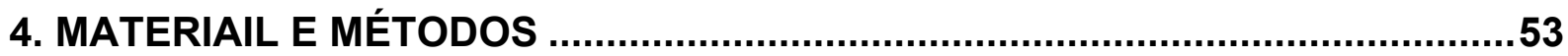

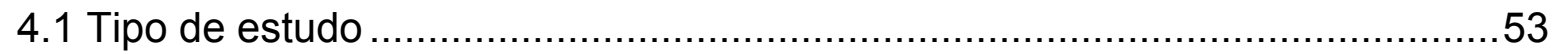

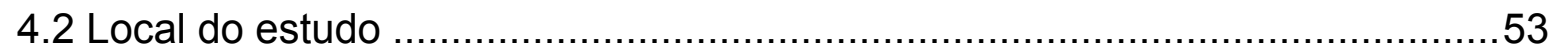

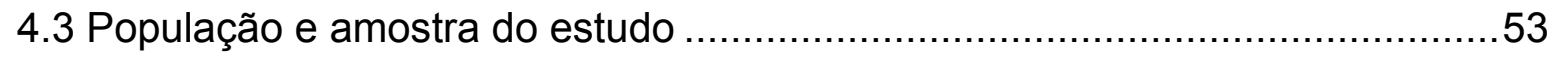

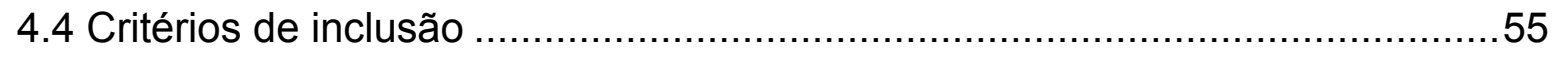

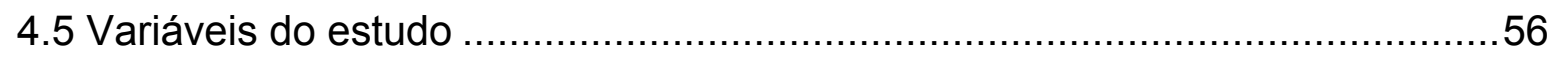

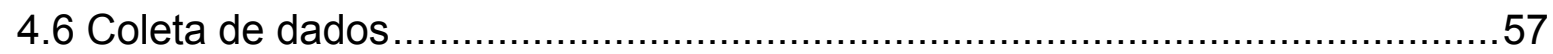

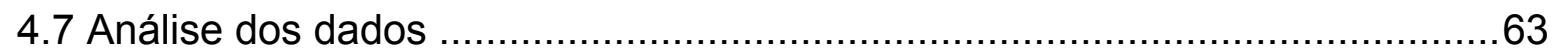

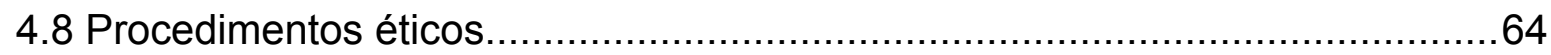

5. RESULTADOS

5.1 Características sociodemográficas dos idosos que vivem na comunidade de Ribeirão Preto, SP.

5.2 Avaliação do desempenho cognitivo e da capacidade funcional dos idosos que vivem na comunidade de Ribeirão Preto, SP.

5.3 Características sociodemográficas dos cuidadores de idosos que vivem na comunidade de Ribeirão Preto, SP......

5.4 Escalas utilizadas para avaliação da sobrecarga e do desconforto emocional dos cuidadores de idosos que vivem na comunidade de Ribeirão Preto, SP. 
5.5 Determinantes da sobrecarga e do desconforto emocional relacionados às características dos cuidadores de idosos que vivem na comunidade de Ribeirão Preto, SP

5.6 Determinantes da sobrecarga e do desconforto emocional relacionados às características dos idosos que vivem na comunidade de Ribeirão Preto, SP.

5.7 Determinantes da sobrecarga e do desconforto emocional relacionados à demanda dos cuidados e à necessidade de suporte informal dos cuidadores de idosos que vivem na comunidade de Ribeirão Preto, SP.

6. DISCUSSÃO

6.1. Características sociodemográficas dos idosos que vivem na comunidade de Ribeirão Preto, SP.

6.2 Avaliação do desempenho cognitivo e da capacidade funcional dos idosos que vivem na comunidade de Ribeirão Preto, SP.

6.3. Características sociodemográficas dos cuidadores de idosos que vivem na comunidade de Ribeirão Preto, SP.

6.4 Escalas de avaliação da sobrecarga e do desconforto emocional dos cuidadores de idosos que vivem na comunidade de Ribeirão Preto, SP.

6.5 Determinantes de sobrecarga e desconforto emocional relacionados às características dos cuidadores de idosos que vivem na comunidade de Ribeirão Preto, SP.

6.6 Determinantes de sobrecarga e desconforto emocional relacionados às características dos idosos que vivem na comunidade de Ribeirão Preto, SP. ....112

6.7 Determinantes de sobrecarga e de desconforto emocional relacionados à demanda dos cuidados e a necessidades de suporte informal dos cuidadores de idosos que vivem na comunidade de Ribeirão Preto, SP.

7. CONCLUSÕES

8. REFERÊNCIAS 
1. Introducãa 


\section{Intraducãa}

\section{INTRODUÇÃO ${ }^{1}$}

O envelhecimento populacional é um dos maiores triunfos da humanidade, porém um dos grandes desafios para os gestores de saúde.

De acordo com Papaleo Netto (2006), o envelhecimento é o processo normal de mudança relacionado ao tempo, podendo ocorrer modificações morfológicas, funcionais, bioquímicas e psicológicas que determinam perda da capacidade de adaptação do indivíduo ao meio ambiente, ocasionando maior vulnerabilidade e incidência de processos patológicos que terminam por levá-lo à morte. A velhice é a fase final do ciclo de vida.

A Organização Pan-Americana de Saúde (OPAS) (2003) define envelhecimento fisiológico, ou, senescência, como um processo sequencial, individual, acumulativo, irreversível, universal, não patológico, de deterioração de um organismo maduro, próprio a todos os membros de uma espécie, de maneira que o tempo o torne menos capaz de enfrentar o estresse do meio ambiente e, portanto, aumente a possibilidade de morte.

Da mesma forma, a velhice pode ser considerada uma fase da vida onde há uma alta prevalência das doenças crônicas não transmissíveis, limitações físicas, perdas cognitivas, declínio sensorial, acidentes e isolamento social (RAMOS, 2003).

A evolução e complicações do envelhecimento variam de acordo com cada indivíduo dentro da sociedade, não dependendo somente do valor biológico, mas devem-se levar, também, em consideração os valores econômicos, sociais, culturais e ambientais de cada sociedade.

A idade cronológica é um fator importante a ser considerado no envelhecimento, entretanto a mesma idade pode denotar envelhecimento distinto entre os indivíduos. Estabelecer algum tipo de corte que delimite a população idosa é difícil, mas quando essa delimitação é necessária, lança-se mão do critério cronológico arbitrário, no qual se considera idosa a pessoa de 60 anos de idade ou

\footnotetext{
${ }^{1}$ Esta tese foi revisada de acordo com a Nova Ortografia da Língua Portuguesa (1990), em vigor a partir de $1^{\circ}$ de janeiro de 2009.
} 
mais, conforme Lei Federal Brasileira n. ${ }^{\circ} 84 / 94$, discorrido no Estatuto do Idoso (BRASIL, 2003).

A Organização Mundial da Saúde estipula duas idades cronológicas do idoso: 65 anos para os países desenvolvidos e 60 anos de idade para os países em desenvolvimento (WORLD HEALTH ORGANIZATION (WHO), 1984). Estes limites clássicos como 60 ou 65 anos servem para determinar a idade de aposentadoria e auxiliar os demógrafos na comparação entre populações, quando a questão é o envelhecimento populacional.

Ao se pensar no envelhecimento, o grande desafio que se faz é alcançálo sem apresentar uma ou mais doenças que limitem sua vida diária e o torne dependente de outras pessoas. Sabe-se que, no geral, mesmo enfrentando uma ou mais afecções no decorrer dos anos vividos, a maioria dos idosos brasileiros é capaz de se autodeterminar e organizar-se sozinhos, ou seja, manter sua independência e autonomia na velhice.

Autonomia deve ser pensada como autodeterminação, liberdade pessoal, independência física, liberdade de escolha e ação, controle nas tomadas de decisão e nas atividades e comportamentos orientados à meta; a independência é, em geral, entendida como a habilidade de se executar funções relacionadas à vida diária, isto é, a capacidade de viver independentemente na comunidade com alguma ou nenhuma ajuda de outros (WHO, 2005).

Constata-se que, para os idosos saudáveis e autônomos, existem propostas da sociedade que tentam mantê-los engajados e que procuram ampliar os espaços de participação social. Tais propostas envolvem diferentes instituições e organizações sociais, nas quais os grupos de convivência ocupam um papel central.

Como o previsto em lei (BRASIL,1994), as ações em saúde do idoso devem objetivar ao máximo manter o idoso na comunidade, junto de sua família, da forma mais digna e confortável possível, porém todo esse cenário é prejudicado quando se depara com problemas que determinam a perda da autonomia e independência na população idosa, e dentre os mais devastadores estão em ênfase os problemas de saúde relacionados ao deficit cognitivo no idoso.

De acordo com Argimon e Stein (2005), o deficit cognitivo em idosos consiste em lentidão leve, generalizada e perda de precisão, progredindo conforme 
o avançar da idade, quando estes são comparados a pessoas mais jovens, e pode ser medido por testes objetivos que relacionem situações do cotidiano. Um nível educacional mais elevado, segundo esses autores, mostrou-se preventivo para o embotamento do estado mental, no decorrer do envelhecimento normal.

O deficit cognitivo é geralmente associado a doenças devastadoras na vida dos indivíduos, acarretando prejuízos no estilo de vida, na capacidade física, mental e é considerado uma das principais causas de incapacidade e dependência na velhice, requerendo altos custos e constante atenção ao longo de sua evolução, que, na maioria das vezes, é representado por um familiar cuidador (CANÇADO e HORTA, 2002).

Assumir a tarefa do cuidado digno ao idoso com deficit cognitivo tem sido dever principalmente da família, a qual, muitas vezes, não possui a adequada preparação, conhecimento ou suporte para assumir tal papel. Isto significa que embora tentem suprir a assistência usando seus próprios recursos, suas forças intrínsecas e sua autoridade de família passam a constituir um sistema informal de cuidado em que o desgaste e o estresse sobreveem, podendo afetar o bem-estar e a saúde da família como um todo (CALDAS, 2002).

A complexidade da tarefa assistencial faz com que, muitas vezes, os cuidadores envolvidos esqueçam-se deles próprios, quanto às necessidades e satisfação em viver. Sentimentos positivos e negativos, conflitos psicológicos, aflição, o medo e a insegurança são comuns ao longo de toda a evolução da doença (MENDES, 2004).

Assim, paralelo ao envelhecimento populacional no Brasil, a sociedade encontra-se de forma despreparada para um número cada vez maior de pessoas idosas, que, muitas vezes, demandam consultas, serviços, diagnósticos, remédios, internações e, principalmente, a supervisão diária intensa de seu cuidador para a prestação do cuidado.

O aumento da incidência do deficit cognitivo bem como o prejuízo da capacidade funcional constitui um importante problema de saúde pública para a população de idosos. O tema envolvendo cuidadores de idosos com essas perdas e que vivem na comunidade é escasso. Para tanto, é importante desenvolver 
pesquisas para que os profissionais da saúde sejam preparados para avaliarem de forma especial essa população que vem sofrendo esses problemas.

Diante do exposto, cabe aqui justificar a importância da pesquisa sobre a temática em questão, iniciando-se por ampla revisão da literatura sobre processo da transição demográfica no mundo e no Brasil, seguida pela transição epidemiológica, deficit cognitivo, capacidade funcional, a família e o cuidador e a sobrecarga do cuidar. 
2. Revisãa da Literatura 


\section{REVISÃO DA LITERATURA}

Este capítulo retrata os aspectos da transição demográfica e epidemiológica, do deficit cognitivo, da capacidade funcional, dos cuidadores de idosos e os problemas mais comuns enfrentados por estes.

\subsection{Transição demográfica}

A transição demográfica é, no geral, um processo de diminuição de taxas de mortalidade e natalidade, podendo ser analisada em quatro fases e três momentos fundamentais (THOMPSON, 1929).

Em um primeiro momento, passa-se de uma fase em que as taxas brutas de natalidade e de mortalidade são altas e, consequentemente, o crescimento vegetativo da população é baixo, que é a pré-transição demográfica; para uma segunda fase, quando se inicia a transição demográfica propriamente dita, em que o nível de mortalidade vivencia um processo consistente de queda, enquanto o de fecundidade ainda se mantém alto. Nesta fase, o ritmo do crescimento natural da população aumenta de maneira sustentada. Esse é o período de mais rápido crescimento demográfico, que só vai se desacelerar a partir do momento em que se iniciar o processo de declínio persistente da fecundidade, inaugurando uma fase caracterizada por incremento populacional a ritmo decrescente. Por fim, há um terceiro momento, a partir do qual já se encontram baixos os níveis, tanto de fecundidade, quanto de mortalidade, entrando-se em uma fase de pós-transição demográfica, em que o crescimento da população é muito lento, nulo, ou até negativo da população (THOMPSON, 1929).

Pode-se considerar que o período da transição demográfica mundial, caracterizada pelos países desenvolvidos, de acordo com a teoria de Thompson (1929), correspondeu ao século XVII, à fase de pré-transição demográfica, ao século XVIII, com a Revolução Industrial, a fase de transição demográfica propriamente 
dita, em meados de 1950, vivenciou a fase de incremento populacional a ritmo decrescente e por fim, no século XXI, a fase de pós-transição demográfica (BRITO, 2007).

O Brasil vivencia a transição demográfica provocada, principalmente, pela queda da fecundidade iniciada em meados dos anos de 1960 e generalizada em todas as regiões brasileiras e estratos sociais. A média brasileira reduziu-se de 5,8 filhos por mulher, em 1960, para 2,3, em 2006. O aumento da longevidade e a redução da mortalidade infantil também contribuem para esta mudança do padrão demográfico (IBGE, 2006).

Os parâmetros demográficos são calculados a partir da proporção de idosos em relação à população total. Ao se observar o crescimento populacional nos países desenvolvidos entre 1950 e 1965, por exemplo, a Europa e a América do Norte tinham uma proporção de idosos semelhante e ainda relativamente baixa, menos de 10,0\% e alcançará em 2050 cerca de $28,0 \%$ de idosos. A América do Norte atingirá uma proporção bem menor, 15\%. América Latina e Caribe e a Ásia terão em 2050 uma proporção de idosos em torno de 18,0\%, contra menos de $5 \%$ em 1950. A África, entre todas as regiões, tem a população menos envelhecida. Durante os cem anos analisados a proporção de idosos na África passará de 3,0\% para 7,0\% (Organização das Nações Unidas - ONU, 2004).

A ONU (2004) menciona que, em termos numéricos, o crescimento da população mundial aumentou nos últimos 200 anos, passando de 1 bilhão no ano de 1800 para 6,612 bilhões de indivíduos. A previsão é de que a população alcançará o crescimento máximo, 9,2 bilhões de habitantes em 2075. No caso dos países mais desenvolvidos, em 1950, o crescimento vegetativo já era bem baixo, pois já estavam na fase final da transição demográfica. Em seu conjunto, deverão alcançar crescimento negativo, após 2010 (ONU, 2004). Nos países em desenvolvimento, como o Brasil, houve aceleração no ritmo de crescimento vegetativo desde 1950. A transição demográfica dos países menos desenvolvidos provavelmente chegará, em 2050, com um ritmo de crescimento semelhante àquele observado entre os mais desenvolvidos no último quinquênio da década de noventa do século passado (CARVALHO, 2001). 
Existe previsão de que, entre os anos de 1980 e 2020, a população mundial de idosos crescerá $160 \%$, passando de 375 para 975 milhões, sendo que cerca de $80 \%$ do crescimento dessa população ocorrerá nos países em desenvolvimento. No Brasil, a previsão é de um aumento de $280 \%$, passando de 7,5 para quase 30 milhões, no período mencionado. Desta forma, o Brasil que em 1960 ocupava a $16^{a}$ posição na lista mundial dos países com as maiores populações de idosos, chegará em 2020 como o sexto colocado (KALLACHE; VERAS; RAMOS, 1987).

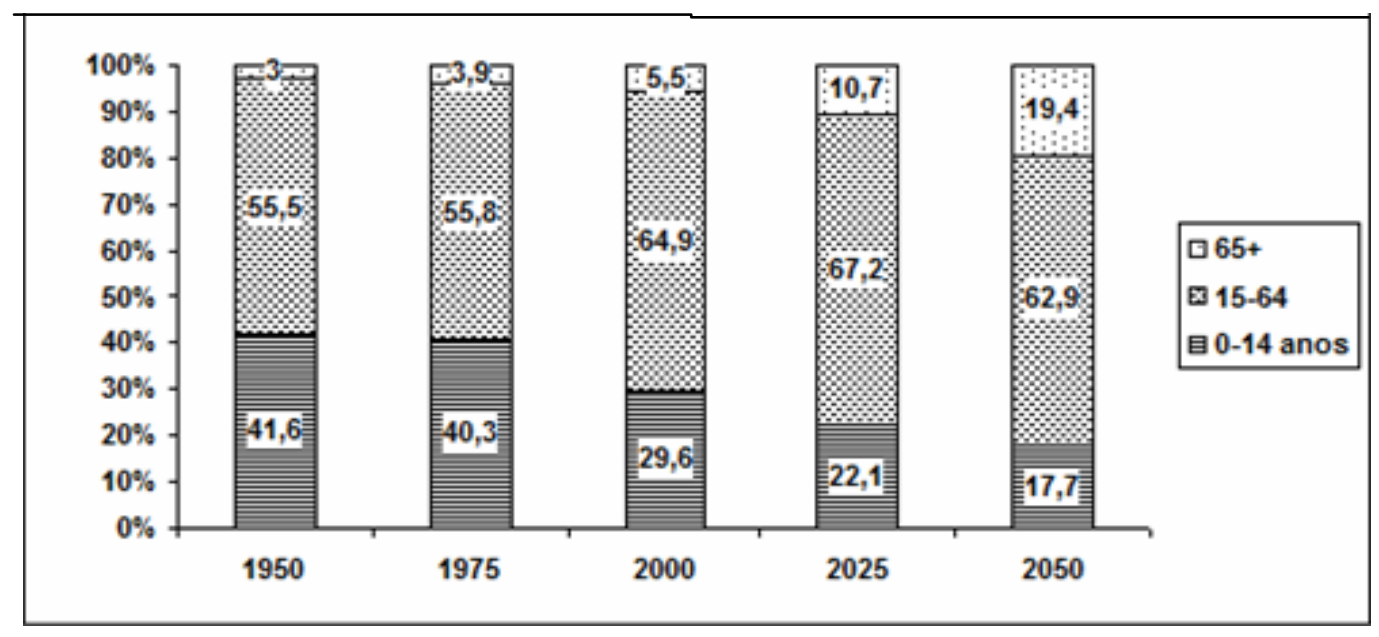

Gráfico 1: Distribuição da população brasileira, por grandes grupos etários (\%), 1950-2050.

Mantidas as tendências observadas nos parâmetros demográficos, o Brasil caminha a passos largos para o aumento da população cada vez mais envelhecida, fenômeno que, sem sombra de dúvidas, já está implicando em adequações nas políticas sociais, particularmente aquelas voltadas para atender às crescentes demandas nas áreas da saúde, previdência e assistência social. Conforme o Gráfico 1, os dados apontam que, o Brasil, nas próximas décadas, estará entre os países com mais acentuado ritmo de envelhecimento populacional. Observa-se, ainda, que em 2025, o valor do índice de crescimento populacional deverá superar em até cinco vezes aquele observado em 1975. Em 2025, para cada conjunto de 100 menores de 15 anos, haverá 46 idosos, contra 10 existentes em 


\section{Revisãa da Literatura}

1975. Por sua vez, em 2050, o número de idosos ultrapassará o de menores de 15 anos.

Entre as regiões brasileiras com maior número de idosos, destaca-se a região Sudeste com 6.732.888 (com 60 anos de idade ou mais), de acordo com o censo de 2000 do IBGE, a segunda região é representada pela Nordeste com 4.020.857 de idosos. Em termos absolutos, o município de São Paulo apresentou quase um milhão de idosos vivendo naquela capital (IBGE, 2000).

Dentre as cidades paulistas, segundo estimativa populacional do IBGE para o ano intercensitário de 2006, o número de idosos na cidade de Ribeirão Preto era de 56.743 habitantes, dos quais 31.637 possuíam de 60 a 69 anos e aqueles que tinham mais de 80 anos perfaziam um total de 7.111 habitantes (DATASUS, 2006).

Além do índice de envelhecimento, em crescimento exponencial, outro aspecto demográfico importante é o aumento da expectativa de vida. Segundo dados da Síntese de Indicadores Sociais, divulgada pelo IBGE (2008), no Brasil entre 1997 e 2007, houve acréscimo de 3,4 anos, atingindo 72,7 anos. As mulheres aumentaram em 3,3 anos a expectativa no período descrito, de 73,2 anos para 76,5 anos, enquanto os homens tiveram avanço de 3,5 anos, de 65,5 anos para 69 anos. Com isso, a população idosa de 70 anos ou mais cresceu em termos numéricos, chegando a 8,9 milhões de pessoas em 2007 , o equivalente a $4,7 \%$ da população total, enquanto os jovens até 14 anos representavam $25,4 \%$ da população.

A esperança de vida muda significativamente de acordo com a região onde ocorre o nascimento. A menor expectativa é para os nascidos na região Nordeste, em que a expectativa média é de 69,7 anos, sendo 66,2 anos para os homens e 73,4 anos para as mulheres. A maior expectativa é da região Sul, onde a média é de 74,7 anos, sendo 71,4 anos para os homens e 78,2 anos para as mulheres. Em segundo lugar encontra-se a região Sudeste, em que a esperança média de vida é de 74,1 anos, com 70,1 anos para os homens e 78,2 anos para as mulheres (IBGE, 2008). A cidade de Ribeirão Preto (SP), em 2000, apresentou uma expectativa de vida de 74,4 anos (DATASUS, 2006).

A pirâmide etária comprova visualmente o processo de envelhecimento populacional, enfatizando a transição demográfica pelo alargamento do topo da 
pirâmide comparada pelos anos de 1997 a 2007 (Figura 1), em que se verificam o grande aumento da população idosa e o estreitamento da base representada pela diminuição da população mais jovem. A mudança no topo da pirâmide demonstra o aumento da expectativa de vida.

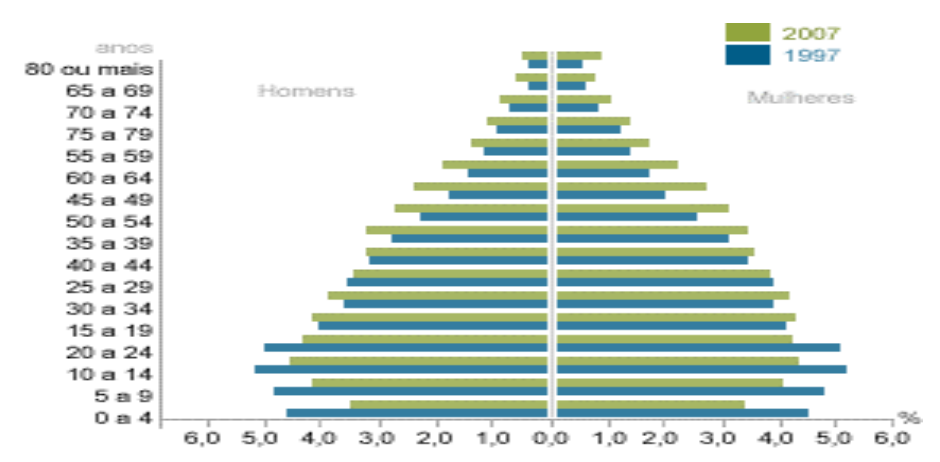

Figura 1 - Composição da população residente por sexo, segundo os grupos de idade, Brasil - IBGE, Pesquisa por Amostra de Domicílio 1997/2007.

Portanto, o efeito combinado da queda da fecundidade e da mortalidade com o aumento da longevidade encontra-se refletido no alargamento do topo da pirâmide, sinalizando transformações no padrão demográfico mundial e brasileiro e repercutindo em transformações socioculturais, econômicas, políticas e, principalmente, transformações no padrão epidemiológico da população.

\subsection{Transição epidemiológica}

Com a transição demográfica, altera-se fundamentalmente o panorama epidemiológico relativo à morbidade e mortalidade de uma determinada população. A transição epidemiológica pode ser definida como as modificações dos padrões de morbidade, invalidez e morte que caracterizam uma população (CHAIMOWICZ, 2005).

As cinco etapas da transição epidemiológica, no contingente americano, são descritas como idade das pestilências e da fome, sendo a primeira, a qual 
retrata a alta mortalidade e fecundidade com predomínio de doenças infectocontagiosas, no período entre a Idade Média e início do século XIX cuja expectativa de vida era de 20 a 40 anos. A segunda etapa, idade do retrocesso das pandemias, caracterizada pela diminuição da mortalidade e fecundidade, no final do século XIX e início do XX, cuja expectativa de vida atingiu média de 50 anos. A terceira, idade das doenças degenerativas e as provocadas pelo homem, aumento das doenças provocadas por acidentes radioativos, pesticidas, inseticidas, os de trânsito e provocadas pelo estresse, início do século $\mathrm{XX}$ atingindo a expectativa superior a 50 anos. A quarta fase, denominada idade do declínio da mortalidade por doenças cardiovasculares, das mudanças no estilo de vida, do envelhecimento da população, do aparecimento de novas doenças e do reaparecimento das doenças controladas, surge a Aids, e há o reaparecimento da tuberculose nas quatro últimas décadas do século $X X$, que se caracteriza por um menor crescimento da população (OMRAN, 1996).

O presente século XXI corresponde à idade da longevidade paradoxal, surgimento de doenças enigmáticas e o desenvolvimento de tecnologias para sobrevivência dos deficientes, sendo caracterizada pela prevalência das doenças crônicas não transmissíveis e as ocasionadas pelo homem, ultrapassando uma expectativa de vida de 90 anos, nas Américas (OMRAN,1996).

Dessa forma entende-se a correlação direta entre os processos de transição demográfica e a epidemiológica. De acordo com as etapas acima explicitadas, o declínio da mortalidade concentra-se seletivamente entre as doenças agudas transmissíveis e tende a beneficiar os grupos mais jovens da população, que passam a conviver com fatores de risco associados às doenças crônicas não transmissíveis (DCNTs) e, na medida em que cresce o número de idosos e aumenta a expectativa de vida, as doenças crônicas não transmissíveis tornam-se mais frequentes.

No Brasil, a transição epidemiológica apresentou alterações, não em quase dois séculos como nos países desenvolvidos, mas na metade do século XX. A mortalidade começou a declinar na década de 1940, com a versão tropical da Revolução Industrial, a fecundidade seguiu a tendência 30 anos depois, e chegou a níveis bem baixos (final do século XX). As doenças infecto-contagiosas que, em 
1950, representavam $40 \%$ das mortes registradas no país, três décadas depois eram representadas por menos de 10\% destas mortes (RADIS, 1984).

De acordo com o IBGE (2000), em 1999, dos 86,5 milhões de pessoas que declararam ter consultado um médico nos últimos 12 meses, $73,2 \%$ eram maiores de 65 anos. Mais da metade dos idosos apresentava algum problema de saúde $(53,3 \%)$, sendo $23,1 \%$ decorrentes das DCNTs.

Lessa (1998) identificou as doenças crônicas mais comuns nas idades mais avançadas representadas, entre outras, por: doenças cardiovasculares, sequelas de doenças cerebrovasculares, osteoarticulares, respiratórias, digestivas, neoplasias, diabetes mellitus e diversos tipos de demência.

As DCNTs são as principais causas de morte e incapacidade em todo o mundo. Em 2001, atribuiu-se às DCNT o total de 33,1 milhões de óbitos, quase $60 \%$ da mortalidade mundial e $45,9 \%$ de carga global de doenças. Se essa tendência for mantida, as DCNTs devem alcançar $73 \%$ dos óbitos e $60 \%$ da carga de doenças no ano de 2020 (OPAS, 2003).

Nos Estados Unidos da América (EUA), as DCNTs são responsáveis por mais de $80 \%$ de todos os óbitos, assim como pelo grande número de incapacidades. O início das DCNTs ocorre de forma precoce, com desenvolvimento lento e assintomático, levando, muitas vezes ao aparecimento de incapacidades e à morte (FRIES, 2002).

No Brasil, em 1950, as doenças crônicas eram responsáveis por $12 \%$ dos óbitos, já em 1980 corresponderam a 40\% dos óbitos. Esses dados demonstram a exigência de mais investimentos em tratamento, hospitalização e reabilitação (VERAS, 1994).

Segundo dados do projeto SABE realizado no município de São Paulo, verificou-se, nos 1.143 idosos com 60 anos ou mais avaliados, a prevalência das seguintes doenças crônicas estudadas: Hipertensão Arterial (HAS) $(52,85)$, artrite/artrose/reumatismo $(30,55)$, problemas cardíacos $(18,2 \%)$, diabetes $(18,3 \%)$, osteoporose $(13,45)$, doença crônica pulmonar $(12 \%)$, Acidente Vascular Encefálico (AVE) $(6,9 \%)$ e tumor maligno (2,9\%). Elevada proporção dos idosos entrevistados declarou sofrer de três ou mais doenças, sendo mais comum nas mulheres $(48 \%)$ do que nos homens (33\%) (LEBRÃO e DUARTE, 2003). 
Schiaveto (2008), por meio do estudo da população de 515 idosos residentes na comunidade de Ribeirão Preto/SP, identificou as (co)morbidades autorreferidas mais prevalentes, a hipertensão arterial (60,3\%), diminuição da acuidade visual $(54,8 \%)$, problemas de coluna $(40,9 \%)$ sendo que $4,3 \%$ dos idosos não apresentaram nenhuma morbidade.

Em outro estudo realizado no município de Ribeirão Preto com 48 idosos, verificaram-se as dez morbidades mais referidas pelos idosos como HAS $(61,7 \%)$, problema de coluna $(49,0 \%)$, insônia e doença cardíaca $(38,3 \%)$, má circulação $(38,2 \%)$, osteoporose $(36,2 \%)$, artrite/artrose $(31,9 \%)$, diabetes mellitus $(27,7 \%)$, AVE $(27,6 \%)$ e incontinência urinária (25,5\%). Na amostra estudada, $68,1 \%$ dos idosos referiram possuir mais que uma doença crônica, caracterizada, principalmente, pela presença de hipertensão arterial e diabetes mellitus (PEDRAZZI et al., 2007).

Da mesma forma, é importante ressaltar a existência das (co)morbidades entre os idosos, representando também um fator fortemente associado às incapacidades funcionais $\mathrm{e}$, consequentemente, à dependência e à morte.

Além das (co)morbidades, Gordilho et al. (2000) e Veras et al. (2002), ao reportarem as doenças mais incapacitantes, enfatizam as doenças como depressão e demência, devido ao fato de levarem à perda da independência e, principalmente, da autonomia.

As alterações demográficas decorrentes do processo de envelhecimento populacional são acompanhadas pelas mudanças epidemiológicas, e são essas as responsáveis pela urgente necessidade de reorganização da atenção à saúde do idoso, no país como um todo.

\subsection{Deficit cognitivo}

Cognição é o termo utilizado para descrever o funcionamento mental, que implica a habilidade para sentir, pensar, perceber, lembrar, raciocinar, formar estruturas complexas de pensamentos, e a capacidade para produzir respostas a 
solicitações e estímulos externos. Tais habilidades são influenciadas por características próprias de cada indivíduo, tais como idade, escolaridade, interesses, comportamento, saúde, atividades desenvolvidas, quantidade de estímulos a que é exposto, além de aspectos psicoemocionais e socioculturais (CANÇADO e HORTA, 2002).

O envelhecimento normal traz consigo um declínio gradual das funções cognitivas, decorrentes de processos neurológicos que se alteram com a idade. A função cognitiva, memória, tem sido amplamente estudada, pois o declínio dessa é uma das maiores preocupações referidas pelos idosos e deve ser cuidadosamente investigada (CANINEU et al., 2004).

Segundo Okamoto (1998), a história do idoso pode ajudar no detalhamento da queixa de perda de memória e indicar se ocorre isoladamente ou em conjunto com outras alterações cognitivas. Portanto, deve-se avaliar o idoso sobre o seu desempenho para as atividades diárias, como dificuldade em controlar o próprio dinheiro, em localizar-se em ambientes diferentes de sua casa (viagens, visitas), em encontrar palavras corriqueiras, em manter passatempos prévios como leituras e jogos, em realizar pequenos consertos em casa e em manusear aparelhos eletrodomésticos. Quando se verifica alteração em muitos desses itens, faz-se necessária a avaliação mais objetiva desses deficits por meio de testes neuropsicológicos aplicados por profissionais capacitados.

Um dos testes neuropsicológicos mais utilizados para a população brasileira para triagem de deficit cognitivo tem sido o Miniexame do Estado Mental (MEEM), por meio do qual se identifica comprometimento suficiente para interferir nas atividades da vida diária, da memória e de outras áreas cognitivas (linguagem, praxia, orientação, função executiva, entre outras) (ALMEIDA, 1998).

Em um estudo realizado no Japão com 1.544 idosos, os pesquisadores classificando os sujeitos, de acordo com escores do MEEM, encontraram que a média dos valores do MEEM declina linearmente com o avançar da idade e que entre os participantes, 232 (15.2\%) foram classificados com moderado deficit cognitivo (FUJIWARA et al., 2002). 
No Brasil, um estudo realizado na capital de São Paulo em um centro de saúde, em que foram avaliados 351 idosos com mais de 60 anos de idade, constatou incidência de deficit cognitivo representado por 13,4\% (ALMEIDA, 1998).

O deficit cognitivo pode ocorrer associado a várias razões, entre elas alteração de memória devido à dificuldade de atenção, decorrente de uso de medicação (principalmente benzodiazepínicos, neurolépticos e antidepressivos). Outra possibilidade para que esteja ocorrendo queixa de memória correlacionada ao deficit cognitivo na avaliação é haver alteração de afeto, em particular a depressão em suas diversas formas, mas uma das razões mais prevalentes associada ao deficit cognitivo e comprometimento das atividades da vida diária é a síndrome demencial (OKAMOTO, 1998).

Da mesma forma é importante salientar sobre o diagnóstico de comprometimento cognitivo leve (CCL), muito discutido na atualidade, que é considerado quando existe um comprometimento de uma área cognitiva, como a memória, porém sem critérios para o diagnóstico de uma síndrome demencial. Em relação a uma população sem queixa, o diagnóstico de CCL pode significar um quadro inicial de demência, ou indicar o aumento, em cerca de oito vezes, da possibilidade de desenvolvê-la (PETERSEN, 1999).

Os indivíduos que foram diagnosticados com $\mathrm{CCL}$ não podem ser classificados como normais, mas também não podem ser classificados como demenciados. Essa condição é a vigência de declínio cognitivo, mas sem comprometimento das atividades sócio-ocupacionais da pessoa. A presença de comprometimento cognitivo suficiente para haver comprometimento das habilidades funcionais nas atividades de vida diária configura a síndrome demencial (CANINEU et al., 2004).

Diante desses fatos, é inevitável reportar o problema da demência, definida como uma síndrome clínica de declínio global caracterizada por declínio cognitivo, com caráter permanente e progressivo ou transitório, mudanças da personalidade e comportamento causada por múltiplas etiologias, suficientemente intensa para causar deterioração nas atividades da vida diária e interferir nas atividades profissionais e sociais do indivíduo (CARAMELLI e BARBOSA, 2002; CALDAS, 2002; REYES e SHI, 2006; PAPALÉO NETTO e KLEIN 2006). 
Essa síndrome, de acordo com Aisen et al. (2001) e Caldas (2002), evolui gradualmente percorrendo três fases: a primeira, denominada fase leve, ocorre falha de memória, perda da concentração, dificuldade de encontrar palavras ou de lembrar dia da semana, mês e ano, mas a lembrança de eventos passados ainda é preservada. Mantêm-se normais as funções cognitivas, motoras, sensoriais o que pode acarretar angústia, agitação e depressão no idoso; a segunda, fase moderada ou intermediária, o grau de dependência aumenta, tanto a memória recente quanto a remota ficam prejudicadas, apresenta dificuldade para cálculo e cópia, não consegue mais desenvolver as atividades da vida diária, podendo ainda apresentar desorientação temporoespacial, como também perambulação e agitação; a última fase, avançada ou grave, o idoso torna-se totalmente dependente nas atividades da vida diária, devido à perda de atividade psicomotora, apresenta incontinências urinária e fecal, não reconhecendo os amigos e familiares, terminando, geralmente restrito ao leito.

Pode ser causada por várias doenças e condições que resultam em danos das células cerebrais. A síndrome demencial, ao ser classificada, segundo Maslow (2008), segue os seguintes critérios:

- Deve-se incluir declínio da memória e de pelo menos uma das seguintes habilidades cognitivas:

1) Habilidade de gerar discurso coerente e entender linguagem falada $e$ escrita;

2) Habilidade de reconhecer ou identificar objetos, assumindo função sensorial preservada;

3) Habilidade de executar atividades motoras, assumindo habilidades motoras, função sensorial e compreensão de tarefas solicitadas preservadas;

4) Habilidade de pensamento abstrato, fazer julgamentos de sons, e planejar e executar tarefas.

O declínio das habilidades cognitivas deve ser severo o suficiente para interferir nas Atividades de Vida Diária (AVDs). 
A literatura mostra que a prevalência da demência varia de um estudo para outro. Na população dos EUA, estimou-se que cerca de $10 \%$ dos idosos com mais de 65 anos sofriam de demência, e os idosos com 85 anos ou mais de idade atingiram a prevalência de $50 \%$ (SPARKS, 2001).

Ao analisarem estudos de prevalência de demência em diversas regiões do mundo, no período de 1994 a 2000, Lopes e Bottino (2002) revelam que a prevalência média de demência, acima dos 65 anos de idade, variou entre 2,2\% na África; $5,5 \%$ na Ásia; 6,4\% na América do Norte; 7,1\% na América do Sul e 9,4\% na Europa, a qual aumenta nas idades mais avançadas.

No Brasil, um estudo de base populacional, realizado na cidade de Catanduva/SP, avaliou 1.660 pessoas com 60 anos ou mais e detectou prevalência variando de 1,3\%, na faixa etária de 65 a 69 anos, a 36,9\% para faixa etária de 85 anos ou mais (HERRERA et al., 1998). Tais dados revelam maior incidência em idosos com idades mais avançadas.

Lopes (2006), em um estudo realizado na população de idosos de Ribeirão Preto, SP, com aplicação de seis testes, em amostra randomizada, encontrou alta prevalência de demência (18,9\%). Identificou também relação direta de aumento na prevalência de demência nos idosos mais velhos, nos de menor nível educacional e socioeconômico e no sexo feminino.

Dentre as inúmeras possíveis causas, incluem-se pelo menos 60 doenças com a predominância da doença de Alzheimer (DA) e da doença vascular cerebral.

A doença de Alzheimer vem sendo estudada desde 1906 quando Alois Alzheimer a descreveu pela primeira vez, ao analisar, numa necropsia, as alterações histológicas do cérebro de uma senhora de 51 anos de idade que apresentava distúrbios de linguagem, memória e de comportamento (CORREIA, 1996).

De acordo com a evolução da doença, os indivíduos apresentam o pensamento lento, a capacidade de atuação nas esferas econômica e social é prejudicada, e a memória mostra-se deficiente. Os primeiros sintomas incluem distúrbios das funções da linguagem, apraxia e agnosias. Pacientes com alguma noção crítica de sua deterioração podem apresentar depressão associada, o que foi observado em $25 \%$ dos casos por Forlenza (2005). 
Agitação e inquietação também são comuns. Sinais motores são raros no início, mas posteriormente podem alterar reflexos e marcha lenta, arrastando os pés. O quadro clínico nos estágios terminais é apresentado pela paralisação da atividade intelectual, no qual o paciente se encontra em estado vegetativo. Podem ocorrer fraqueza e contratura dos membros. O controle das funções vesicais e intestinais é perdido (REYES e SHI, 2006).

Alguns estudos enfatizam a depressão como importante preditora de deficit cognitivo, e que, frequentemente, esta se associa à demência, acentuando as dificuldades diagnósticas. $\mathrm{O}$ diagnóstico diferencial torna-se difícil, porque vários dos sintomas se sobrepõem, e o paciente com alterações cognitivas tem maior dificuldade para perceber e relatar sintomas depressivos. Estima-se que $40 \%$ dos pacientes com Alzheimer na comunidade apresentem sintomas depressivos (LYKETSOS et al., 2000), em diferentes formas de associação: reação psicológica ou devida a dano cerebral secundário à demência, coexistência das duas síndromes sem relação íntima, depressão gerando declínio cognitivo como um dos sintomas e depressão simulando um quadro demencial (LAUTER e DAME, 1991).

Diante desses fatos, entende-se que o quadro de deficit cognitivo, seja ele associado à demência, depressão, ou a outros problemas, implica na possibilidade de incapacidade funcional no idoso, levando à dependência para a realização das Atividades Básicas de Vida Diária (ABVDs). Estas tarefas, que aparentemente são simples, estruturam o cotidiano e oferecem suporte para a realização de outras mais complexas (BRESSAN, 2005).

A perda da independência, entendida como a capacidade de viver independentemente na comunidade com alguma ou nenhuma ajuda de outros, vem atrelada à perda da autonomia, principalmente em idosos com deficit cognitivo, a qual é definida como "a habilidade de controlar, lidar e tomar decisões pessoais sobre como se deve viver diariamente, de acordo com suas próprias regras e preferências" (WHO 2005, p. 14).

Dessa forma, compreende-se que é de extremo valor a discussão sobre a capacidade funcional de idosos que apresentam deficit cognitivo, pois fornecem o formato da história de vida desses idosos. 


\subsection{A capacidade funcional}

A capacidade funcional é uma das grandes vertentes da saúde do idoso e mais recentemente vem emergindo como um componente-chave para avaliação da saúde dessa população.

Segundo Gordilho et al. (2000), capacidade funcional é a capacidade de manter as habilidades físicas e mentais necessárias a uma vida independente e autônoma. Sua prevalência, geralmente, é mensurada por meio da incapacidade em realizar as Atividades de Vida Diária (AVDs) como as Atividades Básicas de Vida Diária (ABVDs) e as Atividades Instrumentais de Vida Diária (AIVDs). As ABVDs, descritas como atividades de auto cuidado como, tomar banho, pentear os cabelos, alimentar-se, higiene, usar o banheiro, são essenciais à sobrevivência diária, e as AIVDs, ações envolvendo a organização da rotina diária como vestir-se, comer, preparar uma pequena refeição, caminhar dentro de casa ou pela vizinhança, fazer compras, emitir julgamentos, ler e escrever, discar ou atender telefone, são atividades necessárias para sustentar uma vida independente na comunidade (BRESSAN, 2005).

Para Matsudo (2000), capacidade funcional pode ser definida como o potencial que os idosos apresentam para decidir e atuar em suas vidas de forma independente no seu cotidiano, apesar de possuir uma incapacidade física, mental ou social. Destacam-se atividades que são desenvolvidas diariamente e estão diretamente relacionadas ao autocuidado, ao cuidado de seu entorno e à participação social, constituindo, portanto um fator importante para a saúde e o bem-estar dos idosos.

Dessa forma, torna-se relevante avaliar a capacidade física em idosos com deficit cognitivo. Essas informações geradas pela avaliação da capacidade funcional possibilitam conhecer o perfil dos idosos, o que poderá auxiliar na definição de estratégias de promoção de saúde para os idosos e seus cuidadores, visando a retardar ou prevenir as incapacidades. O resultado dessa avaliação representa o grau de dependência da ajuda de outras pessoas para o desempenho das atividades cotidianas que $\mathrm{o}$ idoso apresenta (RAMOS, 2003). A incapacidade funcional, decorrente do próprio processo de envelhecimento ou devido às doenças crônicas não transmissíveis, como as demências, pode trazer consequências para a família, para a qualidade de vida dos idosos e surgir a necessidade de serviços de apoio (GIACOMIM et al., 2008). 
Entre os vários instrumentos de avaliação da funcionalidade dos idosos, a Medida da Independência Funcional (MIF) é a que abarca de forma completa esse aspecto, além de avaliar o que o idoso, de fato, realiza em seu dia a dia e não se ele seria capaz em alguma circunstância.

Pedrazzi (2008), ao avaliar a população de idosos com 80 anos ou mais, utilizando a MIF na comunidade de Ribeirão Preto, verificou que $81,6 \%$ dos idosos classificaram-se na categoria independência completa/modificada, e 15\% na dependência mínima.

A validade da MIF, internacionalmente, envolveu a avaliação de propriedades psicométricas e a comparação com outros instrumentos de avaliação funcional (HSUEH, 2002), sua aplicação em grupos de pacientes com deficiências específicas (OTA et al., 1996) e faixas etárias definidas (POLLACK et al., 1996). Os estudos demonstraram que $\mathrm{o}$ instrumento apresentou correlação com os itens avaliados, além da validade e da reprodutibilidade. Foi traduzida para a língua portuguesa no Brasil e realizado um estudo sobre a sua reprodutibilidade, por Riberto et al. (2004) que concluíram que este instrumento tem boa equivalência cultural, as propriedades de reprodutibilidade são boas e permitem seu uso em nosso meio, porém exigem um treinamento formal antes da sua utilização.

Mediante o prejuízo na vida do idoso com deficit cognitivo, com ênfase na perda da capacidade funcional, como um dos principais motivos para a perda da independência do idoso fazendo surgir o papel do cuidador para o auxílio das atividades da vida diária, surge a necessidade de reportar sobre a entidade família e todo o problema que a mesma enfrenta em sua estrutura, principalmente aquele familiar que assume o papel do cuidador.

\subsection{A família e o cuidador}

A família é quem, geralmente, assume a responsabilidade, pela saúde de seus membros, construindo uma unidade que presta cuidado, desenvolvendo ações 
que visam à promoção da saúde, à prevenção e ao tratamento de doenças (MARQUES et al., 2006).

Os resultados do último censo (IBGE, 2006) revelaram que, no Brasil, a maior parte dos idosos reside com a família, sendo esta considerada a principal fonte provedora de cuidados. Devido a importância da posição social que the é atribuída, pelos próprios idosos e pela cultura brasileira, a família tornou-se alvo de estudos e de intervenções.

A família é responsável tanto pela formação individual quanto social de seus membros. Ela, também, exerce suas funções nas áreas educacional, econômica, doméstica e de cuidado com a saúde de seus membros, além de recreação, socialização e afeição (MARQUES et al., 2006).

Angelo e Bousso (2001) ressaltam que é essencial compreender a família como a mais constante unidade de cuidado de saúde para seus membros.

A família é a principal promotora do cuidado, a literatura gerontológica tem caracterizado os cuidadores, classificando-os de acordo com o vínculo entre cuidador e paciente, tipos de cuidados prestados e frequência nos cuidados tais como remunerado, voluntário, leigo, profissional, familiar, primário e secundário, sendo que essas categorias são excludentes e, algumas vezes, se complementam (SOLOMON et al., 1997; BUFFUM e BROD, 1998; KARSCH, 2003).

Solomon et al. (1997), Buffum e Brod (1998) afirmam que a maioria dos idosos com deficit cognitivo associado à demência mora em casa e são cuidados pelos cônjuges ou filhas. Os resultados indicam que há uma crescente tendência de se evitar a institucionalização, fazendo com que os familiares se encarreguem de cuidar de seu familiar demenciado.

A definição de cuidador adotada pela Política Nacional do Idoso (1994) ressalva que o cuidador é a pessoa, membro ou não da família, que, com ou sem remuneração, cuida do idoso doente ou dependente no exercício das suas atividades diárias, tais como alimentação, higiene pessoal, medicação de rotina, acompanhamento aos serviços de saúde e demais serviços requeridos no cotidiano, excluídos as técnicas e os procedimentos identificados com profissões legalmente estabelecidas, particularmente na área da enfermagem. 
A Política Nacional de Saúde do Idoso ainda, regulamentada pela Portaria 1395 de 1999, fortalece a necessidade de se estabelecer uma "parceria" que envolva cuidadores profissionais e cuidadores leigos. A assistência domiciliar aos idosos fragilizados, oferecida pelos profissionais, deve compreender também esclarecimentos e orientações aos cuidadores quanto aos cuidados que devem ser prestados, bem como o que fazer para assegurar a conservação de sua própria saúde.

$\mathrm{Na}$ tentativa de conceituar cuidadores formais e informais, ou cuidadores principais e secundários, e os fatores que designam o tipo de cuidado requerido para cada idoso, a literatura aponta quatro fatores, geralmente utilizados para designar os cuidados da pessoa idosa incapacitada: parentesco (cônjuges); gênero (principalmente, mulher); proximidade física (vive junto) e proximidade afetiva (conjugal, pais e filhos) (KARSCH, 2003).

O cuidador principal é aquele que tem a total ou maior responsabilidade pelos cuidados prestados ao idoso dependente, no domicílio. Os cuidadores secundários são os familiares, voluntários e profissionais que prestam atividades complementares (CALDAS, 2002).

Ainda, para maior entendimento do termo cuidador, a classificação sugerida pelo Ministério da Previdência e Assistência Social - MPAS (1998) propõe o seguinte perfil:

Cuidador Formal, pessoa maior de idade, com $1^{\circ}$ grau completo e que fora submetido a treinamento específico em instituição oficialmente reconhecida, faz o elo entre o idoso, a família e os serviços de saúde ou da comunidade e que geralmente exerce atividade remunerada; Cuidador Profissional, pessoa com diploma de $3^{\circ}$ grau, conferido por instituição de ensino reconhecida e que presta assistência profissional ao idoso, à família e à comunidade; Cuidador Informal, pessoa com ou sem vínculo familiar, não remunerada e que presta cuidados à pessoa idosa no domicílio.

Devido ao aumento da necessidade de pessoas que cuidem de um familiar dependente no domicílio, seja ele familiar ou profissional, foi criado pelo projeto de lei Federal n. 6.966/2008 e inserido na Classificação Brasileira de Ocupações do Ministério do Trabalho e Emprego com o código 5162-10, o exercício 
da profissão de Cuidador de pessoas idosas e dependentes e Cuidador de idosos institucional (MTE/SPPE, 2002). Em parágrafo único define-se como cuidador, o profissional responsável por cuidar da pessoa doente ou dependente, facilitando o exercício de suas atividades diárias, tais como alimentação, higiene pessoal, além de aplicar a medicação de rotina e acompanhá-la junto aos serviços de saúde, ou outros requeridos no seu cotidiano, excluindo, para tal, técnicas ou procedimentos identificados como exclusivos de outras profissões legalmente estabelecidas (BRASIL, 1999).

Entretanto, o exercício da profissão do cuidar ainda não está aprovado por lei, e ainda é considerado como responsabilidade doméstica, desenvolvida no espaço privado, de caráter informal, sem respaldo político e econômico, o qual, na maioria das vezes, segue desprovido de significação, não sendo reconhecido, portanto, poderá desencadear sofrimento psíquico e físico para o cuidador.

Silva e Neri (2000) relatam que os cuidados oriundos de redes informais de apoio constituídas por filhos, por outros parentes e por amigos representam uma fonte de atenção ao idoso. Em culturas como a americana, por exemplo, foi constatado que $80 \%$ dos cuidados dos idosos provêm de tais redes, em que cerca de um terço dos cuidadores é representado por uma única pessoa, em geral, o cônjuge também idoso, ou filhas de meia-idade e viúvas.

As recentes tendências de mudanças na estrutura familiar, com a contribuição do processo de urbanização, anteriormente baseada nos moldes tradicionais, em que o convívio era extenso com destaque para atuação das mulheres, possibilitavam que os cuidados de saúde fossem mais facilmente divididos entre esposa, filhas, noras, cunhadas, tias e irmãs. Atualmente, o arranjo familiar predominante passa a ser a convivência apenas da família nuclear, em um mesmo espaço de moradia, faz com que a atenção recaia quase exclusivamente numa única pessoa, geralmente, a esposa ou uma filha (MPAS, 1998).

Os papéis que os cuidadores assumem para o cuidado com seus idosos têm sido verificados na literatura internacional (ZARIT, 1980; SCHULZ e BEACH, 1999; ACTON e KANG, 2001; BRODATY e GREEN, 2002; KUZU et al., 2005, OKAMOTO et al., 2008). No Brasil, a família também tem assumido a responsabilidade de prover auxílio tanto nas atividades básicas quanto nas 
instrumentais da vida diária do idoso, principalmente face às dificuldades do sistema de assistência ao cliente com problemas crônicos, na condição de dependência (GRATÃO et al., 2010).

Dentre as atividades prestadas pelos cuidadores, as mais comuns são: trocar de roupa, dar banho, medicar, transportar, alimentar e atividades relacionadas à rotina da vida como levar a consultas médicas e passear (CALDEIRAS, 2004).

Okamoto et al. (2008), ao avaliar 111 cuidadores, no Japão, utilizando a Zarit Burden Interview, encontraram que o efeito direto do auxílio nas atividades básicas da vida diária ao idoso demenciado está significantemente associado com o alto índice de burden nos cuidadores.

No estudo de Alvarez (2001), que teve como objetivo compreender o processo global vivenciando pela família cuidadora de idoso doente e fragilizado, no âmbito domicilar na cidade de Florianópolis/SC, menciona que o assumir e realizar o auxílio nas ABVDs do idoso é uma tarefa, geralmente, de caráter ininterrupto (cuidados corporais, alimentação, eliminações, ambiente e controle da saúde) e outras situações levando-o a viver situações conflituosas e desgastantes.

\subsection{Sobrecarga do cuidador}

A revisão da literatura, realizada por Garrido e Almeida (1999), demonstra que a atividade de cuidar de pessoas idosas, muitas vezes, gera sobrecarga na vida do cuidador, principalmente se o idoso apresentar deficit cognitivo. Os autores acrescentam que os distúrbios de comportamento apresentados por pessoas com demência levam o cuidador a apresentar quadros depressivos e de ansiedade, contribuindo também para deterioração das condições físicas destes.

De acordo com Marques et al. (2006), essa sobrecarga gerada sobre os cuidadores pode acarretar no desenvolvimento de sintomas psiquiátricos, fadiga, uso de medicamentos psicotrópicos, além de ter sua própria saúde prejudicada o que leva à falta de condições para cuidar do idoso. Da mesma forma, a atividade de 
cuidar pode ter efeitos sociais e econômicos que comprometem todos os aspectos da vida (BRODATY e GREEN, 2002).

A sobrecarga relacionada à tarefa do cuidar pode ser definida como qualidade ou quantidade de demanda que ultrapassam a capacidade de desempenho, por insuficiência técnica ou de tempo e que a pressão e a responsabilidade no trabalho propiciam, principalmente, o aparecimento da exaustão emocional (MASLACH, 2001).

Estudos realizados indicam que o cuidador de idosos com deficit cognitivo sofre uma sobrecarga considerável e que esse desgaste está ligado à presença de sintomas não cognitivos ou psiquiátricos (BRODATY e GREEN, 2002, MENDES, 2004).

Os cuidadores têm visão de que cuidar é uma missão, mesmo não tendo preparo para cuidar adequadamente do idoso, negligenciando seu autocuidado (GARRIDO e MENEZES, 2004).

A condição de cuidador além de causar situações de estresse, desgaste físico-emocional, também leva à desestruturação familiar, perda de identidade, isolamento social, envelhecimento (ligado à aparência física) e assim o cuidador deixa de se cuidar e procura adaptar-se diante da nova situação (LUZARDO e WALDMAN, 2004).

Quanto mais grave o deficit cognitivo do paciente e quanto menor o seu nível de independência, maior é a quantidade de cuidado e supervisão requeridos por ele, tendo o cuidador menos tempo livre para si mesmo, o que está relacionado de forma positiva com o aumento da ansiedade em relação à função de cuidar (AGUGLIA et al., 2004).

Em estudo realizado nos EUA relacionado ao impacto sobre a saúde física do cuidador, Schulz e Beach (1999) investigaram a relação entre a atividade de cuidar e o risco de morte entre 392 cuidadores idosos. Nesse estudo populacional prospectivo, de quatro anos e meio, houve a sinalização de um maior risco de morte entre os cuidadores que assistiam seus(suas) esposos(as) dependentes e que se sentiam sobrecarregados pelos cuidados administrados. Este risco de morte, após ajuste dos fatores sociodemográficos e do status de saúde 
física dos cuidadores (doenças prevalentes e doenças subclínicas), foi $63 \%$ maior entre os cuidadores de esposos (as) com dependência.

Brodaty e Green (2002), em pesquisa realizada com cuidadores na Austrália, revelam que entre as repercussões físicas na saúde do cuidador podem estar envolvidas algumas condições crônicas como hipertensão arterial, e da mesma forma um maior consumo de medicamentos e frequência às consultas médicas. Já morbidades de caráter psicológico nos cuidadores são representadas frequentemente pela depressão e pode persistir durante o longo tempo da atividade de cuidar.

Gratão et al. (2010), ao analisarem a demanda do cuidador familiar com idoso demenciado, encontraram que o cuidar acarreta sobrecarga física e emocional associada ao comprometimento das AVDs do idoso, principalmente no estágio grave da demência.

O impacto do cuidar de uma pessoa dependente devido a alguma condição crônica, geralmente, é descrito pelo termo burden, burdensome, ou menos utilizado burnout. O conceito de tais termos foi primeiramente publicado por Zarit (1980) e inclui os problemas físicos, psicológicos ou emocionais, sociais e financeiros, experienciados por famílias cuidadoras, representados tanto por aspectos subjetivos quanto objetivos, advindos do impacto do cuidar (ZARIT, 1980; ACTON e KANG, 2001).

O termo burnout difere de burden por ser mais frequentemente usado para trabalhadores formais contratados por regime de trabalho e por apresentar características como a tendência de isolamento, ironia e cinismo por parte daquele que apresenta a síndrome de burnout. Por ser atribuída ao profissional trabalhador, a síndrome de burnout, ou síndrome do esgotamento profissional, foi reconhecida como enfermidade diretamente vinculada à atividade laborativa e instituída no Código Internacional de Doenças (CID 10), pelo Decreto $n^{\circ} 3.048$ em 1999 pela sigla Z 73.0.

Define-se burnout como a reação à tensão emocional crônica gerada a partir do contato direto e excessivo com outros seres humanos, quando estes estão preocupados com o problema, em situação de trabalho que exige atenção constante 
e de grande responsabilidade. Pode estar vinculado ao termo "ritmo de trabalho penoso" classificado como Z.56.3 (OMS, 2003).

Uma vez diagnosticada a "síndrome de burnou tem um trabalhador, este, automaticamente, possui o respaldo de suporte governamental, bem como de atendimento pelo Sistema Único de Saúde (SUS), por ser um trabalhador formal e contribuir com a seguridade social.

Já a expressão burden, na língua inglesa, é mais frequentemente usada para descrever aspectos negativos associados aos cuidados, geralmente, informal e familiar, de indivíduos doentes e equivale aos termos fardo, impacto, sobrecarga e interferência (PLATT, 1985). Para este presente trabalho optou-se pelo termo sobrecarga, sinônimo de burden. Na realidade, sobrecarga pode ser definida como um estressor, caracterizada pelas situações em que as famílias são forçadas a ajustar ou desenvolver novas estratégias de lidar com a pessoa doente e seus sintomas (CHWALISZ e KISLER, 1995; ROSE et al., 2006).

A distinção entre sobrecarga objetiva e subjetiva é uma das formas mais usadas para conceitualizar o termo. Autores como Poulshock e Deimling (1984) classificam a sobrecarga objetiva como problemas de ordem prática, ocorridos no cotidiano dos cuidadores, tais como dificuldades financeiras, problemas de saúde e com a vizinhança. Para Matsuda (1999), o termo é comumente usado ao se referir às mudanças comportamentais do paciente com demência, à habilidade de desempenhar as atividades da vida diária e à duração dos cuidados prestados. Pode ser definida, também, como problemas ou dificuldades verificáveis e observáveis causados pelos comportamentos do paciente (CHWALISZ e KISLER, 1995; SOARES e MUNARI, 2007).

De outra forma, a sobrecarga subjetiva, geralmente, refere-se à forma pela qual o cuidador percebe os efeitos desses estressores na sua própria saúde física, psicológica ou emocional, social e financeira. Garrido e Menezes (2004) a descrevem como sentimentos de ressentimento, exclusão e embaraço. Soares e Munari (2007) enfatizam-na como sendo os sentimentos pessoais sobre o ato de cuidar e está relacionado às consequências da sobrecarga objetiva. Segundo Zarit et al.(1980), a carga subjetiva pode ser definida como as atitudes e reações emocionais diante da experiência de cuidar, enquanto a carga objetiva seria definida 
como as perturbações ou mudanças nos diversos aspectos do âmbito doméstico e da vida dos cuidadores.

Rose et al. (2006) utilizam o termo sobrecarga como uma consequência negativa multidimensional do processo de cuidar, caracterizado por sentimentos de estresse, preocupação e culpa (sobrecarga subjetiva), por comprometimento das atividades da vida diária, efeitos negativos nas interações sociais e familiares e redução na prática das atividades de lazer.

Bandeira et al. (2005) descrevem a sobrecarga como as consequências negativas concretas e observáveis resultantes da existência dos problemas decorrentes do envelhecimento na família, como perturbações na rotina, na vida social e profissional dos familiares, perdas financeiras, tarefas cotidianas de cuidados com o paciente, supervisão dos comportamentos problemáticos dos pacientes (comportamentos embaraçosos, agressões físicas e verbais, condutas sexuais inadequadas, entre outras) e o suporte dado ao paciente.

Dentre as sintomatologias do indivíduo que está vivenciando a sobrecarga, as mais comuns caracterizam-se pelos aspectos comportamentais vivenciados pelos cuidadores que se caracterizam por irritabilidade, agressividade, incapacidade para relaxar, perda da iniciativa, comportamento de alto risco, entre outros; os aspectos físicos englobam fadiga constante e progressiva, distúrbios do sono, dores musculares e osteomusculares, cefaleias, perturbações gastrointestinais, entre outras; já a sintomatologia psíquica engloba falta de concentração e atenção, alteração da memória, lentidão de pensamento, sentimento de solidão e insuficiência,culpa, impaciência, baixa autoestima, depressão, entre outros (ZARIT, 1980; MASLACH, 2001).

Muitas vezes, o sentimento de esgotamento, ou exaustão dos cuidadores associados ao elenco de sintomatologia caracterizada no indivíduo que sofre de sobrecarga, é resultante da grande dedicação e esforço na atividade de cuidar, na qual o cuidador desconsidera suas próprias necessidades, constituindo um problema psicossocial (ZARIT, 1980).

Segundo Canzobre e Sanchés (2001), a sobrecarga seria expressa em diversas áreas. A primeira relacionada a problemas físicos como queixas somáticas múltiplas, entre elas, dor do tipo mecânico no aparelho locomotor, cefaleia tensional, 
astenia, fadiga crônica, alterações no ciclo sono-vigília. A segunda relaciona-se a problemas psíquicos, manifestados por desordens como a depressão, ansiedade, insônia, que constituem a via de expressão do estresse emocional. Por último, como terceiro fator, problemas de índole sociofamiliar, como aumentar conflitos familiares em consequência das obrigações laborais, de dificuldades econômicas e diminuição das atividades sociais e de lazer.

Em suma, o conceito de sobrecarga, no presente estudo definido, envolve as duas dimensões objetiva e subjetiva, vivenciada por cuidadores de idosos que vivem na comunidade, sem diagnóstico prévio de patologias. $O$ aspecto objetivo relaciona-se às consequências negativas concretas e observáveis resultantes do papel de cuidador, tais como perdas financeiras, perturbações na rotina da vida familiar, excesso de tarefas que o familiar deve executar no cuidado diário com o paciente e supervisões aos comportamentos problemáticos do paciente. $\mathrm{O}$ aspecto subjetivo da sobrecarga foi definido como a percepção ou avaliação pessoal dos familiares sobre a situação, envolvendo sua reação emocional e seu sentimento de estar sofrendo uma sobrecarga, atribuída por eles ao papel de cuidador. Refere-se ao grau em que os familiares percebem os comportamentos ou a dependência dos pacientes como fonte de preocupação ou tensão psicológica. Tais definições estão em consonância com outros estudos como de Rose et al.(2006) e Soares e Munari (2007).

Grupos de suporte social são importantes para contribuir com os mecanismos de enfrentamento desses problemas e para diminuir a sobrecarga do cuidador. A revisão da literatura, por meio de uma metanálise, realizada por Acton e Kang (2001) nos EUA, na qual foram analisadas 27 pesquisas sobre intervenções para cuidadores familiares de idosos demenciados, relatou que, no geral, os cuidadores não obtiveram redução do burden. Dentre as intervenções, a mais utilizada pelas pesquisas (10 estudos) foi a psicoeducação aos cuidadores, e as demais foram: grupo de suporte social, educação em saúde, aconselhamento e repouso (respite care). A escala mais utilizada para a avaliação da sobrecarga pelas pesquisas foi a Zarit Burden Interview, ou Escala de Sobrecarga de Zarit. Os achados dessa metanálise foram explicados pelo fato de a sobrecarga ser um fenômeno global e multidimensional, ou seja, as intervenções devem ser feitas em 
conjunto, associadas umas às outras, e não de forma isolada, como foi realizado nesses estudos analisados.

Comprovando os achados do estudo de Acton e Kang (2001), uma pesquisa realizada na Turquia com cuidadores de idosos com doença de Alzheimer, ao utilizar um programa de educação compreensiva individual, associando aconselhamento, orientações gerais sobre a doença de Alzheimer e sobre formas de enfrentamento, obteve resultado positivo para a redução da sobrecarga nos cuidadores (KUZU et al., 2005).

No Brasil, diferentemente de países da Europa e América do Norte, as famílias contam com pouca rede de suporte social ou de saúde, bem como programas para educação ou aconselhamento. Ainda que no caso da doença de Alzheimer, foi criada a Portaria $n^{\circ} 703 / G M / 2002$ (BRASIL, 2002), onde é proposto um programa de assistência aos portadores desta doença e suporte aos cuidadores dentro do Sistema Único de Saúde (SUS), mas que até o momento praticamente não se efetivou, com exceção da distribuição gratuita de medicamentos.

De acordo com a legislação, o programa de assistência aos pacientes demenciados compreende a modalidade de assistência prestada no domicílio do paciente incluído um conjunto de procedimentos diagnósticos, terapêuticos e de reabilitação para aumento da autonomia e capacidade funcional do idoso, bem como, identificar e orientar o cuidador familiar ou informal (BRASIL, 2002).

É de suma importância que, além de identificar o cuidador que presta cuidado ao idoso, deve-se avaliá-lo, de forma sistemática, por meio de instrumentos consistentes e validados para a população brasileira, para que assim se implemente um plano de educação aos mesmos.

Bandeira et al. (2005) enfatizam que avaliações sistemáticas da sobrecarga familiar, utilizando instrumentos de medida validados, têm sido numerosas em nível internacional. No Brasil há poucas publicações em periódicos científicos sobre a avaliação sistemática da sobrecarga dos familiares de idosos demenciados. Destaca-se o trabalho de Scazufca et al. (2002) que avaliaram 82 familiares brasileiros, cuidadores de pacientes idosos com depressão. Garrido e Menezes (2004) também avaliaram a sobrecarga de 49 familiares cuidadores de pacientes idosos com diagnóstico de demência. $\mathrm{O}$ grau de sobrecarga dos familiares 
nesses estudos foi elevado, semelhante aos de pesquisas internacionais, principalmente, quando a saúde física dos familiares estava mais comprometida e quando o paciente apresentava maior severidade da doença,sendo assim, maiores os distúrbios de comportamento e de dependência.

Uma das hipóteses da escassez de pesquisas sistemáticas nessa área pode ser a carência de instrumentos de medida validados e adaptados para o contexto brasileiro.

Estudos que procuram avaliar a experiência dos familiares sem utilizar instrumentos de medida validados encontram dificuldades metodológicas de confiabilidade dos resultados e de comparabilidade com outros estudos.

Inúmeras escalas para avaliação da sobrecarga em cuidadores familiares de idosos foram desenvolvidas em vários países, como Caregiver Strain Index - CSI (ROBINSON, 1983), Zarit Burden Interview - ZBI (ZARIT e ZARIT, 1987), Care Burden Inventory - CBI (NOVAK e GUEST, 1989), Caregiver Reaction Assessment CRA (GIVEN et al., 1992), Family Burden Interview Schedule - FBIS (TESSLER e GAMACHE, 1996), Care Burden Scale - CBS (IIDA e KOHASHI, 2001). Em particular, a ZBI e a FBIS foram traduzidas e validadas para a cultura brasileira por Scazufca (2002) e Bandeira et al. (2005), respectivamente.

Mediante as definições contempladas de sobrecarga neste estudo, optouse pela utilização da Escala de Sobrecarga de Zarit (1987) pela sua boa repercussão em estudos no Brasil e pela disponibilidade de desenvolvimento de pesquisas, podendo assim estimular comparações e complementar o conhecimento a respeito da sobrecarga em cuidadores.

A Escala de Sobrecarga do cuidador de Zarit (1987) avalia tanto a sobrecarga objetiva quanto subjetiva dos familiares. Os fatores direcionados para a sobrecarga objetiva tentam avaliar o impacto no cuidador, associado à prestação de cuidados, em termos de tempo livre, saúde, limitação social, perda de controle, entre outros (“... escassez de tempo para realizar as tarefas; “... tensão no cuidar”; “... afetar a sua saúde”; “... não ter uma vida privada”; “... sentir-se muito sobrecarregado em geral"). Ainda refletem as implicações na relação entre o cuidador e o idoso tal como vergonha, irritação, tensão, entre outros ("sentir-se 
irritado..."; "sentir-se incapaz de cuidar por muito mais tempo"; "sentir-se inseguro acerca do que fazer...".

Os fatores que envolvem a sobrecarga subjetiva englobam as expectativas que o cuidador tem face ao cuidar, relativamente ao futuro, às suas capacidades para cuidar ("terem receio pelo futuro..."; "...o familiar depender de si"; "...ser considerada como a única pessoa para cuidar..."; "...não dispor de economias suficientes...”). Da mesma forma, a avaliação da percepção de autoeficácia do cuidador, ou seja, a percepção acerca do desempenho do seu papel. Tais fatores estão em consonância com o estudo de Sequeira (2010).

Alguns estudos utilizaram os seguintes pontos de corte para diagnóstico da sobrecarga, levando-se em consideração a pontuação das respostas da Escala de Sobrecarga de Zarit, variando de um a cinco pontos (escore global de 22 a 110 pontos): inferior a 46, ausência de sobrecarga; entre 46 e 56, sobrecarga moderada; superior a 56, sobrecarga intensa (GORT et al., 2007; SEQUEIRA, 2010). Ambos os estudos foram realizados na Europa, sendo o primeiro, na Espanha e o segundo, em Portugal.

Outros estudos sugeriram diferentes pontos de corte, como o estudo internacional, realizado no Canadá, por Hebert et al. (2000) e o nacional, realizado no estado do Rio Grande do Sul, por Luzardo et al. (2006), classificando a sobrecarga da seguinte forma: sobrecarga intensa escores entre 61 e 88; moderada a severa, entre 41 e 60, moderada a leve, entre 21 e 40; e ausência de sobrecarga, escores inferiores a 21 pontos. É importante ressaltar que esses pontos de cortes não foram sugeridos pela autora da escala (ZARIT, 1987) e pela tradutora da escala no Brasil (Scazufca, 2002) e sim pelos pesquisadores acima descritos.

Existe na literatura outra forma mais utilizada de se pontuar a sobrecarga, em que se recorre ao valor global, utilizando-se a versão de zero a quatro pontos para cada questão, alcançando o valor mínimo de zero ponto e o máximo de 88 pontos. (ZARIT, 1987; BÉDARD et al., 2001; SCAZUFCA, 2002; TOOTH et al., 2005; GORT et al. 2007; CASSIS et al., 2007; FERNANDES e GARCIA, 2009; FIALHO et al., 2009).

Complementar à escala de Zarit, optou-se também pelo Self Reporting Questionaire (SRQ), escala da OMS, validada para o Brasil por Mari e Willians 
(1986), que avalia sintomas físicos e psicológicos, relacionados aos problemas psiquiátricos comuns nos cuidadores, como ansiedade, depressão e somatização (dores de cabeça, insônia, dores de estômago, perda do apetite entre outros). 0 $S R Q$ tem sido utilizado em pesquisas nacionais para avaliar desconforto emocional em cuidadores (CERQUEIRA e OLIVEIRA, 2002; SCAZUFCA et al., 2002; GARRIDO e MENEZES, 2002).

É necessário o conhecimento por meio de informações obtidas de instrumentos validados para que se possa implementar e avaliar ações que garantam melhor assistência a esses cuidadores e aos seus familiares demenciados, considerando que os mesmos merecem atenção especial sob o aspecto emocional e psicológico.

\subsection{Relevância do estudo}

Dessa maneira, especificamente, diante desse quadro atual no mundo e no Brasil, em que se evidencia o crescimento da população de idosos, concomitante com o alto índice de doenças crônicas, deficit das capacidades cognitiva e física e o importante papel do cuidador, o qual se encontra, muitas vezes, sobrecarregado pelas tarefas desempenhadas para o auxílio do idoso no cotidiano, o presente estudo tem como finalidade a avaliação da população idosa e seus cuidadores na comunidade de Ribeirão Preto.

Diante da Política Nacional de Saúde do Idoso (Brasil, 1994), no item que se refere ao "Apoio ao desenvolvimento de cuidados informais" enfatizam-se o incentivo para a construção de modelos alternativos de cuidados e o oferecimento de suporte para os cuidadores informais dos idosos, especialmente os familiares. A formação de parcerias entre os profissionais de saúde e as pessoas (o familiar) responsáveis pelas atividades da vida diária e pelo seguimento de orientações emitidas pelos profissionais é de grande valia, principalmente, quando a avaliação criteriosa da população indica que a capacidade funcional e a cognitiva estão comprometidas. 
Ainda mais que isso, a Política Nacional do Idoso (Brasil, 1994) recomenda que essas pessoas que cuidam, também, devem receber cuidados especiais, considerando que a tarefa de cuidar de um idoso dependente é desgastante e implica riscos de tornar doente e igualmente dependente o cuidador.

Estudos nesse campo possibilitam o aumento da qualidade de vida desses idosos e seus cuidadores, e a minimização dos comprometimentos decorrentes dessa realidade ao governo e às famílias que vivem com esses idosos.

A opção por este estudo significa que o enfermeiro tem uma função importante na equipe de saúde representada pela assistência ao idoso e à família cuidadora. A falta de conhecimento sobre idoso na comunidade de Ribeirão Preto bem como a sobrecarga da atividade de prestar cuidado no domicílio perfazem a relevância deste estudo. O enfermeiro tem papel fundamental para realizar esse diagnóstico sobre os problemas que a atividade de cuidar possa causar, por meio de instrumentos consistentes e propor estratégias de atenção, frente à Política Nacional do Idoso (Brasil, 1994) e dos resultados da II Assembléia Mundial do Envelhecimento (ONU, 2002).

Diante desses fatores, o presente estudo vislumbra subsidiar as políticas públicas de atenção ao idoso, a articulação de serviços de saúde estaduais, municipais, universidades, ONGs e outras redes, bem como contribuir para divulgação dos dados e conscientização dos idosos e cuidadores para atenção especial com a saúde.

Assim, levando-se em consideração essa temática, optou-se por realizar um estudo com as seguintes questões norteadoras: Como se desenvolve o cuidado familiar com o idoso na comunidade? O idoso que vive na comunidade e que apresenta deficit cognitivo e perda da capacidade funcional pode levar o cuidador familiar à sobrecarga e ao desconforto emocional? 
50

3. Objetivas 


\section{OBJETIVOS}

\subsection{Objetivo geral}

Avaliar a sobrecarga e o desconforto emocional dos cuidadores de idosos e diagnosticar os fatores de risco para essa sobrecarga.

\subsection{Objetivos específicos}

Identificar e caracterizar idosos que vivem na comunidade de Ribeirão Preto, quanto ao perfil social, econômico e de saúde.

Avaliar a função cognitiva dos idosos e a sua relação com sexo, idade, estado conjugal, escolaridade e independência funcional.

Caracterizar e descrever os cuidadores dos idosos quanto ao perfil social, conhecimento para o processo de cuidar, dedicação para o cuidar, atividades do cuidar e apoio recebido.

Avaliar e descrever a sobrecarga e o desconforto emocional dos cuidadores familiares em relação à atividade do cuidar.

Comparar cuidadores com baixa pontuação na escala de sobrecarga de Zarit e de desconforto emocional a fatores demográficos do idoso, sociais, cognitivos, escores do instrumento "MIF" e fatores demográficos relacionados ao cuidador;

Identificar os fatores mais impactantes para a sobrecarga do cuidador dos idosos. 
4. Material e Métados 


\section{MATERIAIL E MÉTODOS}

\subsection{Tipo de estudo}

Trata-se de um estudo epidemiológico, descritivo e transversal, para verificação do nível de sobrecarga dos cuidadores de idosos que vivem na comunidade de Ribeirão Preto.

\subsection{Local do estudo}

O presente estudo inserido no projeto "Condições de vida e saúde de idosos de Ribeirão Preto, São Paulo" foi realizado na área urbana de Ribeirão Preto, estado de São Paulo, com idosos, com mais de 65 anos de idade e respectivos cuidadores, que vivem na comunidade.

\subsection{População e amostra do estudo}

A Tabela 1 apresenta a população estimada para o ano de 2004 neste município. 
Tabela 1 - População de idosos do município de Ribeirão Preto, estado de São Paulo, por idade e sexo, 2004, Ribeirão Preto, 2008.

\begin{tabular}{lccc}
\hline $\begin{array}{l}\text { Faixa Etária } \\
\text { (anos) }\end{array}$ & Masculino & $\begin{array}{c}\text { População } \\
\text { (número de idosos) }\end{array}$ & Total \\
\hline \hline & $5.923(43,9 \%)$ & $7.553(56,1 \%)$ & $13.476(36,0 \%)$ \\
70 a 74 & $4.476(42,2 \%)$ & $6.128(57,8 \%)$ & $10.604(28,3 \%)$ \\
75 a 79 & $2.610(39,6 \%)$ & $3.986(60,4 \%)$ & $6.596(17,6 \%)$ \\
80 e mais & $2.250(33,1 \%)$ & $4.547(66,9 \%)$ & $6.797(18,1 \%)$ \\
Total & $15.259(40,7 \%)$ & $22.214(59,3 \%)$ & $37.473(100,0 \%)$ \\
\hline \hline
\end{tabular}

Fonte: IBGE - Censos Demográficos e Contagem Populacional; para os anos intercensitários, estimativas preliminares dos totais populacionais, estratificadas por idade e sexo pelo MS/SE/DATASUS, 2004 (IBGE, 2006).

O processo de amostragem foi probabilístico, por conglomerados, de duplo estágio. No primeiro estágio, considerou-se o setor censitário como Unidade Primária da Amostragem (UPA). Assim, foram sorteados 30 setores censitários, com probabilidade proporcional ao tamanho do número de domicílios, entre os 600 setores do município. O segundo estágio foi visitar um número fixo de domicílios, com a finalidade de garantir a autoponderação amostral, sendo sorteada a rua e a quadra onde esse processo de busca foi iniciado. Para se chegar ao número de idosos da amostra, foram visitados no mínimo 110 domicílios em cada setor.

Após o sorteio dos setores, foi identificada, no mapa municipal de Ribeirão Preto, a localização de cada setor sorteado e foram visualizados os bairros e ruas que foram visitados. Foram listadas as ruas de cada setor sorteado, para que posteriormente, fosse realizado novo sorteio, determinando quais ruas deveriam ser visitadas pelos entrevistadores. Concomitantemente, foram impressos mapas de cada setor sorteado e divididas equipes de entrevistadores para os mesmos. Todos os idosos foram excluídos da amostra após três visitas sem o atendimento do entrevistador, estando descrito na Folha de Arrolamento (Apêndice A).

As entrevistas foram realizadas seguindo o sentido horário nos quarteirões sorteados dos setores.

Ao final das 110 residências entrevistadas de cada setor, não conseguindo alcançar a densidade intradomiciliar proposta, os entrevistadores continuaram as visitas até que conseguissem o número desejado de idosos por 
setor.Os erros amostrais foram fixados em torno de $10 \%$. Intervalos de confiança para prevalências, estimadas em pós-estratos definidos segundo sexo e idade, foram considerados $10 \%$ como o limite máximo para o erro tolerado. A Tabela 2 apresenta a amostra estimada.

Tabela 2 - Distribuição da amostra, segundo sexo e faixa etária dos idosos (acima de 65 anos) em Ribeirão Preto no ano de 2004, Ribeirão Preto, 2008

\begin{tabular}{lccc}
\hline \hline Faixa etária(anos) & População(número de idosos) & Total \\
\hline \hline 65 a 69 & Masculino & Feminino & $285(35,9 \%)$ \\
70 a 74 & $124(43,5 \%)$ & $161(56,5 \%)$ & $219(27,6 \%)$ \\
75 a 79 & $92(42,0 \%)$ & $127(58,0 \%)$ & $147(18,5 \%)$ \\
80 e mais & $59(40,1 \%)$ & $88(59,9 \%)$ & $144(18,0 \%)$ \\
Total & $48(33,3 \%)$ & $96(66,7 \%)$ & $795(100,0 \%)$ \\
\hline \hline
\end{tabular}

Como forma de prevenção em caso de recusas ou não respostas, foram sorteadas 993 pessoas, número que resulta de correção para taxa de resposta prevista em $80 \%$. No levantamento dos setores foram identificados 733 idosos, porém foram entrevistados 574 , com $22 \%$ de perdas devido a mudanças, óbitos e os que não aceitaram participar da pesquisa.

\subsection{Critérios de inclusão}

1. Idosos com idades acima de 65 anos de idade;

2. Ambos os sexos;

3. Viver em domicílio só ou com familiares, na comunidade;

4. Idosos com cuidadores familiares. 


\subsection{Variáveis do estudo}

Variáveis principais:

1. Sobrecarga no cuidador (Escala de Sobrecarga de Zarit).

2. Desconforto emocional do cuidado: presença ou não de desconforto emocional (Self Reporting Questionnaire - SRQ).

Variáveis explicativas do idoso:

1. Sexo: foram considerados o sexo masculino e o feminino;

2. Estado conjugal: com companheiro (casado, amasiado), sem companheiro (solteiro, divorciado/desquitado, separado e viúvo);

3. Escolaridade: foi classificada em analfabeto, baixa escolaridade (de 1 a 4 anos), média escolaridade(de 5 a 8 anos) e alta escolaridade( 9 ou mais anos);

4. Faixa etária: data de nascimento (com certidão) e a referência da data da entrevista, a variável foi classificada em intervalos de cinco em cinco anos;

5. Estado cognitivo: foi classificado por ter deficit cognitivo e não ter deficit cognitivo, segundo os pontos de corte do MEEM, recomendados por Bertolucci et al. (1994);

6. Medida da independência funcional: foi classificada em independente e dependente, segundo os pontos de corte, recomendados por Riberto et al. (2004);

Variáveis explicativas do cuidador:

1. Sexo: masculino e feminino;

2. Estado conjugal: com companheiro (casado, amasiado), sem companheiro (solteiro, divorciado/desquitado, separado e viúvo);

3. Escolaridade: foi classificada em analfabeto, baixa escolaridade (de $1 \mathrm{a}$ 4 anos), média escolaridade (de 5 a 8 anos) e alta escolaridade (9 ou mais anos); 
4. Faixa etária: data de nascimento (com certidão) e a referência da data da entrevista, a variável foi classificada em cuidadores com 60 anos ou menos e 60 anos ou mais de idade;

5. Grau de parentesco relacionado ao idoso: foi classificado em esposo/a; filho/a, genro/nora; irmão/a, cunhado/a e outros.

6. Vive com idoso: sim e não;

7. Tempo de cuidado: horas diárias;

8. Conhecimento sobre o cuidar: sim e não.

\subsection{Coleta de dados}

Após o sorteio dos setores censitários e das respectivas ruas e quarteirões, que compuseram a pesquisa, os endereços foram listados na folha de arrolamento, na qual os entrevistadores anotaram o número de idosos residentes e a data da visita domiciliar para aplicação do questionário. A equipe de trabalho, para a coleta de dados, foi treinada pela orientadora da pesquisa quanto à administração da entrevista, dos testes cognitivos, da aplicação da Medida da Independência Funcional (MIF), da avaliação da sobrecarga e do desconforto emocional. Após esta etapa, foi realizado um teste- piloto para avaliar o processo de entrevista.

Os entrevistadores foram munidos de identificação-crachá com foto e com um fôlder de apresentação sobre o estudo. Caso a residência estivesse fechada, foi deixado um folheto informando que o domicílio foi sorteado e que os mesmos retornariam para a entrevista. A previsão foi realizar até três visitas em cada domicílio, até a efetivação da mesma.

O idoso e o cuidador foram entrevistados após a aprovação do Comitê de Ética em Pesquisa, no período de novembro de 2008 a julho de 2009.

Os questionários foram devolvidos pelos entrevistadores e contabilizados por meio de um instrumento de controle de trabalho de campo. Na avaliação do instrumento, as dúvidas foram discutidas entre o entrevistador e o coordenador de trabalho de campo. Após a codificação, o questionário foi duplamente digitado. 
Enfim, foram percorridas as seguintes etapas e utilizados os seguintes instrumentos:

Etapa I: Avaliação do idoso

\section{A) Identificação do perfil social do Idoso:}

Este instrumento é composto dos seguintes itens de identificação: idade, sexo, cor da pele, local de nascimento, estado conjugal, se mora em apenas um local, tempo que mora na casa, número de pessoas que moram na casa atualmente e quem são os responsáveis pelo domicílio, número de filhos próprios e adotivos e quantos desses faleceram, religião e tipo de serviço de saúde que o idoso utiliza em primeira opção.

A segunda parte deste instrumento é composta dos seguintes itens para avaliação do perfil social: escolaridade, renda do idoso e da família, tipo de renda, anos de aposentadoria, autoavaliação do idoso em relação à situação econômica, atividades realizadas e tipo de moradia.

\section{B) Miniexame do Estado Mental (MEEM):}

O Miniexame do Estado Mental (MEEM) é uma escala desenvolvida por Folstein et al. (1975), nos Estados Unidos. No Brasil, foi traduzida e validada por Bertolucci et al. (1994), os quais observaram que o escore total dependia do nível educacional do indivíduo, variando de, no mínimo, 0 até a máxima pontuação 30 , com isso o escore de corte (escore que separa o alto nível cognitivo e o baixo nível cognitivo) relacionada à escolaridade ficou da seguinte forma: escores abaixo de 13 para analfabetos, de 18 para baixa e média escolaridade ( 1 a 4 anos e 5 a 8 anos) e 26 para alta escolaridade (mais de 9 anos). Como a população brasileira tem uma escolaridade bastante diversificada e o grau de escolaridade da maioria dos idosos é baixo, os níveis de corte estratificados diminuíram as falhas no diagnóstico, uma vez que o fator mais importante na determinação do MEEM é o nível educacional, também referido por Brucki et al. (2003).

O MEEM tem por objetivo auxiliar na investigação de possíveis deficits cognitivos em indivíduos com risco de desenvolver a síndrome demencial. Este teste 
é composto por diversas questões, agrupadas em sete categorias, cada uma delas desenhadas para avaliar funções cognitivas específicas: orientação para o tempo (5 pontos), orientação para o espaço (5 pontos), memória imediata (3 pontos), atenção e cálculo (5 pontos), evocação, lembrança das 3 palavras ( 3 pontos), linguagem (8 pontos) e capacidade construtiva visual (1 ponto)(Anexo A).

\section{C) Medida de Independência Funcional (MIF):}

A MIF é um instrumento de avaliação da incapacidade de pacientes com restrições funcionais de origem variada, tendo sido desenvolvida na América do Norte na década de 1980 (Granger et al., 1986). Seu objetivo primordial é avaliar de forma quantitativa a carga de cuidados demandada por uma pessoa para a realização de uma série de tarefas motoras e cognitivas de vida diária. Entre as atividades avaliadas estão os autocuidados, transferências, locomoção, controle esfincteriano, comunicação e cognição social, que inclui memória, interação social e resolução de problemas. Cada uma dessas atividades é avaliada e recebe uma pontuação que parte de 1 (dependência total) a 7 (independência completa), assim a pontuação total varia de 18 a 126. Estão descritos dois domínios na MIF, o motor e o cognitivo (Anexo B). Esse instrumento de avaliação funcional foi traduzido e validado para a língua portuguesa no Brasil em 2000 (Riberto et al., 2004) e foram realizados testes de reprodutibilidade e confiabilidade que se mostraram em níveis bons para o valor total, bem como nos domínios motor e cognitivo. É importante ressaltar que a MIF não é um instrumento autoaplicado e que exige treinamento para sua utilização (Anexo E). Dessa forma sua tradução e adaptação cultural dirigiram-se mais especificamente à compreensão dos seus itens pelos profissionais que deveriam aplicá-la e não ao entendimento por pacientes. A MIF faz parte do Sistema Uniforme de Dados para Reabilitação Médica (SUDRM) e é amplamente utilizada e aceita como medida de avaliação funcional internacionalmente, além de este instrumento ser uma escala única, multidimensional, para avaliação abrangente das dimensões e também da inter-relação entre os dois domínios, motor e cognitivo (RIBERTO et al., 2004).

Apresenta-se na Figura 2, o esquema de composição da MIF, as dimensões e as categorias e suas respectivas pontuações. 


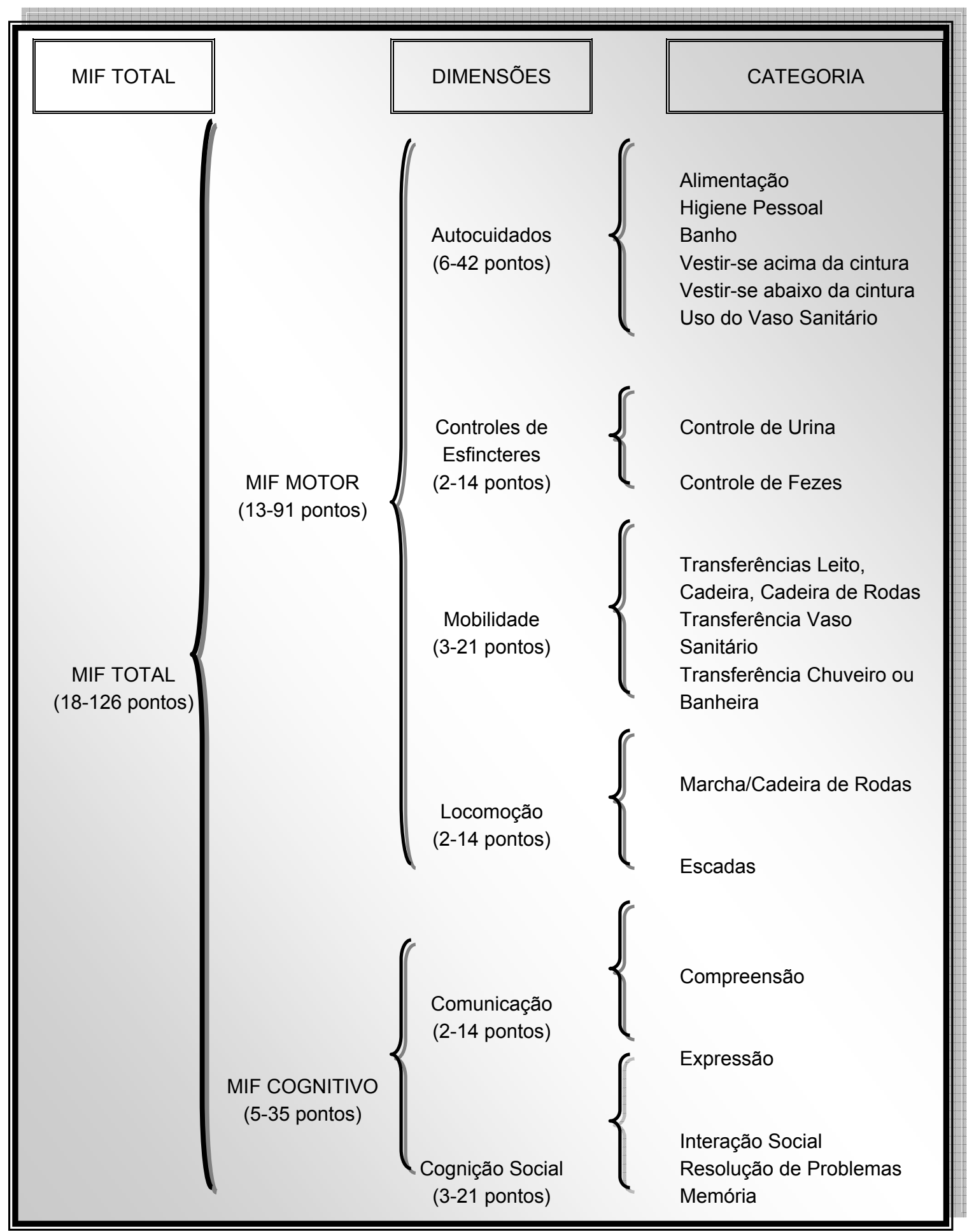

Figura 2 - Organização esquemática da composição da Medida de Independência Funcional (MIF) em MIF total, dimensões e categorias e suas respectivas pontuações (RIBERTO, et al. 2004). 
Na Figura 3, está descrita a pontuação de 1 a 7 , de cada item, sendo: 1 correspondente à dependência total; 2 dependência máxima; 3 dependência moderada; 4 dependência mínima; 5 supervisão; 6 independência modificada (ajuda técnica) e 7 independência completa. Obtém-se escore mínimo de 18 e máximo de 126 pontos que caracterizam os níveis de dependência pelos subescores, descritos na Figura 3 a seguir:

\begin{tabular}{|c|l|c|}
\hline Nível & \multicolumn{1}{|c|}{ Dependência Funcional } & Subescores \\
\hline 1 & Dependência total (assistência total) & 18 pontos \\
\hline 2 & Dependência Máxima (assistência de até 75\% na tarefa) & $19-60$ pontos \\
\hline 3 & Dependência moderada (assistência de até 50\% na tarefa) & \\
\hline 4 & Dependência Mínima (assistência de até 25\% na tarefa) & $61-103$ pontos \\
\hline 5 & Supervisão, estímulo ou preparo & $104-126$ pontos \\
\hline 7 & Independência Modificada & \\
\hline
\end{tabular}

Figura 3 - Níveis de Independência Funcional, com suas respectivas pontuações (RIBERTO et al., 2004)

Etapa II. Avaliação do cuidador

\section{A) Instrumento para caracterização do cuidador}

Este instrumento permitiu conhecer os cuidadores dos idosos nos seguintes aspectos: sexo, idade, estado conjugal, grau de parentesco, conhecimento sobre a doença, se teve curso formal para o cuidar, horas dedicadas ao cuidar, atividades do cuidar e apoio. Foi elaborado pela pesquisadora juntamente com a orientadora e submetido a três especialistas da área de gerontologia para análise, e as sugestões foram identificadas e alguns itens foram modificados (Apêndice B). 
B) Escala de Sobrecarga de Zarit: elaborada por Zarit e Zarit (1987), traduzida e validada para a cultura brasileira por Scazufca (2002). Esta escala, com 22 itens, tem como objetivo avaliar o impacto percebido do cuidar sobre a saúde física e emocional, atividades sociais e condição financeira. As respostas aos 22 itens devem ser dadas segundo uma escala de cinco pontos que descrevem como cada afirmação afeta a pessoa. Cada item da escala tem escores representados da seguinte forma: nunca (0), raramente (1), algumas vezes (2), frequentemente (3), sempre (4). A pontuação indica a frequência de cada item. No último item, o escore varia de 0 a 4 também, mas representa o quanto o entrevistado está se sentindo cansado mediante a tarefa de prestar o cuidado, representado por: nem um pouco (0), um pouco (1), moderadamente (2), muito (3), extremamente (4). O total da escala é obtido somando todos os itens e pode variar de 0 a 88 . Quanto maior a pontuação obtida, maior a sobrecarga percebida pelo cuidador (Anexo C). Associado a essa pontuação foi utilizado ponto de corte para diagnóstico de sobrecarga, segundo estudo internacional de Hebert et al. (2000) e o nacional de Luzardo et al. (2006) a seguinte pontuação: sobrecarga intensa escores entre $61 \mathrm{e}$ 88; moderado a severo, entre 41 e 60, moderado a leve, entre 21 e 40; e ausência de sobrecarga, escores inferiores a 21 pontos.

Foi solicitada a autorização para a autora da escala validada no Brasil, Scazufca, 2002 (Apêndice C).

C) Self Reporting Questionnaire (SRQ-20): este instrumento foi desenvolvido por Harding et al. (1980) e validado no Brasil por Mari e Willians (1986) e tem como objetivo a detecção de desconforto emocional na população geral. As 20 questões que compõem a escala têm duas possibilidades de resposta (sim/não) e foram desenhadas para abordar sintomas emocionais e físicos associados a quadros psiquiátricos (cefaleias frequentes, queixas de insônia e de alterações de apetite, piora da concentração, nervosismo, cansaço, queixas estomacais, diminuição do interesse pelas atividades rotineiras, pensamentos suicidas, sentimentos de tristeza e de desesperança). Quanto maior a frequência de respostas sim, maior o nível de estresse emocional. A pontuação pode variar de 0 a 20 (Anexo D) e utilizado o ponto de corte de $7 / 8$ baseado no estudo brasileiro para 
diferenciar a possibilidade de casos com desconfortos emocionais (MARI e WILLIANS, 1986). Foi solicitada autorização para os autores da escala validada no Brasil, Mari e Williams, 1986 (Apêndice D).

\subsection{Análise dos dados}

Foi elaborada uma planilha de dados no programa Microsoft Excel, contendo um dicionário (codebook) e duas planilhas utilizadas para a validação por dupla entrada (digitação). A análise dos dados foi realizada no aplicativo Statistical Package for the Social Science (SPSS) versão 15.0, de forma descritiva, univariada (tabelas de frequência) e bivariada (tabelas de contingência para variáveis qualitativas). As médias das variáveis categóricas foram analisadas estatisticamente pelo teste $t$ de Student, e ANOVA a um fator foi utilizada para comparação de mais de dois grupos. Além disso, foi calculada correlação de Spearman entre variáveis ordinais e quantitativas e correlação de Pearson entre variáveis quantitativas. As correlações foram consideradas como sendo fracas, moderadas ou fortes, conforme a convenção usual (MUNRO, 2001):
a) fraca, se $|r|<0,3$
b) moderada, se $0,3 \leq|r|<0,7$
c) forte, se $|r| \geq 0,7$

Após essa primeira análise, foi realizada regressão linear múltipla para construir um modelo estatístico para as melhores variáveis preditoras da sobrecarga dos cuidadores, variáveis com $p<0,10$, e para controlar os potenciais de confusão das associações das análises univariadas e das correlações nas análises bivariadas. Dessa forma, obtiveram-se como variáveis dependentes a Escala de Sobrecarga de Zarit e o SRQ e como preditores ou variáveis explanatórias (independentes) a MIF, desempenho cognitivo, sexo do cuidador, tempo de cuidado. Utilizou-se, também, a sobrecarga como preditora de desconforto emocional. 
Em todos os testes, o nível de significância utilizado foi $\alpha=0,05$. No entanto, é preciso ressaltar que os valores de $\mathrm{p}$ foram interpretados supondo que a casuística constitui uma amostra aleatória simples de uma população com características semelhantes.

\subsection{Procedimentos éticos}

O projeto foi apreciado e aprovado pelo Comitê de Ética em Pesquisa da Escola de Enfermagem de Ribeirão Preto da Universidade de São Paulo (Processo 0884/2008) (Anexo F).

Elaborado Termo de Consentimento Livre e Esclarecido para o idoso e para o cuidador (Apêndice E e F) pelo pesquisador, assinado em duas vias, conforme as diretrizes e normas regulamentares de pesquisa envolvendo seres humanos, Resolução n ${ }^{\circ} .196$ do Conselho Nacional de Saúde, de 10 de outubro de 1996. 
5. Resultadas 


\section{RESULTADOS}

\subsection{Características sociodemográficas dos idosos que vivem na comunidade de Ribeirão Preto, SP.}

Verificam-se, na Tabela 3, as características sociodemográficas dos 574 idosos entrevistados. Destaca-se que grande parte $(33,4 \%)$ se encontra na faixa etária de 80 anos ou mais de idade (idade mínima de 65 e máxima de 103 anos) e do sexo feminino $(67,8 \%)$. A média de idade foi 76,6 anos $( \pm 7,6)$. Entre as mulheres, a média de idade foi 76,5 anos $( \pm 7,7$ anos), entre os homens, 74,9 anos $( \pm 7,3)$ (dados não mostrados na Tabela 3 ).

Dos 574 idosos, $326(56,8 \%)$ referiram não ter companheiro, ou seja, os viúvos, solteiros e divorciados. Analisando apenas os viúvos, foram encontrados $54,5 \%$ das mulheres e $15,7 \%$ dos homens (dados não mostrados na Tabela 3 ).

No que se refere à escolaridade, $314(54,7 \%)$ estudaram de 1 a 4 anos, seguidos de $116(20,2 \%)$ analfabetos. Quanto à situação econômica do idoso, 363 $(63,2 \%)$ eram aposentados seguidos de $188(32,8 \%)$ que recebiam pensão, incluindo, na maioria, as mulheres (179; 46\%), e apenas uma minoria (62;10,8\%) referiu ter trabalho próprio (dados não mostrados na Tabela 3). Referente à renda individual do idoso, a média foi de $\mathrm{R} \$ 947,20$, sendo que para os homens foi superior ao das mulheres, perfazendo uma diferença de $R \$ 300,00$. A média da renda familiar (incluindo o idoso) foi de $\mathrm{R} \$ 1.460,00$.

O número de pessoas que coabitam com o idoso variou de 1 a 26 , média de três pessoas, sendo que $133(23,25 \%)$ referiram residir somente com o cônjuge.

Observam-se, ainda, na Tabela 3, os mesmos dados sociodemográficos do idoso relacionados ao fato de ter ou não cuidador para o auxílio nas atividades de vida diária. Caracterizando os idosos que têm cuidador, no total de $124(21,6 \%)$ idosos, revela-se a maioria com 80 anos ou mais ( $81 ; 65,3 \%$ ), associação estatisticamente significativa; idosos do sexo feminino ( $91 ; 73,4 \%$ ), os sem companheiros (326; $56,8 \%$ ), associação estatisticamente significativa. Destacaramse ainda, idosos com baixa escolaridade $(61 ; 49,2 \%)$, diferença das médias 
estatisticamente significantes; idosos de menor renda individual, porém, os de maior renda familiar e aqueles idosos que convivem no arranjo "cônjuge, filhos, genro e/ou nora" (36; 29\%), associação estatisticamente significativa.

Tabela 3 - Distribuição dos idosos residentes na comunidade de Ribeirão Preto, segundo faixa etária, sexo, estado conjugal, escolaridade, renda, com quem mora e desempenho cognitivo, relacionada ao fator sem/com cuidador. Ribeirão Preto, 2010.

\begin{tabular}{|c|c|c|c|c|c|c|c|}
\hline \multirow[t]{2}{*}{ Perfil dos idosos } & \multicolumn{2}{|c|}{ Com cuidador } & \multicolumn{2}{|c|}{ Sem cuidador } & \multicolumn{2}{|c|}{ Total } & \multirow[t]{2}{*}{ p-valor } \\
\hline & $\mathbf{N}^{\circ}$ & $(\%)$ & $\mathbf{N}^{\circ}$ & $(\%)$ & $\mathbf{N}^{\circ}$ & (\%) & \\
\hline Faixa etária & $81,8(8,2)$ & & $74,4(6,4)$ & & $76(7,6)$ & & $<0,001^{*}$ \\
\hline $65-69$ & 16 & 12,9 & 154 & 34,2 & 170 & 29,6 & \\
\hline $70-74$ & 15 & 12,1 & 124 & 27,6 & 126 & 22,0 & \\
\hline $75-79$ & 15 & 12,1 & 89 & 19,8 & 117 & 20,4 & \\
\hline 80 anos ou mais & 81 & 65,3 & 111 & 24,7 & 161 & 28,0 & \\
\hline Sexo & & & & & & & $0,131^{* *}$ \\
\hline Feminino & 91 & 73,4 & 298 & 66,2 & 389 & 67,8 & \\
\hline Masculino & 33 & 26,6 & 152 & 33,8 & 185 & 32,2 & \\
\hline \multicolumn{8}{|l|}{ Estado conjugal } \\
\hline Tem companheiro? & & & & & & & $<0,001^{* *}$ \\
\hline Sim & 37 & 29,8 & 211 & 46,9 & 248 & 43,2 & \\
\hline Não & 87 & 70,2 & 239 & 53,1 & 326 & 56,8 & \\
\hline Escolaridade & $3,09(4,2)$ & & $4,6(4,3)$ & & $4,3(4,3)$ & & $<0,001^{*}$ \\
\hline Analfabeto & 45 & 36,3 & 71 & 15,8 & 116 & 20,2 & \\
\hline 1 a 4 anos & 61 & 49,2 & 253 & 56,2 & 314 & 54,7 & \\
\hline 5 a 8 anos & 9 & 7,3 & 58 & 12,9 & 67 & 11,7 & \\
\hline 9 a 11 anos & 5 & 4,0 & 27 & 6,0 & 32 & 5,6 & \\
\hline 12 anos ou mais & 4 & 8,9 & 41 & 9,1 & 45 & 7,8 & \\
\hline Renda mensal idoso & $\mathrm{R} \$ 876,8$ & & $\mathrm{R} \$ 966,6$ & & $\mathrm{R} \$ 947,2$ & & $0,531^{*}$ \\
\hline Renda mensal família & $\mathrm{R} \$ 1609,6$ & & $\mathrm{R} \$ 1418,8$ & & $\mathrm{R} \$ 1460$ & & $0,265^{\star}$ \\
\hline Com quem os idosos moram & & & & & & & $<0,001^{* *}$ \\
\hline Sozinho & 10 & 8,1 & 76 & 16,9 & 86 & 15,0 & \\
\hline Somente com o cônjuge & 12 & 9,7 & 121 & 26,9 & 133 & 23,2 & \\
\hline Cônjuge e filho(s) & 8 & 6,5 & 46 & 10,2 & 54 & 9,4 & \\
\hline Cônjuge, filhos, genro e nora & 36 & 29,0 & 12 & 2,7 & 48 & 8,4 & \\
\hline Somente com os filhos & 7 & 5,6 & 40 & 8,9 & 47 & 8,2 & \\
\hline Arranjos trigeracionais & 17 & 13,7 & 41 & 9,1 & 58 & 10,1 & \\
\hline Arranjos intrageracionais & 8 & 6,4 & 16 & 3,6 & 24 & 4,2 & \\
\hline Somente com os netos & 1 & 0,8 & 14 & 3,1 & 15 & 2,6 & \\
\hline Não familiares & 3 & 2,4 & 6 & 1,3 & 9 & 1,6 & \\
\hline Outros & 22 & 17,8 & 78 & 17,3 & 100 & 17,5 & \\
\hline Desempenho cognitivo & & & & & & & $<0,001^{* *}$ \\
\hline Baixo & 70 & 56,5 & 43 & 9,6 & 113 & 19,7 & \\
\hline Alto & 54 & 43,5 & 407 & 90,4 & 461 & 80,3 & \\
\hline TOTAL & 124 & 21,6 & 450 & 78,4 & 574 & 100 & \\
\hline
\end{tabular}

Salário Mínimo Nacional em janeiro de 2009 R \$ 450,00.

* Teste $t$ de student,

** Associação de $x^{2}$. 


\subsection{Avaliação do desempenho cognitivo e da capacidade funcional dos idosos que vivem na comunidade de Ribeirão Preto, SP.}

O MEEM é um instrumento psicométrico usado mundialmente para avaliar estado cognitivo em pessoas idosas, tanto normais como portadoras de quadros demenciais.

A média total encontrada para o MEEM da população de idosos estudada foi de 22,6 $( \pm 6,5)$. Considerando a influência da educação sobre o MEEM, Bertolucci et al. (1994) propuseram que o ponto de corte para o diagnóstico genérico de "declínio cognitivo" em sujeitos brasileiros fosse de 13 pontos para analfabetos, 18 pontos para escolaridade baixa/média e 26 pontos para alta escolaridade. Entretanto, segundo Brucki et al. (2003), o corte para desempenho cognitivo em pessoas idosas avaliadas pelo MEEM deveria ser inferior a 20 (analfabetos), 25 (1 a 4 anos de escolaridade), 27 (5 a 8 anos de escolaridade), 28 (de 8 a 11 anos de escolaridade) e 29 (12 anos ou mais).

Observou-se que os idosos entrevistados apresentaram escores acima dos propostos por Bertolucci et al. (1994) e inferiores aos sugeridos por Brucki et al. (2003), como mostra a Tabela 4, o grupo dos analfabetos entrevistados atingiu 16,8 pontos como média de escore; nos demais grupos de escolarização, o nível fundamental obteve 23,2 pontos; os que estudaram de 5 a 8 anos, 25,2 pontos, de 8 a 11 anos obtiveram média de 26,1 e os que estudaram mais de 12 anos, 27,4. Esses dados demonstram que os idosos participantes não se encontram em estados demenciais ou de declínio cognitivo, independentemente do nível de escolaridade, de acordo com os parâmetros do instrumento utilizado por Bertolucci et al. (1994), e contraditoriamente seriam diagnosticados caso se utilizassem parâmetros do instrumento sugerido por Brucki et al. (2003). Por meio dos pontos de corte de Bertolucci et al. (1994), 19,7\% da população de idosos desta pesquisa apresentaram deficit cognitivo, quando relacionado ao grau de escolaridade, e dos pontos de corte de Brucki et al. (2003), a maioria, 52,3\%, dos idosos, apresentou deficit cognitivo. 
Tabela 4 - Distribuição das médias do MEEM, segundo grau de escolaridade dos idosos residentes na comunidade de Ribeirão Preto e os pontos de corte do MEEM, segundo Bertolucci et al. (1994) e Brucki et al. (2003). Ribeirão Preto, 2010.

\begin{tabular}{cccc}
\hline Escolaridade & Média MEEM (DP) & $\begin{array}{c}\text { Escore MEEM } \\
\text { Bertolucci et al.(1994) }\end{array}$ & $\begin{array}{c}\text { Escore MEEM } \\
\text { Brucki et al.(2003) }\end{array}$ \\
\hline \hline Analfabetos & $16,8(6,8)$ & 13 & 20 \\
1 a 4 anos & $23,2(6,9)$ & 18 & 25 \\
5 a 8 anos & $25,2(5,4)$ & 18 & 27 \\
9 a 11 anos & $26,1(6,2)$ & 26 & 28 \\
12 anos ou mais & $27,4(5,8)$ & 26 & 29 \\
Deficit cognitivo? & - & $19,7 \%$ & $52,3 \%$ \\
\hline \hline
\end{tabular}

$\mathrm{Na}$ Tabela 4, mediante as diferenças entre as médias do MEEM encontradas, comparadas aos pontos de corte sugeridos na literatura, considerando que a população estudada foi considerada de baixo nível educacional (média=4,2 anos de estudo) e de idosos presumivelmente saudáveis, vivendo em uma comunidade familiar, optou-se pelo ponto de corte sugerido por Bertolucci et al. (1994), para que não se retratassem possíveis casos de falsos positivos referentes a estados demenciais ou de declínio cognitivo.

Visualiza-se, na Tabela 5, o desempenho dos idosos no MEEM, levandose em consideração o sexo e a escolaridade, em anos completos, segundo Bertolucci et al. (1994).

Tabela 5 - Distribuição dos idosos, segundo a escolaridade, relacionada ao desempenho no MEEM e sexo do idoso. Ribeirão Preto, 2010.

\begin{tabular}{|c|c|c|c|c|c|c|c|}
\hline \multirow{3}{*}{$\begin{array}{l}\text { Escolaridade } \\
\text { (anos) }\end{array}$} & \multicolumn{6}{|c|}{ " DESEMPENHO NO MEEM } & \multirow[b]{3}{*}{$\begin{array}{l}\text { Média } \\
\text { (DP) }\end{array}$} \\
\hline & \multicolumn{2}{|c|}{ Feminino } & \multicolumn{2}{|c|}{ Masculino } & \multicolumn{2}{|c|}{ Total } & \\
\hline & $\begin{array}{l}\text { Baixo } \\
N(\%)\end{array}$ & $\begin{array}{l}\text { Alto } \\
\mathrm{N}(\%)\end{array}$ & $\begin{array}{l}\text { Baixo } \\
N(\%)\end{array}$ & $\begin{array}{l}\text { Alto } \\
(\%)\end{array}$ & $\begin{array}{l}\text { Baixo } \\
N(\%)\end{array}$ & $\begin{array}{l}\text { Alto } \\
\mathrm{N}(\%)\end{array}$ & \\
\hline Analfabeto & $27(32,9)$ & $66(21,5)$ & $5(16,1)$ & $18(11,7)$ & $32(28,3)$ & $84(18,2)$ & $1016,8(6,9)$ \\
\hline 1 a 4 anos & $33(40,2)$ & $175(57)$ & $11(35,5)$ & $95(61,7)$ & $44(38,9)$ & $270(58,6)$ & $23,2(5,4)$ \\
\hline 5 a 8 anos & $9(11,0)$ & $34(11,1)$ & $4(12,9)$ & $20(13,0)$ & $13(11,5)$ & $54(11,7)$ & $25,2(6,2)$ \\
\hline 9 ou + & $13(15,9)$ & $32(10,5)$ & $11(35,5)$ & $21(13,6)$ & $24(21,2)$ & $53(11,5)$ & $27,3(5,2)$ \\
\hline Total & $82(21,1)$ & $307(78,9)$ & $31(16,8)$ & $154(83,2)$ & $113(19,7)$ & $461(80,3)$ & $22,6(6,5)$ \\
\hline
\end{tabular}

$r=0,403, p<0,001$. 
Ao avaliar os idosos quanto ao desempenho no MEEM, dos $113(19,7 \%)$ que apresentaram deficit cognitivo, $82(21,1 \%)$ eram do sexo feminino e $31(16,8 \%)$, do sexo masculino. Entretanto, houve predomínio do deficit cognitivo em ambos os sexos, entre os que frequentaram a escola entre um e quatro anos, sendo que entre os homens, também, obtiveram o mesmo valor aqueles que estudaram de nove ou mais anos.

A correlação de Pearson, encontrada entre a escolaridade em anos completos e o escore bruto do MEEM, foi moderada e estatisticamente significante ( $r$ $=0,403, p<0,001$ ), demonstrando que a diminuição do tempo da educação formal foi um fator que influenciou o desempenho dos idosos no teste do MEEM.

Observa-se, na Tabela 6, os dados sociodemográficos e a medida da independência funcional dos 574 idosos entrevistados relacionados ao desempenho cognitivo. 
Tabela 6 - Características dos idosos, segundo faixa etária, sexo, estado conjugal, com quem mora e categorias da MIF relacionadas ao desempenho cognitivo. Ribeirão Preto, 2010.

\begin{tabular}{|c|c|c|c|c|c|c|c|}
\hline \multirow{2}{*}{$\begin{array}{l}\text { Avaliação do idoso } \\
\text { Desempenho Cognitivo }\end{array}$} & \multirow{2}{*}{$\begin{array}{l}\text { Baixo } \\
\mathrm{N}\end{array}$} & \multicolumn{3}{|c|}{ Alto } & \multirow{2}{*}{$\begin{array}{c}\text { Total } \\
\mathrm{N}\end{array}$} & \multirow{2}{*}{$\%$} & \multirow[t]{2}{*}{ p-valor } \\
\hline & & $\%$ & $\mathrm{~N}$ & $\%$ & & & \\
\hline Faixa etária $\quad$ Média (DP) & $81,5(8,5)$ & & $747,7(6,7)$ & & & & $=<0,001^{*}$ \\
\hline $65-69$ & 15 & 13,3 & 155 & 33,6 & 170 & 29,6 & \\
\hline $70-74$ & 15 & 13,3 & 111 & 24,1 & 126 & 22,0 & \\
\hline $75-79$ & 22 & 19,5 & 95 & 20.6 & 117 & 20,4 & \\
\hline $80+$ & 61 & 54,0 & 100 & 21,7 & 161 & 28,0 & \\
\hline \multicolumn{8}{|l|}{ Sexo } \\
\hline Feminino & 82 & 21,1 & 307 & 78,9 & 389 & 67,8 & \\
\hline Masculino & 31 & 16,8 & 154 & 83,2 & 185 & 32,2 & $0,134^{\star *}$ \\
\hline Total & 113 & 19,7 & 461 & 80,3 & 574 & 100 & \\
\hline Tem companheiro? & & & & & & & $<0,001^{* *}$ \\
\hline Sim & 34 & 30,1 & 214 & 46,4 & 248 & 43,2 & \\
\hline Não & 79 & 69,9 & 247 & 53,6 & 326 & 56,8 & \\
\hline Com quem mora & & & & & & & $0,003^{* *}$ \\
\hline Sozinho & 17 & 15,0 & 69 & 15,0 & 86 & 15,0 & \\
\hline Somente com o cônjuge & 21 & 18,6 & 112 & 24,3 & 133 & 23,2 & \\
\hline Cônjuge, filhos, genro e/ou nora & 22 & 19,4 & 80 & 17,3 & 102 & 17,6 & \\
\hline Somente com os filhos & 9 & 8,0 & 38 & 8,2 & 47 & 8,2 & \\
\hline Arranjos trigeracionais & 10 & 8,8 & 48 & 10,4 & 58 & 10,1 & \\
\hline Arranjos intrageracionais & 7 & 6,2 & 17 & 3,7 & 24 & 5,2 & \\
\hline Somente com os netos & 1 & 0,9 & 14 & 3,0 & 15 & 2,6 & \\
\hline Não familiares & 4 & 3,5 & 5 & 1,1 & 9 & 1,6 & \\
\hline Outros & 22 & 19,4 & 78 & 16,9 & 100 & 16,5 & \\
\hline \multicolumn{8}{|l|}{ MIF } \\
\hline Dependência Completa & 8 & 7,1 & 0 & 0 & 8 & 1,4 & $<0,001^{* *}$ \\
\hline Dependência Moderada & 12 & 10,6 & 3 & 0,7 & 15 & 2,6 & \\
\hline Dependência Mínima & 37 & 32,7 & 30 & 6,5 & 67 & 11,7 & \\
\hline \multicolumn{8}{|l|}{ Independência } \\
\hline Modificada/Completa & 56 & 49,6 & 428 & 92,8 & 484 & 84,3 & \\
\hline
\end{tabular}

Destaca-se a prevalência de deficit cognitivo em idosos com 80 anos ou mais $(61 ; 54 \%)$, dados estatisticamente significantes $(p<0,001)$. Da mesma forma ocorre em idosos classificados, na MIF, no item "independência modificada ou completa" (56; 49,6\%), entre idosos viúvos $(63 ; 55,8 \%)$ e entre aqueles que convivem com cônjuge, filhos, genro e/ou nora (22; 19,4\%). Verifica-se que aqueles idosos com dependência completa foram todos classificados por apresentarem 
deficit cognitivo. A maioria dos idosos foi classificada como independentes (484; $84,3 \%)$ e apenas $8(1,4 \%)$ como totalmente dependentes. Apenas a categoria sexo do idoso não foi estatisticamente significante.

Os resultados a seguir referem-se ao sexo e à funcionalidade dos idosos, segundo avaliação pela Medida da Independência Funcional (MIF) (Tabela 7).

Tabela 7 - Distribuição das médias da MIF Global, MIF Motora e MIF Cognitiva relacionada ao sexo dos idosos. Ribeirão Preto, 2010.

\begin{tabular}{lcrrr}
\hline \hline \multicolumn{1}{c}{ Avaliação do idoso } & Feminino & Masculino & Total & \multicolumn{1}{c}{ Teste t } \\
& Média(DP) & Média(DP) & \multicolumn{1}{c}{ Média(DP) } & \multicolumn{1}{c}{-valor } \\
\hline \hline MIF total & $113,1(21)$ & $115,8(19,7)$ & $113,9(20,6)$ & $\mathbf{0 , 1 5 2}$ \\
MIF Motora & $82,1(15,4)$ & $83,8(14,9)$ & $82,7(13)$ & $\mathbf{0 , 2 1 4}$ \\
MIF Cognitiva & $30,9(6,6)$ & $31,9(5,7)$ & $31,3(6,4)$ & $\mathbf{0 , 0 9 8}$ \\
\hline \hline
\end{tabular}

* Teste $t$ de student

$\mathrm{Na}$ avaliação da independência funcional, não se identificaram grandes diferenças entre médias da MIF total, MIF cognitiva e MIF motora entre os homens e as mulheres, embora as mulheres tenham apresentado escores inferiores aos dos homens. As diferenças não foram estatisticamente significantes.

A Tabela 8 demonstra a correlação entre a funcionalidade dos idosos, segundo a MIF e as variáveis sociodemográficas: idade, escolaridade, renda do idoso e a renda familiar.

A correlação positiva entre a MIF Global, MIF Cognitiva e MIF Motora e a idade, embora significativa, apresentou força de baixa magnitude. Já, entre a funcionalidade e a escolaridade, houve correlação negativa, de moderada força, estatisticamente significativa, como mostra a Tabela 6, ou seja, nesta população os idosos com maior nível de escolaridade apresentaram menor comprometimento funcional. 
Tabela 8 - Coeficientes de correlação da MIF com variáveis sociodemográficas, idade, escolaridade, renda dos idosos e da família. Ribeirão Preto, 2010.

\begin{tabular}{lcccc}
\hline \hline Pearson & $\begin{array}{c}\text { Idade do } \\
\text { sujeito }\end{array}$ & Escolaridade & Renda do idoso & Renda da família \\
\hline \hline MIF Global & $0,184^{*}$ & $-0,422^{*}$ & 0,070 & 0,031 \\
MIF Motora & $0,162^{*}$ & $-0,411^{*}$ & 0,061 & 0,026 \\
MIF Cognitiva & $0,208^{*}$ & $-0,383^{*}$ & $0,081^{* *}$ & 0,038 \\
\hline${ }^{*} \mathrm{p}<0,001 ;{ }^{* *} \mathrm{p}<0,05$ & & & &
\end{tabular}

Na Tabela 9, observam-se os valores do desempenho cognitivo e o sexo dos idosos relacionados às categorias da MIF. Os resultados mostram que não houve diferenças entre os sexos, e reafirmam que, tanto os idosos do sexo masculino quanto os femininos, classificados na MIF por Dependência Completa, têm deficit cognitivo.

Tabela 9 - Distribuição dos idosos, segundo categorias da MIF, relacionada ao desempenho cognitivo e ao sexo dos idosos. Ribeirão Preto, 2010.

\begin{tabular}{lrrrrrr}
\hline \hline & \multicolumn{3}{c}{ DESEMPENHO NO MEEM } & & Masculino & \\
\hline \hline Independência & Baixo & Alto & Total & Baixo & Alto & Total \\
Funcional & $\mathbf{N}(\%)$ & $\mathbf{N}(\%)$ & $\mathbf{N}(\%)$ & $\mathbf{N}(\%)$ & $(\%)$ & $\mathbf{N}(\%)$ \\
Depend. Completa & $5(6,1)$ & - & $5(1,0)$ & $3(9,7)$ & - & $3(1,6)$ \\
Depend. Moderada & $11(13,4)$ & $1(0,3)$ & $12(3,3)$ & $1(3,2)$ & $2(1,3)$ & $3(1,6)$ \\
Depend. Mínima & $27(32,9)$ & $20(6,5)$ & $47(12,1)$ & $10(32,3)$ & $10(6,5)$ & $20(10,8)$ \\
Ind.Modif./Completa & $39(47,6)$ & $286(93,2)$ & $325(83,6)$ & $17(54,8)$ & $142(92,2)$ & $159(86)$ \\
\hline \hline
\end{tabular}

Após realização do teste $t$ de Student para comparar as médias da MIF Global, MIF Cognitiva e MIF Motora, relacionadas às variáveis categóricas do desempenho cognitivo, obtiveram-se diferenças estatisticamente significativas $(p<0,001)$ para todas as médias, como mostra a Tabela 10. Nota-se média maior da MIF para idosos com alto desempenho cognitivo, e menor MIF para os que têm deficit cognitivo, em todos os domínios da MIF, o que revela a hipótese de que idosos com deficit cognitivo podem apresentar maiores chances de desenvolver incapacidade funcional. 
Tabela 10 -Distribuição da média e desvio-padrão dos domínios da MIF relacionada ao desempenho cognitivo. Ribeirão Preto, 2010.

\begin{tabular}{ccccc}
\hline \hline \multirow{2}{*}{ Desempenho Cognitivo } & $\begin{array}{c}\text { Média MIF } \\
\text { Global (DP) }\end{array}$ & $\begin{array}{c}\text { Média MIF } \\
\text { Motora (DP) }\end{array}$ & $\begin{array}{c}\text { Média MIF } \\
\text { Cognitiva (DP) }\end{array}$ & $\begin{array}{c}\text { Test t } \\
\text { p-valor }\end{array}$ \\
\hline \hline Baixo & $93,0( \pm 34,2)$ & $69,1( \pm 25,3)$ & $24,0( \pm 10,2)$ & $\mathrm{p}<0,001$ \\
Alto & $119,1( \pm 10,6)$ & $86,0( \pm 8,8)$ & $33,1( \pm 3,0)$ & $\mathrm{p}<0,001$ \\
Total & $114,0( \pm 20,6)$ & $82,7( \pm 15,3)$ & $31,3( \pm 6,4)$ & $\mathrm{p}<0,001$ \\
\hline \hline
\end{tabular}

$\mathrm{Na}$ Tabela 11, estão descritos dados referentes às médias do MEEM e aos domínios da MIF relacionados ao fato de "ter ou não cuidador" para auxílio nas AVDs. Revela-se o predomínio de idosos com cuidador associado às baixas médias de escores do MEEM e domínios da MIF. Observa-se, então, que, idosos com cuidadores são, na maioria, os mais dependentes e com menores escores de MEEM. As diferenças foram estatisticamente significantes, revelando que, quanto maior o prejuízo no desempenho cognitivo e/ou maior a dependência funcional dos idosos, maior a necessidade de apoio do cuidador.

Tabela 11 - Distribuição da média, desvio-padrão da MIF e do MEEM, relacionada ao fator sem/com cuidador. Ribeirão Preto, 2010.

\begin{tabular}{lcccc}
\hline \hline Perfil dos idosos & Com cuidador & $\begin{array}{c}\text { Sem cuidador } \\
\text { Média } \\
\text { Média (DP) }\end{array}$ & $\begin{array}{c}\text { Total } \\
\text { Média (DP) }\end{array}$ & $\begin{array}{c}\text { Teste t } \\
\text { p-valor }\end{array}$ \\
\hline \hline MEEM & $15,2(8,3)$ & $24,7(4,07)$ & $22,6(6,4)$ & $<0,001$ \\
MIF Global & $89,1(30,6)$ & $120,8(8,3)$ & $113,9(20,6)$ & $<0,001$ \\
MIF Motora & $65,2(23,4)$ & $87,5(6,3)$ & $82,7(15,3)$ & $<0,001$ \\
MIF Cognitiva & $23,9(9,5)$ & $33,32(2,8)$ & $31,3(6,4)$ & $<0,001$ \\
\hline \hline
\end{tabular}

Os dados a seguir referem-se ao cuidador, na experiência do cuidado, revelando necessidades de atenção à saúde para essa parcela populacional. 


\subsection{Características sociodemográficas dos cuidadores de idosos que vivem na comunidade de Ribeirão Preto, SP.}

$\mathrm{Na}$ Tabela 12, observam-se as características sociodemográficas dos cuidadores comparadas ao sexo dos mesmos. Na presente pesquisa, foram entrevistados 124 cuidadores, 107 (85,6\%) deles eram do sexo feminino e 17 $(14,4 \%)$, do sexo masculino. A idade média dos cuidadores foi de $56,6( \pm 13,4)$, sendo que os cuidadores homens correspondiam àqueles com a média de idade mais alta $(61,8 ; \pm 18)$ comparados às cuidadoras mulheres $(55,7 ; \pm 55,7)$. Esses dados são estatisticamente significantes $(p<0,05)$.

No item "ter companheiro" foram inseridos cuidadores casados e amasiados. Os enquadrados na resposta "não ter companheiro" foram considerados os solteiros, viúvos, separados e divorciados. A maioria das cuidadoras referiu ter companheiro $(71 ; 66,4 \%)$ e entre os homens cuidadores, a maioria respondeu não ter companheira $(12 ; 70,6 \%)$.

Referente à escolaridade, a maior parte dos cuidadores, tanto do sexo feminino $(40 ; 37,4 \%)$ quanto do sexo masculino $(7 ; 41,25 \%)$, estudou de um a quatro anos. Poucos eram analfabetos e poucos estudaram mais de 13 anos.

Quanto ao grau de parentesco, a maioria dos cuidadores está na categoria "filha/o, genro/nora" (69; 55,6\%), seguidos pelos cônjuges (22; 17,7\%). Para as mulheres cuidadoras, $62(57,95 \%)$ eram filhas ou noras, $18(16,8 \%)$ eram esposas cuidadoras, semelhante se comparado com os cuidadores homens, em que $7(41,2 \%)$ eram filhos ou genro e $4(23,5 \%)$ eram esposos cuidadores. Chama a atenção que apenas $12(9,7 \%)$ dos cuidadores não eram familiares, eram vizinhos, amigos, ou um profissional contratado. Dos cuidadores, a grande proporção respondeu viver junto com o idoso $(99 ; 79,8 \%)$ e ter conhecimento sobre como cuidar do idoso $(115 ; 92,7 \%)$. 
Tabela 12 - Distribuição dos cuidadores dos idosos, segundo faixa etária, estado conjugal, escolaridade, parentesco, se vive com o idoso, conhecimento sobre o cuidar, relacionada ao sexo do cuidador. Ribeirão Preto, 2010.

\begin{tabular}{|c|c|c|c|c|c|c|c|}
\hline \multirow[t]{2}{*}{ Perfil dos cuidadores } & \multicolumn{2}{|c|}{ Feminino } & \multicolumn{2}{|c|}{ Masculino } & \multicolumn{2}{|c|}{ Total } & \multirow[t]{2}{*}{ p-valor } \\
\hline & $\mathbf{N}^{\circ}$ & $(\%)$ & $\mathbf{N}^{\circ}$ & $(\%)$ & $\mathbf{N}^{\circ}$ & $(\%)$ & \\
\hline "FaixaetáriaM(DP) & $\begin{array}{l}55,7(12,5) \\
\end{array}$ & & 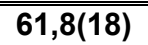 & & $56,6(13,4)$ & & $0,0,082^{*}$ \\
\hline 60 anos ou menos & 73 & 68,2 & 8 & 47,1 & 81 & 65,3 & \\
\hline+60 anos & 34 & 31,8 & 9 & 52,9 & 43 & 34,7 & \\
\hline Tem companheiro? & & & & & & & $0,004^{* *}$ \\
\hline Sim & 71 & 66,4 & 5 & 29,4 & 76 & 61,3 & \\
\hline Não & 36 & 33,6 & 12 & 70,6 & 48 & 38,7 & \\
\hline Escolaridade & & & & & & & - \\
\hline Analfabeto & 9 & 8,4 & 1 & 5,9 & 10 & 8,0 & \\
\hline 1 a 4 anos & 40 & 37,4 & 7 & 41,2 & 47 & 37,9 & \\
\hline 5 a 8 anos & 29 & 27,1 & 5 & 29,4 & 34 & 27,4 & \\
\hline 9 a 11 anos & 22 & 20,6 & 3 & 17,6 & 25 & 20,2 & \\
\hline 12 anos ou mais & 7 & 6,5 & 1 & 5,9 & 8 & 6,5 & \\
\hline Parentesco & & & & & & & $0,596^{* *}$ \\
\hline Esposo/a & 18 & 16,8 & 4 & 23,5 & 22 & $\begin{array}{r}17,7 \\
\text { continua. }\end{array}$ & \\
\hline Filho/a, genro/nora & 62 & 57,9 & 7 & 41,2 & 69 & 55,6 & \\
\hline Irmão/ã, cunhado/a & 11 & 10,3 & 3 & 17,6 & 14 & 11,3 & \\
\hline Neto/a & 6 & 5,6 & 1 & 5,9 & 7 & 5,6 & \\
\hline Não Familiar & 10 & 9,3 & 2 & 11,8 & 12 & 9,7 & \\
\hline Vive com idoso? & & & & & & & $0,130^{* *}$ \\
\hline Sim & 83 & 77,6 & 16 & 94,1 & 99 & 79,8 & \\
\hline Não & 24 & 22,4 & 1 & 5,9 & 25 & 20,2 & \\
\hline $\begin{array}{l}\text { Conhecimento sobre } \\
\text { cuidar }\end{array}$ & & & & & & & $0,441^{* *}$ \\
\hline Sim & 100 & 93,5 & 15 & 88,2 & 115 & 92,7 & \\
\hline Não & 7 & 6,5 & 2 & 11,8 & 9 & 7,3 & \\
\hline
\end{tabular}

5.4 Escalas utilizadas para avaliação da sobrecarga e do desconforto emocional dos cuidadores de idosos que vivem na comunidade de Ribeirão Preto, SP.

A sobrecarga dos cuidadores foi avaliada pela Escala de Sobrecarga de Zarit. O coeficiente de alpha de Cronbach foi 0,642 , o qual revela que a consistência interna da escala detectou moderado grau de fidelidade. Na Tabela 13, está 
descrita a distribuição das respostas da escala, bem como a porcentagem para cada uma delas.

A escala tem 5 níveis de respostas: nunca (0), raramente (1), algumas vezes (2), frequentemente (3), sempre (4), sendo que na última questão as respostas são: nem um pouco (0), um pouco (1), moderadamente (2), muito (3), extremamente (4). Quanto maior o número da resposta maior a pontuação para a sobrecarga.

Quando se analisam as respostas enquadradas na categoria "nunca", percebe-se maior frequência de respostas para as perguntas: "O $\mathrm{Sr} / \mathrm{Sra}$ se sente envergonhado(a) o comportamento do idoso?", "O Sr/Sra não se sente à vontade de ter visitas em casa, por causa do idoso?" e "O $\mathrm{Sr} / \mathrm{Sra}$ sente que $\mathrm{S}$ afeta negativamente seus relacionamentos com outros membros da família ou amigos?". 
Tabela 13 - Distribuição das respostas da Escala de Sobrecarga de Zarit dos cuidadores que vivem na comunidade de Ribeirão Preto, Ribeirão Preto, 2010.

\begin{tabular}{|c|c|c|c|c|c|}
\hline Questões da Escala de Sobrecarga & $\begin{array}{c}0 \\
\mathrm{n}(\%)\end{array}$ & $\begin{array}{c}1 \\
\mathrm{n}(\%)\end{array}$ & $\begin{array}{c}2 \\
\mathrm{n}(\%)\end{array}$ & $\begin{array}{c}3 \\
\mathrm{n}(\%)\end{array}$ & $\begin{array}{c}4 \\
n(\%)\end{array}$ \\
\hline $\begin{array}{l}\text { 1) O Sr/Sra sente que S pede mais ajuda do que } \\
\text { ele(a) necessita? }\end{array}$ & $78(62,4)$ & $16(12,8)$ & $11(8,8)$ & $7(5,6)$ & $13(10,4)$ \\
\hline $\begin{array}{l}\text { 2) O Sr/Sra sente que por causa do tempo que o } \\
\text { Sr/Sra gasta com } S \text {, o Sr/Sra não tem tempo } \\
\text { suficiente para si mesmo? }\end{array}$ & $48(38,4)$ & $13(10,4)$ & $22(17,6)$ & $15(12)$ & $27(21,6)$ \\
\hline $\begin{array}{l}\text { 3) O Sr/Sra se sente estressado(a) entre cuidar de } \mathrm{S} \\
\text { e suas outras responsabilidades com a família e o } \\
\text { trabalho? }\end{array}$ & $57(45,6)$ & $12(9,6)$ & $26(20,8)$ & $11(8,8)$ & $19(15,2)$ \\
\hline $\begin{array}{l}\text { 4) O Sr/Sra se sente envergonhado(a) com o } \\
\text { comportamento de S? }\end{array}$ & $\underline{99(79,2)}$ & $9(7,2)$ & $12(9,6)$ & $1(0,8)$ & $4(3,2)$ \\
\hline $\begin{array}{l}\text { 5) O Sr/Sra se sente irritado quando S está por } \\
\text { perto? }\end{array}$ & $90(72)$ & $10(8)$ & 15(12) & $6(4,8)$ & $4(3,2)$ \\
\hline $\begin{array}{l}\text { 6) O Sr/Sra sente que } S \text { afeta negativamente seus } \\
\text { relacionamentos com outros membros da família ou } \\
\text { amigos? }\end{array}$ & $\underline{95(76)}$ & $6(4,8)$ & $14(11,2)$ & $2(1,6)$ & $8(6,4)$ \\
\hline 7) $\mathrm{O} \mathrm{Sr} / \mathrm{Sra}$ sente receio pelo futuro de $\mathrm{S}$ ? & $38(30,4)$ & $6(4,8)$ & $25(20)$ & $\underline{28(22,4)}$ & $\underline{28(22,4)}$ \\
\hline 8) O Sr/Sra sente que $S$ depende do $\mathrm{Sr} / \mathrm{Sra}$ ? & $11(8,8)$ & $2(1,6)$ & $7(5,6)$ & $\underline{25(20)}$ & $\underline{80(64)}$ \\
\hline $\begin{array}{l}\text { 9) O Sr/Sra se sente tenso(a) quando S está por } \\
\text { perto? }\end{array}$ & $86(68,8)$ & $10(8)$ & $12(9,6)$ & $8(6,4)$ & $9(7,2)$ \\
\hline $\begin{array}{l}\text { 10) O Sr/Sra sente que a sua saúde foi afetada por } \\
\text { causa do seu envolvimento com } S \text { ? }\end{array}$ & $75(60)$ & $9(7,2)$ & $20(16)$ & $8(6,4)$ & $13(10,4)$ \\
\hline $\begin{array}{l}\text { 11) O Sr/Sra sente que o Sr/Sra não tem tanta } \\
\text { privacidade como gostaria, por causa de } S \text { ? }\end{array}$ & $77(61,6)$ & $7(5,6)$ & $15(12)$ & $5(4)$ & $21(16,8)$ \\
\hline $\begin{array}{l}\text { 12) O Sr/Sra sente que a sua vida social tem sido } \\
\text { prejudicada porque o } \mathrm{Sr} / \mathrm{Sra} \text { está cuidando de } S \text { ? }\end{array}$ & $66(52,8)$ & $6(4,8)$ & $\underline{27(21,6)}$ & $5(4)$ & $21(16,8)$ \\
\hline $\begin{array}{l}\text { 13) O Sr/Sra não se sente à vontade de ter visitas } \\
\text { em casa, por causa de } S \text { ? }\end{array}$ & $\underline{97(77,6)}$ & $11(8,8)$ & $6(4,8)$ & $1(0,8)$ & $10(8)$ \\
\hline $\begin{array}{l}\text { 14) O Sr/Sra sente que S espera que o } \mathrm{Sr} / \mathrm{Sra} \text { cuide } \\
\text { dele(a), como se o } \mathrm{Sr} / \mathrm{Sra} \text { fosse a única pessoa de } \\
\text { quem ele(a) pode depender? }\end{array}$ & $37(29,6)$ & $6(4,8)$ & $16(12,8)$ & $15(12)$ & $51(40,8)$ \\
\hline $\begin{array}{l}\text { 15) O Sr/Sra sente que não tem dinheiro suficiente } \\
\text { para cuidar de } S \text {, somando-se as suas outras } \\
\text { despesas? }\end{array}$ & $60(48)$ & $11(8,8)$ & $18(14,4)$ & $13(10,4)$ & $23(18,4)$ \\
\hline $\begin{array}{l}\text { 16) O Sr/Sra sente que será incapaz de cuidar de } S \\
\text { por muito mais tempo? }\end{array}$ & $75(60)$ & $9(7,2)$ & $23(18,4)$ & $6(4,8)$ & $12(9,6)$ \\
\hline $\begin{array}{l}\text { 17) O Sr/Sra sente que perdeu o controle da sua vida } \\
\text { desde a doença de S? }\end{array}$ & $85(68)$ & $8(6,4)$ & $12(9,6)$ & $7(5,6)$ & $13(10,4)$ \\
\hline $\begin{array}{l}\text { 18) O Sr/Sra gostaria de simplesmente deixar que } \\
\text { outra pessoa cuidasse de S? }\end{array}$ & $89(71,2)$ & $8(6,4)$ & $13(10,4)$ & $10(8)$ & $5(4)$ \\
\hline $\begin{array}{l}\text { 19) O Sr/Sra se sente em dúvida sobre o que fazer } \\
\text { por } S \text { ? }\end{array}$ & $\underline{74(59,2)}$ & $12(9,6)$ & $26(20,8)$ & $11(8,8)$ & $2(1,6)$ \\
\hline $\begin{array}{l}\text { 20) O Sr/Sra sente que deveria estar fazendo mais } \\
\text { por } S \text { ? }\end{array}$ & $46(36,8)$ & $8(6,4)$ & $\underline{32(25,6)}$ & $18(14,4)$ & $21(16,8)$ \\
\hline 21) O Sr/Sra sente que poderia cuidar melhor de $S$ ? & $56(44,8)$ & $10(8)$ & $25(20)$ & $15(12)$ & $19(15,2)$ \\
\hline $\begin{array}{l}\text { 22) De uma maneira geral, quanto se sente } \\
\text { sobrecarregado(a) por cuidar de } S^{*}\end{array}$ & $44(35,2)$ & $30(24)$ & $\underline{31(24,8)}$ & $13(10,4)$ & $7(5,6)$ \\
\hline
\end{tabular}

Burden Interview (ZARIT e ZARIT, 1987). Tradução e validação para o português (SCAZUFCA, 2002)

Respostas correspondem: nunca (0), raramente (1), algumas vezes (2), frequentemente (3), sempre (4);* Neste item as respostas são: nem um pouco (0), um pouco (1), moderadamente (2), muito (3), extremamente (4). 
Na presente pesquisa, a tendência foi que, tais situações, não causaram sobrecarga para o cuidador. Já nas situações em que o cuidador referiu sentir receio pelo futuro do idoso e sentir que o idoso depende do cuidador foram respostas mais relevantes para a sobrecarga, apresentando maiores frequências de respostas "frequentemente" e "sempre".

$\mathrm{Na}$ última questão, em que se fala "de uma maneira geral, quanto se sente sobrecarregado(a) por cuidar de $\mathrm{S}^{*}$, a maioria dos cuidadores respondeu "nunca" (44; 35,2\%) seguido pela resposta "moderadamente"(31; 24,8\%).

No que se refere ao desconforto emocional avaliado pelo $S R Q$, obteve-se alpha de Crombach 0,852 , revelando ótimo grau de fidelidade, relacionado à consistência interna da escala. Na Tabela 14, estão descritas as respostas da escala, bem como a porcentagem para cada resposta. As respostas são dicotômicas, pontuando um para as respostas "sim" e zero para as respostas "não". A prevalência de respostas "sim" comparadas às respostas "não" refere-se às questões "sentir-se nervoso, tenso ou preocupado" (sim, 85; 68,0\%) e "sentir-se triste ultimamente" (sim, 74; 59,2\%). 
Tabela 14 - Distribuição das respostas da Escala SRQ dos cuidadores de idosos que vivem na comunidade de Ribeirão Preto. Ribeirão Preto, 2010.

\begin{tabular}{lcc}
\hline \hline Questões Escala SRQ & Não n(\%) & Sim n(\%) \\
\hline \hline Tem dores de cabeça frequentes? & $87(69,6)$ & $38(30,4)$ \\
Tem falta de apetite? & $104(83,2)$ & $21(16,8)$ \\
Dorme mal? & $73(58,4)$ & $52(41,6)$ \\
Assusta-se com facilidade? & $79(63,2)$ & $46(36,8)$ \\
Tem tremores nas mãos? & $104(83,2)$ & $21(16,8)$ \\
Sente-se nervoso(a), tenso(a) ou preocupado(a)? & $\underline{40(32,0)}$ & $\underline{85(68,0)}$ \\
Tem má digestão? & $91(72,8)$ & $34(27,2)$ \\
Tem dificuldade de pensar com clareza? & $87(69,6)$ & $38(30,4)$ \\
Tem se sentido triste ultimamente? & $\underline{51(40,8)}$ & $\underline{74(59,2}$ \\
Tem chorado mais do que de costume? & $87(69,6)$ & $38(30,4)$ \\
Encontra dificuldades para realizar com satisfação suas atividades & $91(72,8)$ & $34(27,2)$ \\
diárias? & & \\
Tem dificuldades para tomar decisões? & $86(68,8)$ & $39(31,2)$ \\
Tem dificuldades no serviço (seu trabalho é penoso, Ihe causa & $105(84,0)$ & $20(16,0)$ \\
sofrimento? & & \\
É incapaz de desempenhar um papel útil em sua vida? & $114(91,2)$ & $11(8,8)$ \\
Tem perdido o interesse pelas coisas? & $88(70,4)$ & $37(29,6)$ \\
Você se sente uma pessoa inútil, sem préstimo? & $110(88,0)$ & $15(12,0)$ \\
Tem tido a ideia de acabar com a vida? & $118(94,4)$ & $7(5,6)$ \\
Sente-se cansado(a) o tempo todo? & $79(63,2)$ & $46(36,8)$ \\
Tem sensações desagradáveis no estômago? & $88(70,4)$ & $37(29,6)$ \\
Você se cansa com facilidade? & $74(59,2)$ & $51(40,8)$ \\
\hline \hline Self Reporting Questionaire (SRQ-20) (HARDIN; ARANGO; BALTAZAR, 1980; tradução e \\
validação para o português por MARI e WILLIANS,1986). &
\end{tabular}

\subsection{Determinantes da sobrecarga e do desconforto emocional relacionados às características dos cuidadores de idosos que vivem na comunidade de Ribeirão Preto, SP.}

Observa-se, na Tabela 15, as médias de sobrecarga e desconforto emocional do cuidador comparadas às características como sexo, idade e nível educacional do cuidador, o grau de parentesco com o idoso, se vive com o idoso e se tem conhecimento sobre o cuidar. A média total de sobrecarga dos cuidadores foi de $27,8( \pm 17,5)$. O menor escore foi 02 e o maior escore foi 65 pontos. Cuidadores do sexo feminino obtiveram média superior a dos cuidadores do sexo masculino, 28,06 e 26,23 respectivamente. Dentre as características que atingiram maiores médias de sobrecarga, destacam-se os cuidadores com60 anos ou mais de idade $(30,8 ; \pm 17,2)$, os que estudaram de um a quatro anos $(31,1 ; \pm 19,6)$, os cuidadores 
não familiares $(32,2 ; \pm 22,5$, que viviam com o idoso $(28,8 ; \pm 15,8)$ e entre aqueles que não tinham conhecimento sobre a atividade de cuidar $(31,7 ; \pm 13,2)$.

Mediante as características sociodemográficas dos cuidadores, a diferença entre as médias das idades foi estatisticamente significante $(p<0,05)$.

$\mathrm{Na}$ Tabela 15, verificam-se maiores médias de desconforto emocional para os cuidadores do sexo feminino $(6,3 ; \pm 4,6)$, com 60 anos ou mais de idade $(6,2$; $\pm 17,2)$, os que estudaram de 1 a 4 anos $(7,0 ; \pm 4,2)$, os cuidadores netos/as $(7,4$; $\pm 6,1)$, que viviam com 0 idoso $(6,4 ; \pm 4,5)$ e entre aqueles que não tinham conhecimento sobre a atividade de cuidar $(6,9 ; \pm 2,5)$. Contudo, apenas o sexo e a idade apresentaram correlação significante com a sobrecarga. Porém, o nível educacional e o fato de viver ou não com o idoso apresentaram resultado marginalmente significante $(p=0,054$ e $p=0,062$, respectivamente).

Tabela 15 -Distribuição das características dos cuidadores de idosos, segundo as médias de sobrecarga e de desconforto emocional. Ribeirão Preto, 2010.

\begin{tabular}{|c|c|c|c|c|}
\hline \multirow{2}{*}{$\begin{array}{c}\text { Características do } \\
\text { cuidador }\end{array}$} & \multirow{2}{*}{$\begin{array}{c}\text { Zarit-Média (DP) } \\
27,8(17,5)\end{array}$} & \multicolumn{3}{|c|}{ SRQ-Média (DP) } \\
\hline & & p-valor & $6,0(4,4)$ & p-valor \\
\hline Sexo do cuidador & & $0,691^{*}$ & & $0,042^{*}$ \\
\hline Feminino & $28,1(17,5)$ & & $6,3(4,6)$ & \\
\hline Masculino & $26,2(16,4)$ & & $4,0(2,8)$ & \\
\hline Idade & & $0,049^{*}$ & & $0,810^{*}$ \\
\hline 60 anos ou menos & $29,9(17,6)$ & & $5,8(4,6)$ & \\
\hline & & & & continua \\
\hline+60 anos & $30,8(17,2)$ & & $6,2(4,1)$ & \\
\hline Nível Educacional & & $0,100^{\star *}$ & & $0,054^{* *}$ \\
\hline Analfabeto & $26,1(16,9)$ & & $4,9(3,2)$ & \\
\hline 1 a 4 anos & $31,1(19,6)$ & & $7,0(4,2)$ & \\
\hline 5 a 8 anos & $26,7(14,2)$ & & $6,2(4,9)$ & \\
\hline 9 a 11 anos & $21,6(14,9)$ & & $4,1(3,2)$ & \\
\hline 12 anos ou mais & $31(22,3)$ & & $6,1(6,1)$ & \\
\hline Parentesco & & $0,647^{\star \star *}$ & & $0,256^{\star * *}$ \\
\hline Esposo/a & $31,7(18,1)$ & & $6,9(3,7)$ & \\
\hline Filho/a, genro/nora & $27,3(14,7)$ & & $6,1(4,6)$ & \\
\hline Irmão/ã, cunhado/a & $21,9(13,7)$ & & $5,6(4,6)$ & \\
\hline Neto/a & $24,7(11,4)$ & & $7,4(5,1)$ & \\
\hline Não Familiar & $32,2(22,5)$ & & $3,8(3,8)$ & \\
\hline Vive com idoso? & & 0,273 & & 0,062 \\
\hline Sim & $28,8(15,8)$ & & $6,4(4,5)$ & \\
\hline Não & $24,4(23,6)$ & & $4,7(3,7)$ & \\
\hline Conhecimento sobre & & 0,398 & & 0,341 \\
\hline cuidar & & & & \\
\hline Sim & $27,5(17,8)$ & & $5,9(4,5)$ & \\
\hline Não & $31,7(13,2)$ & & $6,9(2,5)$ & \\
\hline
\end{tabular}


Na Tabela 16, está descrita a correlação de Pearson das variáveis horas por dia despendidas na tarefa do cuidar e quantos dias durante a semana e nos finais de semana o cuidador utiliza para o ato de cuidar do idoso, associados à sobrecarga e ao desconforto emocional. Ao analisar a sobrecarga, quanto às horas por dia, durante a semana e nos finais de semana, as médias corresponderam a $12,4( \pm 7,5)$ e $12,3 \quad( \pm 7,9)$, respectivamente, dados estes estatisticamente significantes. Com relação ao desconforto emocional, observou-se correlação positiva com as horas de cuidado durante a semana e nos fins de semana $(p<0,01)$.

No que se refere aos dias durante a semana e nos finais de semana, as médias encontradas foram, 4,95 e 1,94, respectivamente. Ao se correlacionar a idade do cuidador, em total de anos, com as médias de sobrecarga e desconforto emocional encontrou-se relevância estatística $(p<0,05)$.

Esses dados mostram que para 0 ato de cuidar, os cuidadores dispensaram a maior parte do dia, acarretando assim ao cuidador pouca possibilidade para se autocuidar e também para desenvolver atividades de lazer e descanso.

Tabela 16 - Correlação de Pearson referente à sobrecarga e ao desconforto emocional relacionada à idade, às horas e aos dias de cuidado. Ribeirão Preto, 2010.

\begin{tabular}{lccccc}
\hline \hline $\begin{array}{c}\text { Correlação } \\
\text { Pearson }\end{array}$ & $\begin{array}{c}\text { Idadecu } \\
\text { idador }\end{array}$ & $\begin{array}{c}\text { Horas/semana } \\
\text { (Média=12,4horas) }\end{array}$ & $\begin{array}{c}\text { Horas/Fim de semana } \\
\text { (Média=12,3 horas) }\end{array}$ & $\begin{array}{c}\text { Dia/semana } \\
(\mathrm{M}=4,95)\end{array}$ & $\begin{array}{c}\text { Dia/fim de } \\
\text { sem. }(\mathrm{M}=1,94)\end{array}$ \\
\hline \hline Sobrecarga & $0,178^{* *}$ & $0,252^{*}$ & $0,260^{*}$ & $-0,018$ & 0,040 \\
SRQ & $-0,022$ & $0,237^{*}$ & $0,227^{*}$ & $-0,043$ & 0,019 \\
\hline${ }^{*} \mathrm{p}<0,01 ;{ }^{* *} \mathrm{p}<0,05$ & & & &
\end{tabular}

Ao se analisar a sobrecarga dos cuidadores, na Tabela 17, os pontos de corte da Escala de Sobrecarga de Zarit estão estratificados em "Ausência de sobrecarga", "Sobrecarga leve", "Sobrecarga moderada" e "Sobrecarga intensa". Dos 124 cuidadores, $50(40 \%)$ foram classificados com ausência de sobrecarga, 47 $(37,6 \%)$, sobrecarga leve, $25(20 \%)$, sobrecarga moderada e apenas3 $(2,4 \%)$ com sobrecarga intensa. Dentre os cuidadores identificados por sobrecarga leve, estão incluídos os cuidadores com média de 58,8 anos de idade e sobrecarga intensa 
estão incluídos aqueles com média de 62 anos. Ao se compararem médias de escores de desconforto emocional, observam-se as maiores pontuações de SRQ para os cuidadores com sobrecarga moderada $(10,1 ; \pm 3,6)$. Ao se comparar as médias de escores de desconforto emocional, observam-se as maiores pontuações para os cuidadores com sobrecarga intensa, esta correlação, segundo coeficiente de Pearson, tem força moderada $(r=0,490)$ e estatisticamente significante $(p \quad 0,001)$.

Tabela 17 - Distribuição das médias da idade do cuidador e de valores de SRQ relacionada às categorias ordinais de sobrecarga. Ribeirão Preto, 2010.

\begin{tabular}{lcccc}
\hline \hline \multicolumn{1}{c}{ Dados do cuidador } & $\begin{array}{c}\text { Ausência } \\
\text { sobrecarga }\end{array}$ & $\begin{array}{c}\text { Sobrecarga } \\
\text { Leve }\end{array}$ & $\begin{array}{c}\text { Sobrecarga } \\
\text { moderada }\end{array}$ & $\begin{array}{c}\text { Sobrecarga } \\
\text { intensa }\end{array}$ \\
\hline \hline Idade do cuidador & $53(14,2)$ & $58,8(13,3)$ & $58,6(12,1)$ & $62(6,0)$ \\
SRQ(p $\mathbf{0 , 0 0 1}, \mathbf{R}=\mathbf{0}, 490)$ & $3,6(4,2)$ & $6,1(3,0)$ & $10,1(3,6)$ & $9,3(7,8)$ \\
\hline Total(\%) & $50(40 \%)$ & $47(37,6 \%)$ & $25(20 \%)$ & $3(2,4 \%)$ \\
\hline \hline Ponto de corte: $\leq$ 20 ausência de sobrecarga; 21 a 40 sobrecarga leve; 41 a 60 sobrecarga \\
moderada; $\geq 61$ sobrecarga intensa.
\end{tabular}

Quando se analisam as mesmas variáveis, acima descritas, com o ponto de corte para $S R Q$, estratificado como: $\leq 7$ desconforto emocional não significativo; $\geq 8$ desconforto emocional significativo, não se observam diferenças significantes entre elas, com exceção das médias da sobrecarga.

Dos 124 cuidadores, $95(68,8 \%)$ apresentaram desconforto emocional não significativo, sendo que $39(31,2 \%)$ apresentaram desconforto emocional significativo.

Os cuidadores classificados com desconforto emocional significativo pontuaram média para sobrecarga de $36,2( \pm 14,9)$, e os demais, $23,8(17,3)$.

Diante desses dados, pode-se verificar que algumas variáveis foram estatisticamente significantes, quando se relacionam à sobrecarga e ao desconforto emocional do cuidador.

$\mathrm{Na}$ Tabela 18, está descrita a regressão linear múltipla, tendo como desfecho os escores totais da Escala de Sobrecarga de Zarit e SRQ,relacionada às variáveis preditoras do cuidador, sexo, horas de cuidado diário durante a semana e nos finais de semana e tendo, também, os valores de SRQ como preditores da sobrecarga. 
Tabela 18 - Resultado da análise de regressão múltipla, tendo como desfecho a Escala de Sobrecarga de Zarit com as variáveis explicativas do cuidador consideradas. Ribeirão Preto, 2010.

\begin{tabular}{lcccc}
\hline \hline Variáveis cuidador & \multicolumn{2}{c}{ Sobrecarga Zarit } & \multicolumn{3}{c}{ SRQ } \\
& $\boldsymbol{\beta}$ & p-valor & $\boldsymbol{\beta}$ & p-valor \\
\hline Sexo cuidador & $-0,039$ & 0,656 & $-0,161$ & 0,042 \\
Horas/semana & 0,237 & 0,009 & 0,130 & 0,113 \\
Sobrecarga Zarit & - & - & 0,454 & 0,000 \\
\hline \hline
\end{tabular}

Os dados mostraram que o sexo do cuidador foi considerado bom preditor do desconforto emocional assim como o tempo gasto em horas diárias de cuidado para a sobrecarga, revelando dados estatisticamente significantes, ajustando-se para as demais variáveis citadas. A sobrecarga do cuidador foi um forte e relevante preditor do desconforto emocional. Os dados sugerem que a sobrecarga é um fator de risco para o desconforto emocional nos cuidadores.

\subsection{Determinantes da sobrecarga e do desconforto emocional relacionados às características dos idosos que vivem na comunidade de Ribeirão Preto, SP.}

Visualiza-se, na Tabela 19, as características dos idosos associadas à sobrecarga e ao desconforto emocional. Os cuidadores que auxiliam idosos com idade de 65 a 69 anos foram os que obtiveram média de sobrecarga superior aos demais. Da mesma forma as características dos idosos como sexo masculino $(28,1 ; \pm 16,3)$, idosos divorciados/desquitados $(39 ; \pm 19,9)$, aqueles que estudaram de 5 a 8 anos $(38,8 ; \pm 13,9)$ e entre os com deficit cognitivo $(29,9 ; \pm 18,6)$ repercutiram maiores médias para sobrecarga. No que se refere à dependência funcional, os idosos com dependência moderada, segundo corte de pontos da MIF, elevaram a média de sobrecarga do cuidador $(33,5$; $\pm 16,8)$, seguido por aqueles com completa dependência funcional $(32,3 ; \pm 9,2)$.

Apesar de apresentarem maiores médias para a sobrecarga, tais resultados não foram estatisticamente significantes com exceção da medida da independência funcional $(p<0,05)$. Compreende-se que quanto mais dependente é o idoso, maior a chance de acarretar sobrecarga ao cuidador.

Ao analisar o desconforto emocional, observa-se que algumas características do idoso se repetem em termos de provocarem maiores níveis de desconforto emocional assim como de sobrecarga. Características essas como, idosos do sexo masculino $(6,7 ; \pm 4,6)$, divorciados/desquitados $(6,3 ; \pm 5,0)$, os idosos 
que completaram 5 a 8 anos de escolaridade $(7,4 ; \pm 3,9)$, aqueles com deficit cognitivo $(6,1 ; \pm 4,3)$ e aqueles que cuidam de idosos dependentes, são mais sobrecarregados do que os demais.

Os idosos na faixa etária de 75 a 79 anos de idade foram os que mais acarretaram sintomas de desconforto emocional nos cuidadores $(6,6 ; \pm 4,6)$, também, idosos categorizados como completamente dependentes $(6,9 ; \pm 2,7)$ seguidos pelos idosos categorizados com mínima dependência $(6,8 ; \pm 4,7)$. No entanto, houve significância estatística apenas entre a associação da sobrecarga com o deficit cognitivo e a MIF. Já o desconforto emocional (SRQ) apresentou associação significativa apenas com a MIF.

Tabela 19 - Distribuição das características sociodemográficas e a MIF dos idosos relacionada às médias de sobrecarga e de desconforto emocional do cuidador. Ribeirão Preto, 2010.

\begin{tabular}{|c|c|c|c|c|}
\hline Características dos idosos & $\begin{array}{c}\text { Média da } \\
\text { Sobrecarga (DP) }\end{array}$ & p-valor & $\begin{array}{c}\text { Média } \\
\text { SRQ (DP) }\end{array}$ & p-valor \\
\hline Faixa etária & & 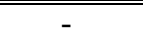 & & 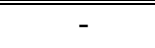 \\
\hline $65-69$ & $30,0(16,6)$ & & $5,2(2,9)$ & \\
\hline $70-74$ & $21,3(11,6)$ & & $5,1(4,1)$ & \\
\hline \multirow[t]{2}{*}{$75-79$} & $26,6(17,2)$ & & $6,6(4,6)$ & \\
\hline & & & & continua \\
\hline 80 anos ou mais & $28,7(18,7)$ & & $6,1(4,7)$ & \\
\hline Sexo & & $0,876^{*}$ & & $0,243^{*}$ \\
\hline Feminino & $27,5(18)$ & & $5,6(4,4)$ & \\
\hline Masculino & $28,1(16,3)$ & & $6,7(4,6)$ & \\
\hline Estado conjugal & & $0,692^{* * *}$ & & $0,880^{* * *}$ \\
\hline Casado & $27,1(16,9)$ & & $5,7(4,1)$ & \\
\hline Viúvo & $28,1(18,2)$ & & $6,2(4,6)$ & \\
\hline Solteiro & $24,5(15,5)$ & & $5,0(4,9)$ & \\
\hline Divorciado/desquitado & $39,0(19,9)$ & & $6,3(5,0)$ & \\
\hline Escolaridade & & - & & - \\
\hline Analfabeto & $27,1(15,6)$ & & $6,7(4,6)$ & \\
\hline 1 a 4 anos & $27,7(18,9)$ & & $5,6(4,4)$ & \\
\hline 5 a 8 anos & $36,8(13,9)$ & & $7,4(3,9)$ & \\
\hline 9 a 11 anos & $17,8(22,1)$ & & $3,2(2,9)$ & \\
\hline 12 anos ou mais & $27,7(12,3)$ & & $3,3(4,2)$ & \\
\hline Deficit Cognitivo (MEEM) & & $0,035^{*}$ & & $0,137^{*}$ \\
\hline Sim & $29,9(18,6)$ & & $6,1(4,3)$ & \\
\hline Não & $24,8(15,8)$ & & $5,8(4,7)$ & \\
\hline MIF & & $0,004^{* *}$ & & $0,014^{* *}$ \\
\hline Dependência Completa & $32,3(9,2)$ & & $6,9(2,7)$ & \\
\hline Dependência Moderada & $33,5(16,8)$ & & $6,7(5,3)$ & \\
\hline Dependência Mínima & $29,9(19,3)$ & & $6,8(4,7)$ & \\
\hline Independência Modificada/Completa & $22,3(15,2)$ & & $4,5(3,6)$ & \\
\hline
\end{tabular}


Na Tabela 20, a correlação de Pearson demonstra que valores da MIF Global, MIF Cognitiva e MEEM são estatisticamente significativos relacionados com a sobrecarga do cuidador ( $p$ 0,05), apesar de terem apresentado força de baixa magnitude.

Tabela 20 - Distribuição da correlação de Pearson entre sobrecarga e desconforto emocional do cuidador relacionadaà idade, aos anos de escolaridade, ao escore total da MIF e MEEM dos idosos que vivem na comunidade de Ribeirão Preto. Ribeirão Preto, 2010.

\begin{tabular}{llccccc}
\hline $\begin{array}{c}\text { Correlação } \\
\text { Pearson }\end{array}$ & $\begin{array}{c}\text { Idade } \\
\text { Idoso }\end{array}$ & $\begin{array}{c}\text { Frequentou a } \\
\text { escola(anos) }\end{array}$ & $\begin{array}{c}\text { MIF } \\
\text { Global }\end{array}$ & $\begin{array}{c}\text { MIF } \\
\text { Motora }\end{array}$ & $\begin{array}{c}\text { MIF } \\
\text { Cognitiva }\end{array}$ & MEEM \\
\hline \hline Sobrecarga & 0,077 & $-0,022$ & $-0,179^{* *}$ & $-0,153$ & $-0,201^{* *}$ & $-0,189^{* *}$ \\
SRQ & 0,057 & $-0,154$ & $-0,153$ & $-0,146$ & $-0,132$ & $-0,134$ \\
\hline${ }^{*} p<0,05$. & & & & & &
\end{tabular}

Ao se analisar a sobrecarga dos cuidadores, na Tabela 21, os pontos de corte da Escala de Sobrecarga de Zarit estão estratificados em "Ausência de sobrecarga", "Sobrecarga moderada" e "Sobrecarga intensa". Dentre os cuidadores diagnosticados por sobrecarga intensa, estão incluídos os que cuidam de idosos mais velhos, média de 91 anos, com menores anos de escolaridade $(2,3 ; \pm 2,1)$ eidosos com menores médias de MEEM $(12,7 ; \pm 6,4)$. Idosos com menor média de MIF global, motora e cognitiva são auxiliados por cuidadores classificados com moderada sobrecarga.

Tabela 21 - Distribuição das médias da idade do idoso, anos de escolaridade, MEEM, MIF Global, MIF Motora e MIF Cognitiva relacionada às categorias ordinais da Escala de Sobrecarga de Zarit. Ribeirão Preto, 2010.

\begin{tabular}{lcccc}
\hline $\begin{array}{c}\text { Dados do idoso e } \\
\text { cuidador }\end{array}$ & $\begin{array}{c}\text { Ausência } \\
\text { sobrecarga }\end{array}$ & $\begin{array}{c}\text { Sobrecarga } \\
\text { Leve }\end{array}$ & $\begin{array}{c}\text { Sobrecarga } \\
\text { moderada }\end{array}$ & $\begin{array}{c}\text { Sobrecarga } \\
\text { intensa }\end{array}$ \\
\hline \hline Idade do idoso & $82(8,0)$ & $81(8,3)$ & $82,9(8,7)$ & $91,3(11,1)$ \\
Anos escolaridade & $3,2(4,9)$ & $3,2(4,1)$ & $2,8(8,7)$ & $2,3(2,1)$ \\
MEEM & $17,1(7,6)$ & $15(8,8)$ & $12,8(8,5)$ & $12,7(6,4)$ \\
MIF Global & $96,9(27,3)$ & $84,9(33,8)$ & $81,7(29,7)$ & $91,3(16,7)$ \\
MIF Motora & $70,6(20,5)$ & $61,4(25,7)$ & $61(23,6)$ & $69,7(17,2)$ \\
MIF Cognitiva & $26,4(8,5)$ & $23,4(10,2)$ & $20,7(10,0)$ & $21,7(2, \%)$ \\
\hline \hline
\end{tabular}


Diante do exposto, verifica-se que algumas variáveis dos idosos foram estatisticamente significantes, quando se relacionam à sobrecarga e ao desconforto emocional do cuidador. Dessa forma, realizou-se análise de regressão linear, tendo como desfecho (variável dependente) os escores totais da Escala de Sobrecarga de Zarit e $\mathrm{SRQ}$ e as variáveis preditoras dos idosos como MIF global e o desempenho cognitivo, mostrados na Tabela 22.

Tabela 22 - Resultado da análise de regressão linear, tendo como desfecho a Escala de Sobrecarga de Zarit e a $S R Q$ com as variáveis explicativas MIF e MEEM do idoso. Ribeirão Preto, 2010.

\begin{tabular}{lccrc}
\hline \hline Variáveis idosos & \multicolumn{2}{c}{ Sobrecarga Zarit } & \multicolumn{3}{c}{ SRQ } \\
& \multicolumn{1}{c}{$\boldsymbol{\beta}$} & p-valor & $\boldsymbol{\beta}$ & \multicolumn{1}{c}{-valor } \\
\hline \hline MIF Global & $-0,179$ & 0,046 & -0153 & 0,089 \\
MEEM & 0,127 & 0,157 & $-0,046$ & 0,565 \\
\hline \hline
\end{tabular}

$\mathrm{Na}$ análise da regressão linear, tendo como desfecho o escore total da escala de Sobrecarga de Zarit e como variável preditora a MIF Global dos idosos, observou-se uma correlação estatisticamente significante $(\beta=-0,179 ; p=0,046)$. Portanto, tais dados indicam que a dependência do idoso é um possível fator de risco para sobrecarga do cuidador.

\subsection{Determinantes da sobrecarga e do desconforto emocional relacionados à demanda dos cuidados e à necessidade de suporte informal dos cuidadores de idosos que vivem na comunidade de Ribeirão Preto, SP.}

$\mathrm{Na}$ Tabela 23, estão representados os domínios da MIF, detalhando as atividades diárias, de acordo com o ponto de corte para dependência completa, dependência moderada, dependência mínima e independência modificada ou completa, associados às médias de sobrecarga. Observam-se as maiores médias de sobrecarga para os cuidadores que auxiliam idosos com dependência completa, principalmente, relacionados à alimentação $(50,5)$, seguida pelo cuidar do idoso 
quando faz uso do vaso sanitário $(42,0)$, os quais se referem à MIF motora. Obtiveram médias altas para a sobrecarga de Zarit, no domínio da MIF cognitiva, cuidadores que auxiliam idosos completamente dependentes para resolução de problemas e memória $(42,2)$.

Tabela 23 - Valores médios das dimensões da Escala de Sobrecarga de Zarit, segundo os domínios da MIF. Ribeirão Preto, 2010.

\begin{tabular}{lcccc}
\hline \hline & \multicolumn{4}{c}{ Escala de Sobrecarga de Zarit - Média } \\
\multicolumn{1}{c}{ Domínios da MIF } & Dep. Comp. & Dep. Mod & Dep. Mín. & Indep. \\
\hline \hline Alimentação & $\underline{50,5}$ & 23,5 & 28,0 & 25,6 \\
Higiene Pessoal & 32,3 & 30,2 & 29,1 & 24,3 \\
Banho & 32,3 & 28,4 & 23,4 & 24,7 \\
Vestir-se acima da cintura & 34,9 & 23,4 & 25,8 & 25,8 \\
Vestir-se abaixo da cintura & 34,2 & 19,7 & 25,1 & 24,7 \\
Uso do vaso sanitário & $\underline{42,0}$ & 18,8 & 29,3 & 26,5 \\
Controle da urina & 32,7 & 37,4 & 24,7 & 23,2 \\
Controle das fezes & 35,7 & 25,4 & 39,3 & 24,2 \\
Transf. para cama e cadeira & 31,9 & 33,8 & 37,0 & 28,7 \\
Transf. para o vaso sanitário & 32,0 & 31,3 & 32,6 & 27,8 \\
Transf. para chuveiro & 30,7 & 24,2 & 30,0 & 27,5 \\
Marcha/ Cadeira de rodas & 28,7 & 36,0 & 31,3 & 28,5 \\
Escadas & 31,4 & 35,7 & 26,0 & 17,9 \\
Compreensão auditiva/visual & 29,6 & 33,0 & 32,2 & 19,7 \\
Expressão verbal/não verbal & 32,1 & 24,0 & 35,4 & 23,7 \\
Interação social & 33,6 & 28,0 & 31,5 & 23,5 \\
Resolução de problemas & $\underline{42,2}$ & 34,6 & 33,9 & 20,8 \\
Memória & $\underline{42,2}$ & 41,2 & 26,7 & 22,3 \\
\hline \hline
\end{tabular}

Dep.Comp.: Dependência Completa; Dep.Mod.: Dependência Modificada; Dep.Min.:

Dependência Mínima; Ind.: Independência.

Observa-se, na Tabela 24, que as médias de sobrecarga foram maiores para os cuidadores que referiram não receber ajuda para o auxílio das atividades do idoso referentes ao retorno às consultas, à alimentação e à higiene oral, quando comparados aos que referiram receber ajuda. Porém, quando a ajuda era recebida para outras atividades, como o sono/repouso, a atividade física e eliminações, as médias de sobrecarga do cuidador foram maiores, comparando-se às médias de sobrecarga daqueles que não recebiam ajuda. Entretanto, apenas a ajuda recebida 
referente ao retorno às consultas correlacionou-se de forma estatisticamente significante $(p<0,05)$ com a sobrecarga dos cuidadores.

Analisando o desconforto emocional, de acordo com as médias do $S R Q$, observa-se que os cuidadores que referiram não receber auxílio para atividades de alimentação, sono/repouso e retorno às consultas obtiveram as maiores médias, comparados aos que recebiam ajuda, embora não tenham alcançado o ponto de corte (7/8). Já os cuidadores que receberam suporte informal, referente às atividades de auxílio para as eliminações e higiene oral obtiveram média maior no $S R Q$ do que aqueles que não receberam apoio o que leva à compreensão de que esses cuidadores estão na linha-limite do desconforto emocional. Entretanto, tais diferenças entre as médias obtidas no $S R Q$ não foram estatisticamente significantes.

Tabela 24 - Distribuição das médias das respostas dos cuidadores, segundo a ajuda que recebem para auxílio nas atividades da vida diária do idoso. Ribeirão Preto, 2010.

\begin{tabular}{lcccccr}
\hline \hline \multicolumn{2}{c}{$\begin{array}{l}\text { AJUDA RECEBIDA } \\
\text { PARA O CUIDAR? }\end{array}$} & \multicolumn{2}{l}{ Sobrecarga Média(DP) } & \multicolumn{2}{c}{ Teste-t } & \multicolumn{2}{l}{ SRQ Média(DP) } & Teste-t \\
Pim & Não & p-valor & Sim & Não & p-valor \\
\hline \hline Higiene corporal & $27,4(14,5)$ & $29,7(15,5)$ & 0,468 & $\underline{6,6(4,2)}$ & $5,8(4,1)$ & 0,313 \\
Higiene oral & $30,7(16,1)$ & $\underline{31,0(14,5)}$ & 0,946 & $6,3(3,8)$ & $6,5(3,8)$ & 0,786 \\
Eliminações & $\underline{31,5(16,2)}$ & $29,2(14,6)$ & 0,532 & $\underline{7,0(3,9)}$ & $6,1(3,9)$ & 0,372 \\
Cuidado com a pele & $\mathbf{2 7 , 8 ( 1 5 , 3 )}$ & $30,9(14,4)$ & 0,334 & $6,2(4,1)$ & $6,5(4,0)$ & 0,719 \\
Alimentação & $27,6(15,4)$ & $\underline{32,1(19,1)}$ & 0,202 & $5,6(3,8)$ & $\underline{6,8(4,3)}$ & 0,164 \\
Medicação & $29,8(14,9)$ & $29,2(19,6)$ & 0,869 & $5,9(3,6)$ & $6,3(4,6)$ & 0,637 \\
Sono/repouso & $\underline{33,5(15,3)}$ & $30,4(15,2)$ & 0,389 & $6,1(3,5)$ & $\underline{6,7(4,6)}$ & 0,526 \\
Atividade física & $\underline{32,7(17,1)}$ & $30,2(20,9)$ & 0,636 & $5,7(3,9)$ & $6,6(4,8)$ & 0,436 \\
Lazer & $\mathbf{2 7 , 8 ( 1 5 , 4 )}$ & $29,4(19,6)$ & 0,651 & $6,1(4,6)$ & $5,7(4,4)$ & 0,716 \\
Retorno às consultas & $\mathbf{2 4 , 9 ( 1 4 , 8 )}$ & $\underline{32,5(19,8)}$ & $\mathbf{0 , 0 1 9}$ & $5,8(4,4)$ & $\underline{6,6(4,7)}$ & 0,338 \\
\hline \hline
\end{tabular}

Dessa forma, capítulo posterior, faz-se a discussão dos resultados levantados com embasamento na literatura nacional e internacional acerca da temática em questão. 
6. Discussãa 


\section{DISCUSSÃO}

Neste tópico, iniciam-se a discussão dos resultados referentes à caracterização dos idosos, bem como de seus cuidadores, e a avaliação da sobrecarga e desconforto emocional dos cuidadores.

\subsection{Características sociodemográficas dos idosos que vivem na comunidade de Ribeirão Preto, SP.}

O envelhecimento é um fenômeno diferencial para homens e mulheres, uma vez que as mulheres apresentam maior longevidade quando comparadas aos homens. Ao analisar a Tabela 3, observa-se, na distribuição do total de idosos, residentes na comunidade de Ribeirão Preto, o predomínio de mulheres e idosos de idades mais avançadas, média geral de idade de 76,6 anos, superior à média de expectativa de vida referida por algumas pesquisas nacionais e internacionais como de Bédard et al. (2001), Scazufca et al. (2002), Scazufca (2002), Tooth et al.(2005), porém,a média de idade foi semelhante aos estudos de Cassis et al. (2007), Gort et al. (2007), Fernandes e Garcia (2009) e Gratão et al. (2010).

Quando se relaciona a média de idade ao fato de o idoso ter ou não cuidador, observa-se que os idosos de idade mais avançada, média de 81,8 anos de idade, são os que têm cuidador, dados semelhantes foram encontrados em pesquisas nacionais, como de Giacomin et al. (2008), Gratão et al. (2010) e internacional, como o de Tooth et al. (2005).

Pode-se afirmar que o predomínio de mulheres nas pesquisas nacionais e internacionais sobre população idosa prevalece, tanto na população total, quanto naquelas que recebem auxílio de cuidador (BÉDARD et al., 2001; SCAZUFCA et al., 2002; TOOTH et al., 2005; GORT et al., 2007; CASSIS et al., 2007; FERNANDES e GARCIA, 2009). 
Berquó (1996) discute a feminização do envelhecimento, em que o número absoluto de mulheres idosas, quando confrontado com o de homens de 65 anos ou mais, era superior e que, também, a proporção de idosas em relação à população total de mulheres tem se mantido, sistematicamente, superior àquela correspondente aos homens idosos. A autora ressalta, ainda, que esse fato é decorrente de uma situação de mortalidade diferencial por sexo que prevalece há muito tempo, sendo que, desde 1950 as mulheres apresentam maior esperança de vida ao nascer, representando seis anos de vida mais do que os homens.

A prevalência de mulheres na população idosa vem acompanhada da prevalência de viúvas. De acordo com Veras et al. (2002), em quase todos os países, inclusive os desenvolvidos, o número de viúvas é maior quando comparado ao de viúvos. $O$ autor ressalta ainda que o número de mulheres que vivem sozinhas é muito menor nos países em desenvolvimento, mas ainda é mais alto entre as mulheres do que entre os homens. Além da maior longevidade das mulheres, as normas sociais e culturais, prevalecentes na sociedade brasileira levam os homens a se casarem com mulheres mais jovens que eles, e o fato de casar mais de uma vez para os viúvos idosos é maior do que para viúvas. Berquó (1996) refere que essas diferenças são responsáveis pela superioridade de viúvas, em relação aos viúvos, da ordem de 3,6 para 1, respectivamente.

Os idosos foram classificados, conforme Tabela 3, de acordo com o estado conjugal, como tendo ou não companheiro. Os que tinham companheiro correspondiam aos casados ou que moravam com um companheiro, e os classificados como não tendo companheiro, os viúvos, divorciados e solteiros. A diferença entre as variáveis foi estatisticamente significante. Os idosos solteiros, viúvos ou divorciados foram os mais prevalentes relacionados ao fato de ter cuidador. O estudo de Giacomin et al. (2005), que determinou a prevalência e fatores associados com as necessidades de cuidadores de 1.606 idosos da comunidade de Bambuí/MG, mostrou que o isolamento social é fator de risco para incapacidades, o fato de ser solteiro esteve significativamente associado à necessidade de cuidador.

Ao considerar a renda per capita dos idosos, a grande maioria mencionou que recebia aposentadoria e/ou pensão, e uma minoria referiu ter trabalho próprio. A média geral, em reais, de renda individual do idoso, mensal, foi de $R \$ 947,20$, 


\section{Discussãa}

aproximadamente 2,1 salários mínimos*, superior a outros estudos brasileiros (SCAZUFCA et al., 2002; PEDRAZZI, 2008; TALMELLI et al., 2010).

Quando comparada a renda entre os idosos com cuidador e os sem cuidador, verifica-se que aqueles têm renda inferior a esses, $R \$ 876,80$ (1,94 SM) e $\mathrm{R} \$ 966,60$ (2,1 SM), respectivamente. O estudo de Giacomin et al. (2005) também demonstrou que $23 \%$ dos idosos avaliados tinham cuidadores no domicílio, sendo que dos que tinham cuidador, apenas 13,2\% recebiam mais de 2 salários mínimos, os demais recebiam menos de 2 salários mínimos. Já os idosos que não tinham cuidadores, 35,8\% recebiam mais de dois salários mínimos. Apesar de neste estudo a renda per capita ser um pouco superior aos demais estudos, esses dados revelam a grande dificuldade vivida por esses idosos, pois os gastos, geralmente, com alimentação, habitação, tratamento de saúde e medicações comprometem a renda familiar, o que revela que a renda recebida, muitas vezes, não é suficiente para atender a todas as necessidades básicas do idoso.

Com relação à escolaridade, os dados demonstram que a população estudada teve pouco acesso a estudos, considerando-se que a maioria dos idosos era analfabeta ou estudou de um a quatro anos. Berquó (1996) afirma que o analfabetismo dentre a população idosa é muito frequente, sendo que entre 1950 e $1993,40 \%$ dos homens e $48 \%$ das mulheres idosas declararam-se analfabetos. $O$ estudo de Gratão et al. (2010) encontrou que escolaridade foi um fator forte, negativo e independentemente associado à necessidade de cuidador, enquanto que o maior nível educacional foi associado a um melhor status funcional e menor risco para incapacidade cognitiva entre idosos.

$\mathrm{Na}$ distribuição do arranjo domiciliar, a maioria dos entrevistados respondeu viver apenas com o cônjuge. O estudo de Ramos (2003) evidenciou que apenas uma minoria dos idosos vivia só e que a grande maioria coabitava em domicílios multigeracionais (duas ou três gerações). A pesquisa de Pedrazzi et al. (2010), ao avaliar a população de idosos com 80 anos ou mais na cidade de Ribeirão Preto/SP, evidenciou que idosos mais velhos $(26,5 \%)$ viviam apenas com o cônjuge, principalmente, entre os idosos com idade entre 80 e 84 anos, tornando-se menos constante com o avanço da idade. A sociedade brasileira vem apresentando

*No ano de 2009, o salário mínimo era de $\mathrm{R} \$ 450,00$. 
importantes transformações na estrutura familiar, migrando de um padrão de família extensa, multigeracional, para o padrão de família nuclear.

$\mathrm{Na}$ avaliação do arranjo domiciliar dos idosos com cuidador, evidencia-se que esses vivem, na maioria, em domicílios multigeracionais, representados pela coabitação de cônjuges, filhos(as), genros e noras. Tais dados estão de acordo com o estudo de Giacomin et al. (2005) que demonstrou os arranjos multigeracionais serem mais do que uma opção sociocultural, mas uma forma de sobrevivência dos idosos, pois o fato de morar sozinho esteve associado negativa e independentemente com a necessidade de cuidador. Isso pode refletir melhores condições daqueles que são capazes de morar sozinhos comparativamente aos que coabitam com mais gerações.

Além do fato de coabitarem em domicílios multigeracionais, em se tratando de idosos com cuidador, observa-se que tal fato reflete na média de renda familiar, em que desses, é superior a aqueles sem cuidadores $(R \$ 1.609,60$ e $R \$$ $1.418,80$, respectivamente). Entendendo-se que quanto maior o número de pessoas coabitando no domicílio maior a chance de se ter uma renda familiar superior se comparado aos domicílios com poucas pessoas, mas que, também, pode refletir no aumento dos gastos do domicílio.

Esse é mais um dado que demonstra a grande dificuldade dos idosos e suas famílias em lidar com os problemas do envelhecimento, em que a manutenção do ambiente, os materiais, a segurança do idoso, o transporte, os medicamentos e a alimentação requerem altos custos, e a renda recebida do idoso e da família, na maioria das vezes, é insuficiente para manter um padrão desejável para uma melhor condição de vida.

\subsection{Avaliação do desempenho cognitivo e da capacidade funcional dos idosos que vivem na comunidade de Ribeirão Preto, SP.}

O desempenho cognitivo dos idosos foi avaliado pelo Miniexame do Estado Mental (MEEM). Optou-se pelo nível de corte sugerido por Bertolucci et al. (1994) como já explicado nos resultados. Os autores constataram a grande 
influência da escolaridade quando comparada à versão original de Folstein et al. (1975).

Bertolucci et al. (1994) encontraram resultados que indicam que o fator mais importante para determinação do deficit cognitivo (utilizando o MEEM Miniexame do Estado Mental) é o nível educacional. Ressaltam, ainda, que os dados demonstraram que indivíduos analfabetos tiveram pior desempenho, o que alerta quanto ao uso de um único escore para uma população heterogênea como a do Brasil. Neste estudo foi observado que vários subitens do MEEM sofriam influência da escolaridade, tais como as orientações temporal e espacial, atenção, leitura, cópia do desenho dos pentágonos e escrita. Assim, na orientação temporal, o item estação do ano foi substituído por semestre e, na orientação espacial, o item condado foi mudado para bairro. No item atenção e cálculo, houve o uso exclusivo do sete seriado, uma vez que se considerou a soletração invertida da palavra "mundo" muito difícil para os indivíduos de menor escolaridade: em nosso meio, vários analfabetos conseguem fazer cálculos, bem como não temos a cultura de soletrar palavras, como em outros países.

O MEEM é recomendado pelo Departamento Científico de Neurologia Cognitiva e do Envelhecimento da Academia Brasileira de Neurologia para rastreio de alterações cognitivas, dessa forma, respeitando os níveis de corte, escores abaixo de 13 para analfabetos, de 18 para baixa e média escolaridade (1 a 4 anos de escolaridade, e 5 a 8 anos) e 26 para escolaridade alta(mais de 9 anos), segundo Bertolucci et al. (1994), os idosos foram classificados com deficit cognitivo e com alto desempenho cognitivo.

Na população desta atual pesquisa, $19,7 \%$ dos idosos apresentaram deficit cognitivo, sendo que a maioria deles do sexo feminino, com idade acima de 80 anos, semelhante a outros estudos nacionais e internacionais (ALMEIDA, 1998; FUJIWARA et al., 2002; LEBRÃO e DUARTE, 2003, BRITO-MARQUES e CABRALFILHO, 2005; RIBEIRO et al. 2010).

Segundo o estudo do Projeto SABE, realizado em São Paulo, por meio de levantamento realizado no ano de 2000 com 2.143 pessoas com 60 anos ou mais, residentes na capital paulista, revelou-se que $6,9 \%$ da população, nesta faixa etária, apresentaram problemas cognitivos, aumentando progressivamente com a idade e 
maior incidência nas mulheres, sendo que a escolaridade interferiu nesse resultado, tendo os analfabetos valores elevados, isto é, 16,8\% (LEBRÃO e DUARTE, 2003).

De acordo com os dados da Tabela 4, as idosas tiveram menor performance para capacidade cognitiva. As diferenças de desempenho cognitivo entre os gêneros podem ser explicadas pelo fato de, em geral, as mulheres, da população estudada, apresentarem níveis de escolaridade e de renda mais baixo do que os homens. Ribeiro et al. (2010), que avaliaram o desempenho de idosos em testes cognitivos da bateria CERAD e sua relação com variáveis sociodemográficas e saúde percebida de 158 idosos integrantes do estudo PENSA (Processo do Envelhecimento Saudável) na cidade de Campinas/SP, encontraram que menor nível educacional e menor renda são fatores relacionados ao menor acesso a estímulos importantes, ao desenvolvimento de repertórios cognitivos ao longo de toda a vida. Diante desses dados, a população feminina pode apresentar um perfil de menor estimulação e, consequentemente, menor preservação da capacidade cognitiva na velhice.

Dessa forma, entende-se a importância do efeito do contexto sociocultural e econômico sobre a cognição, idosos que habitam em países com economia mais desenvolvida podem ser favorecidos por escolaridade mais alta, renda e estilo de vida mais favorável ao desenvolvimento de repertórios cognitivos e a sua manutenção na velhice.

Do total de idosos com deficit cognitivo, $70(61,9 \%)$ tinham cuidador para o auxílio das atividades da vida diária, porém 43 (38,15\%) desses idosos não tinham cuidador. Chama atenção o fato de 17 (15\%) idosos com deficit cognitivo, desta pesquisa, residirem sozinhos. Morar só pode ser uma opção para idosos que se esforçam para manter sua independência e autonomia, ou mesmo, inevitável para aqueles que, apesar de se sentirem sós, não possuem outras pessoas com as quais possam corresidir. Alguns estudos relacionam a solidão ao processo de depressão, o que poderia justificar o fato de alguns idosos com deficit cognitivo estarem vivendo sós (Lauter e Dame, 1991; Rourke e Tuokko, 2004).

A relação do estado conjugal com o desempenho cognitivo mostrou que a maioria dos idosos, com deficit cognitivo, não tem companheiro, e relacionado aos de alto desempenho cognitivo, a proporção é quase semelhante entre os que têm 
companheiro, e os que não têm companheiro. O estudo de Steen et al. (2001), realizado na Itália, avaliou a relação entre o desempenho cognitivo e a habilidade nas Atividades de Vida Diária (AVDs) de 427 idosos não demenciados, com idades de 85 a 95 anos e mostrou que o melhor desempenho cognitivo estava associada ao fato de não ser casado. Esses autores argumentaram que as mulheres da amostra estudada, em geral, casadas com parceiros mais velhos, teriam uma sobrecarga com os cuidados dedicados ao cônjuge, resultando em efeitos negativos na cognição. E no caso dos participantes não casados que apresentaram alto desempenho cognitivo, entendeu-se que não ter um cônjuge levaria a um maior engajamento nos diversos aspectos sociais da vida, o que lhes possibilitaria benefícios cognitivos. Tais achados corroboram com a presente pesquisa, sendo que, a maioria dos idosos do sexo feminino, não tem deficit cognitivo e não tem companheiro, porém, os idosos do sexo masculino, casados, apresentam deficit cognitivo.

Quanto ao nível educacional, a escolaridade mais alta esteve associada a escores mais altos de MEEM, representados na Tabela 3, replicando dados relatados por Brito-Marques e Cabral-Filho (2005) e Ribeiro et al. (2010). A escolaridade, muitas vezes, é considerada fator protetor contra o envelhecimento cognitivo patológico. Um maior convívio com atividades que solicitam diferentes funções cognitivas tais como leitura, aritmética, raciocínio, abstração e planejamento pode acarretar um efeito positivo na preservação das funções cognitivas na velhice (RIBEIRO et al., 2010).

Ainda que se reconheça a importância de investigar a prevalência dos casos de idosos com deficit cognitivo na comunidade, são raros os estudos disponíveis no Brasil e nos países em desenvolvimento em geral, havendo pouco consenso sobre o impacto dessa condição neurológica sobre a população idosa e seus familiares.

Além da avaliação do deficit cognitivo, no presente estudo, avaliou-se a independência funcional, utilizando-se o instrumento da Medida da Independência Funcional (MIF), e correlacionou-a com o desempenho cognitivo e com varáveis sociodemográficas dos idosos. A MIF não somente avalia o grau de independência 
do examinado nas atividades de vida, mas procura quantificá-la, sendo um instrumento útil para avaliação funcional de idosos.

De acordo com os valores encontrados na MIF, no geral, os idosos apresentaram independência modificada/independência completa, ou seja, sem comprometimento da independência funcional (MIF média=113,9; $\pm 20,6$ ). Tais dados foram semelhantes ao estudo de Sposito et al. (2010) que avaliou 125 idosos em uma cidade do interior do estado de São Paulo, com o objetivo de verificar a relação entre o bem-estar subjetivo, independência funcional e desempenho de membros inferiores (força muscular, velocidade de marcha e equilíbrio) de idosos em seguimento ambulatorial, encontraram média para MIF Global de $112,9( \pm 12,86)$, MIF Motora de 82,07 $( \pm 9,69)$ e MIF Cognitiva de 30,87 $( \pm 4,81)$. Giacomin et al. (2008) avaliaram a capacidade funcional de idosos em Belo Horizonte pelo relato de incapacidade (não conseguir) para realizar pelo menos uma das seguintes atividades da vida diária: comer, vestir-se, ir ao banheiro, banhar-se e levantar-se de uma cadeira sem apoio e constataram que $84 \%$ deles eram totalmente independentes para essas atividades.

$\mathrm{Na}$ análise entre a MIF e as variáveis sociodemográficas como idade, sexo, escolaridade e renda, observou-se que a escolaridade correlacionou-se positivamente com o desempenho funcional dos idosos, este dado corroborou com os achados de Rosa et al. (2003) sobre fatores determinantes da capacidade funcional de idosos no município de São Paulo. Assim, foi demonstrado que os idosos com nível mais baixo de escolaridade apresentaram chance cinco vezes maior de ter dependência para as atividades diárias, por outro lado, não foram encontradas correlações significantes no presente estudo entre a funcionalidade e as variáveis de renda individual e familiar como nos estudos de Rosa et al. (2003) e Talmelli et al. (2010).

Relacionado ao gênero, houve pouca diferença entre as médias da MIF total, motora e cognitiva comparadas entre homens e mulher, não encontrando relevância estatística, porém, os resultados mostraram que as mulheres tiveram escores menores do que os homens nos três domínios. Encontrou-se maior número de idosas do sexo feminino nas categorias dependência total e moderada 
comparadas ao idoso do sexo masculino. No estudo de Giacomin et al. (2005), as associações entre incapacidade funcional e sexo foram significativas $(p<0,005)$.

Destacaram-se, nesse contexto, a correlação negativa da idade com o desempenho funcional do idoso, embora com força de baixa magnitude entre as variáveis. Hipotetiza-se, dessa forma, que quanto mais longevo for o idoso, menores são os escores da MIF, ou seja, menor é a independência funcional. Dois grandes estudos com idosos da comunidade do município de São Paulo observaram que o comprometimento no desempenho das ABVDs está, por um lado, associado ao avançar da idade e, por outro, está ligado a uma questão de gênero, em especial o feminino (RAMOS, 2003; LEBRÃO e DUARTE, 2003).

Ao se associar a capacidade funcional à cognitiva, encontrou-se correlação significativa positiva entre o MEEM e a MIF (total e em seus dois componentes), conforme mostra Tabela 10, revelando que, de fato, 0 comprometimento cognitivo pode levar perda da capacidade funcional. Estudos têm sugerido que os declínios da capacidade funcional podem preceder a manifestação mais evidente de deficit cognitivo (WANG et al., 2006).

Steen et al. (2001) relatam que a maioria dos idosos entre 85 e 95 anos que apresenta deficit cognitivo é dependente para a realização das atividades de vida diária. Ainda destacam que tanto a capacidade cognitiva como a mobilidade são preditores independentes para a dependência nas atividades de vida diária em idosos nesta faixa etária.

A independência no idoso está relacionada diretamente à sua capacidade em desenvolver as AVDs sem auxílio, à autonomia e à liberdade em decidir por sua própria vontade, gerenciando sua vida. $\mathrm{O}$ idoso pode ser dependente, requerendo ajuda para o autocuidado, mas, mesmo assim preservar sua autonomia. Capacidade funcional não significa apenas a capacidade de realização de tarefas cotidianas, mas, também, a preservação das atividades mentais e a possibilidade de integrar-se socialmente (ROSA et al., 2003).

Estudos sobre a funcionalidade de idosos mostram que as ABVDs são as últimas a serem comprometidas em decorrência do envelhecimento ou dos agravos à saúde. Numa hierarquia de complexidade, encontra-se inicialmente $\mathrm{O}$ comprometimento das atividades avançadas (AAVDs), seguida das atividades 
instrumentais (AIVDs) e, por último, as ABVDs, as quais estão estreitamente relacionadas às atividades de autocuidado (MATSUDO, 2000).

Dessa forma, seria importante associar à MIF outros instrumentos que avaliem os diferentes níveis de complexidade das atividades, principalmente referentes às atividades instrumentais de vida diária (AIVDs) e às atividades avançadas (AAVDs), na medida em que se faz necessário realizar intervenções precoces, tendo em vista a prevenção de dependência e a recuperação da independência funcional do idoso.

Quando a independência e/ou a autonomia do idoso estão prejudicadas, surge a necessidade de um cuidador. Na presente pesquisa, revelou-se predomínio de idosos com cuidador associado ao deficit cognitivo e às baixas médias da MIF. Esses dados corroboram com outros estudos nacionais e internacionais (CASSIS et al., 2007; FERNANDES e GARCIA, 2009; STEEN et al., 2001; TOOTH et al., 2005;).

$O$ reconhecimento de que os cuidadores são um componente essencial nos cuidados de saúde, principalmente nas situações crônicas de deficit cognitivo e incapacidades físicas, tem motivado os pesquisadores nessa linha de investigação.

\subsection{Características sociodemográficas dos cuidadores de idosos que vivem na comunidade de Ribeirão Preto, SP.}

Os resultados deste estudo mostram que, na comunidade avaliada, uma parcela considerável da população idosa que vive na comunidade $(21,8 \%)$ apresentou necessidade de cuidador.

Os dados revelam que a maioria dos cuidadores identificou-se como cuidadores familiares, sendo as mulheres indicadas como cuidadoras tradicionais, uma vez que $86,4 \%$ dos cuidadores entrevistados eram do sexo feminino, concordando com vasta literatura nacional como os estudo de Taub et al. (2001; Scazufca et al. (2002), Cassis et al. (2007), Fernandes e Garcia (2009), Fialho et al. (2009) e Gratão et al. (2010), e internacional como de Bédard et al. (2001), Tooth et al. (2005) e Gort et al. (2007). Os dados reforçam o papel social da mulher, 
historicamente determinado, no qual a função de prover o cuidado da casa, dos filhos e do esposo é atribuída a ela. Ademais, o fato de que as mulheres, no passado, não desempenhavam funções fora de casa, propiciava maior disponibilidade e aprendizagem destas para o cuidado da família.

Segundo o grupo de estudo do Ministério da Previdência e Assistência Social (1998), essa discussão ganha importância a partir das recentes tendências de mudanças na própria estrutura familiar, com a contribuição do processo de urbanização, anteriormente baseada nos moldes tradicionais, em que o convívio era ampliado e extenso e a mulher se destacava nos cuidados familiares, possibilitando que os cuidados especiais com idosos fossem mais facilmente divididos entre a esposa, filhas, noras, cunhadas, tias e irmãs. Atualmente, o arranjo familiar predominante passa a ser a convivência apenas da chamada família nuclear, em um mesmo espaço de moradia, e ainda destacando a mulher como primeira escolha para a função de cuidador, fazendo com que a sobrecarga de atenção recaia quase que exclusivamente numa única pessoa, geralmente a esposa ou uma filha.

Embora os dados continuem demonstrando um maior número de mulheres cuidadoras, ressalta-se a crescente participação dos homens de diferentes idades e graus de parentescos, esposos, filhos e netos, cuidando de idosos. Uma proporção de $13,6 \%$ dos cuidadores era do sexo masculino. Estudos como de Scazufca et al. (2002) e Lund (2005) revelaram que $41,5 \%$ e $39 \%$, respectivamente, eram cuidadores do sexo masculino.

A média de idade dos cuidadores foi de 56,6 $( \pm 13,4)$ anos, semelhante a estudos, na maioria, nacionais (TAUB et al., 2001; SCAZUFCA et al., 2002; GORT et al., 2007; AMENDOLA et al., 2008; GRATÃO et al., 2010), porém, inferior a outros estudos, na maioria, internacionais (BÉDARD et al., 2001; ROURKE e TUOKKO, 2004; TOOTH et al., 2005. RODRIGUES et al., 2006). Em países desenvolvidos, a expectativa de vida é superior a dos países em desenvolvimento, justificando a maior média de idade dos cuidadores comparada à média dos cuidadores nas pesquisas do Brasil.

A média de idade dos cuidadores do sexo masculino foi superior à do sexo feminino. Na presente pesquisa, os cuidadores homens, na maioria eram idosos, com média de idade de 61,8 anos. Dentre esses, a maioria eram filhos 
$(41,2 \%)$, seguidos pelos cônjuges $(23,4 \%)$, semelhantes às cuidadoras do sexo feminino.

Rodrigues et al. (2006), elaboraram um estudo com cuidadores de idosos pertencentes ao Programa de Assistência ao Idoso no Domicílio (USP), identificaram que $24,1 \%$ dos cuidadores de idosos eram cônjuges e $39,8 \%$, filhos, muitos deles com mais de 60 anos de idade. O estudo de Amêndola et al. (2008), realizado em São Paulo com 66 cuidadores de idosos dependentes, revelou que a maioria dos cuidadores era filho seguido por esposo, o que foi semelhante aos achados do presente estudo. Em contrapartida, outros estudos, internacionais, sobre cuidadores relatam que a maioria deles corresponde a cônjuges (BÉDARD et al., 2001; TOOTH et al., 2005). Há normas sociais e culturais, prevalecentes na sociedade de países desenvolvidos, que possibilitam aos idosos assumirem o papel de cuidador, já que a maioria das famílias é nuclear, representadas por famílias com poucos ou nenhum filho. Já nos países em desenvolvimento, geralmente os idosos têm mais de um filho, o que possibilita aos filhos assumirem a responsabilidade do cuidado de seus pais idosos.

Quanto ao estado conjugal dos cuidadores, muitos referiram ter companheiro, incluindo os casados e amasiados, porém com diferenças relacionadas ao gênero, a maioria das mulheres referiu ter um companheiro, contrário aos dados dos homens que referiram, na maior parte, não ter companheira, incluindo os solteiros, viúvos e divorciados. O estudo de Scazufca et al.( 2002) avaliou 82 cuidadores de idosos com depressão na cidade de São Paulo, sendo que $75,6 \%$ dos cuidadores tinham um parceiro, porém não foi discriminada a diferença entre os sexos dos cuidadores. A presença de um companheiro pode trazer benefícios com relação a menor número de sentimentos de solidão e maior apoio.

Grande parte dos cuidadores referiu residir junto com o idoso, perfazendo um total de $79,8 \%$. Tais achados corroboraram com estudos nacionais e internacionais (BÉDARD et al., 2001; SCAZUFCA et al., 2002;TOOTH et al., 2005; GORT et al., 2007; CASSIS et al., 2007; FERNANDES e GARCIA, 2009; FIALHO et al., 2009 e GRATÃO et al., 2010). Essa situação pode ser vista como favorável para o idoso que recebe os cuidados, uma vez que suas demandas de cuidado podem ser atendidas prontamente. Já para o cuidador pode ser vista como negativa pela 
grande exposição dos efeitos do processo de cuidar que ele vivencia diariamente, o que pode gerar níveis elevados de tensão.

No que se refere ao grau de escolaridade, grande parte dos cuidadores estudou de um a quatro anos, perfazendo um perfil de baixa escolaridade, dados que se revelaram inferiores a estudos nacionais sobre cuidadores (SCAZUFCA et al., 2002; AMENDOLA et al., 2008). Outros estudos nacionais demonstraram resultados semelhantes aos do atual estudo. O estudo de Fernandes e Garcia (2009) que investigou os determinantes de tensão de 30 cuidadores familiares de idosos dependentes na cidade de Brasília/DF revelou que o nível de escolaridade caracterizou-se como baixo: $13,3 \%$ eram analfabetos, $23,3 \%$, alfabetizados informalmente, $26,7 \%$ haviam concluído o ensino fundamental ( 1 a 4 anos), $23,3 \%$, o ensino médio e $13,3 \%$, ensino superior. $O$ baixo nível de escolaridade pode contribuir para o papel de ser cuidador, na medida em que a sociedade exige níveis mais elevados de educação para o mercado de trabalho formal, tornando-se mais difícil para os indivíduos com baixa escolaridade. Assim, é mais provável que essas pessoas se dediquem aos serviços domésticos e à tarefa do cuidar.

Ao analisar a faixa etária dos cuidadores, $31,8 \%$ estão acima de 60 anos de idade (mínimo de 61 e máximo de 88 anos de idade), portanto vivenciaram um período de movimento social de difícil acesso às escolas. Além disso, a família habitualmente inseria as crianças nas atividades domésticas, principalmente, as rurais. Por outro lado, os $68,2 \%$ dos cuidadores têm menos de 60 anos (mínimo de 14 e máximo de 60 anos de idade). Apesar de esses cuidadores serem mais jovens, os dados constataram que o baixo nível de escolaridade se mantém também entre estes, constituindo-se assim em um problema social.

Os dados acerca da escolaridade apresentaram correlação positiva com o nível de renda familiar dos cuidadores nesta pesquisa. A média da renda familiar (incluído o idoso) foi de $R \$ 1.460,00$, que correspondeu a 3,2 salários mínimos (salário mínimo em 2009 era de $\mathrm{R} \$ 450,00$ ). Tais dados estão de acordo com o estudo de Fernandes e Garcia (2009), revelando que 66,7\% tinham renda familiar mensal de um a três salários mínimos, $20 \%$ recebiam de quatro a seis salários mínimos e 13,3\% tinham provento maior do que seis salários mínimos. Vale salientar que, quando a provisão de cuidado transcorre em condições de escassez de 
recursos materiais, ela tende a ser vista como um dever ou opção sem alternativa pelo cuidador, constituindo-se, assim, como uma atividade estressante.

Ao avaliar o conhecimento sobre o ato de cuidar do idoso, a maior parte dos entrevistados referiu ter conhecimento (92,7\%), apesar de $94,4 \%$ responderem que não tiveram curso formal em alguma instituição sobre o cuidado. $O$ aprendizado foi adquirido pela experiência pessoal diária, dados semelhantes aos encontrados por Gratão (2006) que avaliou 104 cuidadores de idosos com demência na comunidade de Ribeirão Preto, SP.

Segundo Karsch (2003), o cuidador familiar de idosos incapacitados precisa ser alvo de orientação, não somente referente à doença instalada, mas, de como proceder nas situações mais difíceis, e receber em casa visitas periódicas de profissionais, médico, pessoal de enfermagem, de fisioterapia e outras modalidades de supervisão e capacitação. Isso deveria ser considerado como requisito básico e primordial para satisfazer as necessidades do idoso.

\subsection{Escalas de avaliação da sobrecarga e do desconforto emocional dos cuidadores de idosos que vivem na comunidade de Ribeirão Preto, SP.}

Neste estudo, recorreu-se à pontuação global da Escala de Sobrecarga de Zarit, utilizando-se a versão de zero a quatro pontos, obtendo um escore total que varia entre 0 e 88 pontos, de acordo com a maioria dos estudos na área (ZARIT et al., 1980; BÉDARD et al., 2001; SCAZUFCA, 2002; TOOTH et al., 2005; CASSIS et al., 2007; FERNANDES e GARCIA, 2009; FIALHO et al., 2009). Optou-se, também, por construir uma tabela com resultados da população estudada, utilizando o ponto de corte para diagnóstico de sobrecarga: sobrecarga intensa escores entre 61 e 88; moderado a severo, entre 41 e 60, moderado a leve, entre 21 e 40; e ausência de sobrecarga, escores inferiores a 21 pontos (HEBERT et al., 2000; LUZARDO et al., 2006).

A Escala de Sobrecarga de Zarit utilizada obteve alpha de Cronbach de 0,642, representando índice de valor moderado referente à consistência interna da 
escala para essa amostra e inferior ao valor apresentado por Scazufca (2002) quando validou a escala para a população brasileira, obtendo alpha de Cronbach igual a 0,87. Uma das hipóteses para o resultado pode ser representada pela dificuldade de entendimento dos cuidadores a respeito das perguntas da escala, uma vez que a maioria dos cuidadores foi avaliada como de baixo nível educacional.

A média total da Escala de Sobrecarga do cuidador, no presente estudo, foi de $27,8( \pm 17,5)$. Considera-se, então, que a maioria dos cuidadores foi classificada na categoria de leve a moderada sobrecarga.

Em estudos internacionais que utilizaram a Escala de Sobrecarga de Zarit, sobre cuidadores de idosos com demência, encontrou-se média mais elevada como o estudo prospectivo de Gort et al.(2007), realizado na Espanha, que analisou a habilidade da Escala de Sobrecarga de Zarit para identificar a exaustão de 66 cuidadores de idosos com demência e os fatores de risco para a sobrecarga relacionados aos cuidadores e aos idosos, encontrou média de 74,6. Já o estudo de Bérdard et al. (2001), realizado no Canadá, teve a proposta de desenvolver Escala de Sobrecarga de Zarit de forma abreviada, com 12 itens apenas. Os autores avaliaram 413 cuidadores de idosos com deficit cognitivo, na comunidade de Ontário, aplicaram essa nova versão da escala, destacaram que reduzindo o número de itens não afetou as propriedades da escala original e a média foi de 30 pontos (máximo 48 para versão abreviada). Aminzadeh et al. (2006), por meio de um estudo prospectivo, avaliaram 141 idosos, sendo $76,6 \%$ com demência e cuidadores informais (familiares e amigos) em um serviço de geriatria em Ottawa (Canadá). Os cuidadores foram avaliados pela Escala de Sobrecarga de Zarit e a Escala Abreviada de Zarit (12 itens), as médias encontradas foram 31,3 e 15,9, respectivamente.

O estudo epidemiológico de Rourke e Tuokko (2004) encontrou média para sobrecarga inferior à da presente pesquisa. Esses autores aplicaram a Escala de Sobrecarga de Zarit em 137 cuidadores informais (família ou amigos) de idosos com depressão na comunidade de Vancouver (Canadá) e encontraram média de 24,7 .

Em estudos nacionais sobre cuidadores de idosos demenciados, foram encontradas médias de sobrecarga superiores a esta pesquisa, como o de Garrido e 
Menezes (2004) em que foram avaliados 49 idosos com demência e seus cuidadores de um hospital-escola do município de São Paulo, por meio de um estudo transversal. Os cuidadores foram avaliados pelos instrumentos SRQ e Escala de Sobrecarga de Zarit, a média para sobrecarga foi de 32,4. Luzardo et al. (2006), por meio do estudo exploratório e descritivo, avaliaram 36 idosos com doença de Alzheimer e seus cuidadores familiares no serviço de neurogeriatria de um hospitalescola de Porto Alegre (RS).Os cuidadores obtiveram média de 34,08 pela Escala de Sobrecarga de Zarit. Cassis et al. (2007) realizaram estudo retrospectivo, por meio da análise dos prontuários dos pacientes idosos e correlacionaram o estresse do cuidador com as características clínicas do paciente portador de demência, no Centro de Referência em Distúrbios Cognitivos de um hospital-escola de São Paulo, capital, e 67 cuidadores, avaliados pela Escala de Sobrecarga de Zarit, apresentaram média de sobrecarga de 32 pontos. Fialho et al. (2009), por meio de um estudo transversal,avaliaram 83 cuidadores de idosos demenciados acompanhados num ambulatório universitário de Belo Horizonte (MG) e encontraram média de sobrecarga do cuidador, pela Escala de Sobrecarga de Zarit, de 31,4 pontos.

Moraes e Silva (2009) realizaram um estudo transversal com 122 cuidadores de idosos com doença de Alzheimer, atendidos em um ambulatório universitário da região metropolitana de Londrina (PR), e revelaram médias de 37,3, também, por meio da Escala de Sobrecarga de Zarit.

Outros estudos utilizaram a Escala de Sobrecarga de Zarit para avaliar pacientes não demenciados, como de Amêndola et al. (2008), por meio de um estudo transversal com 66 cuidadores de idosos dependentes atendidos pelo Programa de Saúde da Família das Unidades Básicas de Saúde da comunidade de São Paulo, SP,revelaram média de sobrecarga de 32,12 pontos. Scazufca et al. (2002) avaliaram 82 cuidadores de idosos com depressão, atendidos em um Instituto de Psiquiatria do hospital universitário da cidade de São Paulo, por meio de uma pesquisa seccional, e encontraram média de 31,1 , também superiores à média encontrada nesta pesquisa.

Observa-se nos diversos estudos que determinadas doenças como demência, depressão, e mesmo a dependência física dos idosos causam maiores 
graus de sobrecarga, se comparadas a uma população de idosos que vivem na comunidade sem diagnóstico de tais patologias. Compreende-se que, quanto maiores a dependência e a perda da autonomia do idoso maior se torna a demanda dos cuidados, sobrecarregando, dessa forma, os cuidadores que prestam os cuidados diariamente. Da mesma forma, os estudos sobre cuidadores de idosos demenciados revelam que o distúrbio do comportamento do idoso provocado pela doença é um dos fatores mais importantes no agravo da sobrecarga (GARRIDO e MENEZES, 2004; LUZARDO et al., 2006; AMINZADEH et al., 2006; GORT et al., 2007).

Não há estudos que relatam a sobrecarga de cuidadores que cuidam de idosos na comunidade, sem diagnóstico prévio de demência ou outras doenças, pelo médico, porém não há como comprovar a hipótese de que alguns que vivem na comunidade possam ter a doença, porém sem o diagnóstico. Ainda prevalece o mito social que a perda de memória pode estar relacionado à velhice.

Contraditoriamente às pesquisas internacionais e nacionais relatadas e em consonância com este estudo, a pesquisa de Cerqueira e Oliveira (2002) comparou grupos de cuidadores de idosos que participavam do programa de apoio a cuidadores na cidade de Botucatu (SP), cada grupo era composto de 10 a 20 cuidadores. Os grupos percorreram por 10 a 12 sessões, acompanhados por psicólogos que utilizavam técnicas psicodramáticas com os temas: significado e motivações do cuidado prestado, sinais de alerta de desgaste físico e mental do cuidador, entre outros. Os autores relataram que o grupo que cuidava de idosos com múltiplos diagnósticos, mas que não apresentavam sintomas de depressão e demência, e nem outros problemas comportamentais, antes dos encontros, obteve média inferior de sobrecarga (avaliados pela Escala de Sobrecarga de Zarit), 17,4, comparados aos outros grupos de cuidadores que cuidavam de idosos com os sintomas acima relatados, 37,1. Após as sessões, depois de 12 meses, os grupos foram reavaliados, e ambos os grupos obtiveram melhoras, relatando valores de sobrecarga de 13,5 e 36,6, respectivamente. Esses dados reforçam que os idosos com sintomas de depressão, demência e distúrbios do comportamento provocam altos níveis de sobrecarga em seus cuidadores. 
Zarit (1987) relata que cuidadores apresentam taxas mais altas de depressão e outros sintomas psiquiátricos e mostram-se mais propensos a problemas de saúde quando comparados a pessoas da mesma idade, porém que não são cuidadores. $O$ autor afirma ainda, que os cuidadores participam menos de atividades sociais e têm mais problemas ocupacionais.

Apesar de os idosos da presente pesquisa residirem no domicílio, os dados nos mostram que o deficit cognitivo e a incapacidade funcional dos idosos levam a maior demanda de cuidado. Diante disso ao avaliar o idoso, o enfermeiro deve planejar o cuidado deste do domicílio, com a participação do cuidador. Tal proposta deve ser contemplada na atenção ao idoso na rede básica de saúde.

Ao se analisarem as perguntas inseridas na Escala de Sobrecarga de Zarit, detalharam-se as frequências de respostas dos cuidadores. Quanto às respostas "nunca se sente sobrecarregado(a)", foi encontrada maior frequência de respostas dos cuidadores relacionados a sentir-se envergonhado com 0 comportamento do idoso, que o cuidar afeta negativamente o relacionamento com outros membros da família ou amigos e não sentir vontade de ter visitas em casa. Já o maior potencial para sobrecarga, em que os cuidadores responderam "sempre se sente sobrecarregado(a)", relacionou-se com as situações como sentir receio pelo futuro do idoso e sentir que o idoso depende do cuidador.

Em relação ao sentimento de sobrecarga, o estudo de Luzardo et al. (2006) mostrou que 58,3\% dos cuidadores indicaram que o idoso com demência nunca pedia ajuda além do necessário e $38,9 \%$ se sentiam estressados algumas vezes entre o cuidar e as outras responsabilidades com a família e o trabalho. Em relação ao comportamento do idoso, $80,6 \%$ dos cuidadores relataram nunca "se sentir envergonhados", e $61,1 \%$ nunca se sentiam irritados ou tensos $(55,6 \%)$ quando o idoso estava por perto. Da mesma forma, $75 \%$ dos cuidadores relataram que seu familiar dependia deles.

Em alguns estudos realizados no Brasil, verificou-se que os cuidadores de idosos com demência revelam uma menor sobrecarga relacionada com o fato de se sentir "envergonhados", "tensos", e apresentam mais sobrecarga relacionada com os "aspectos econômicos", pois mais de $50 \%$ dos cuidadores referem que, na maioria 
das vezes, não têm recursos financeiros suficientes para cuidar de forma adequada (Scazufca, 2002; Garrido e Menezes, 2004).

De maneira complementar à escala de sobrecarga, neste estudo foi utilizada a escala $S R Q$, em que se avaliaram problemas físicos e psicológicos que caracterizam o desconforto emocional do cuidador, com intuito de melhor compreender a fadiga vivenciada pelo cuidador. A escala apresentou alpha de Crombach 0,852 , revelando ótimo grau de fidelidade.

A média encontrada nos cuidadores avaliados foi de 6,0 , não caracterizando cuidadores que vivenciam desconforto emocional, já que o ponto de corte utilizado foi $7 / 8$.

Ao analisar as respostas da escala $S R Q$, identificaram-se as maiores frequências de respostas "sim", contribuindo para possível diagnóstico de desconforto emocional nos cuidadores, foram fatores relacionados a sentir-se tenso, nervoso ou preocupado bem como sentimento de tristeza. Cassis et al. (2007) descreveram que é comum sentimentos de preocupação e de tristeza nos cuidadores, e muitos aspectos podem estar envolvidos a esses sentimentos como gravidade da doença do paciente, convivência diária e ininterrupta associada à prestação de cuidados e à dependência do mesmo.

\subsection{Determinantes de sobrecarga e desconforto emocional relacionados às características dos cuidadores de idosos que vivem na comunidade de Ribeirão Preto, SP.}

$\mathrm{Na}$ análise das características dos cuidadores relacionadas à sobrecarga, cuidadores do sexo feminino e com idade superior a 60 anos obteve-se média superior quando comparada ao cuidador do sexo masculino, compatível com os estudos de cuidadores de idosos com demência, de Aminzadeh et al. (2006), Gort et al. (2007), Fialho et al. (2009), Moraes e Silva (2009) e o estudo com cuidador de idosos com depressão de Scazufca et al. (2002). 
Cuidadores mais velhos parecem mais susceptíveis à sobrecarga, porém os mais jovens podem sofrer mais isolamento e maiores restrições sociais, proporcionais às maiores possibilidades de atividades sociais e de lazer diante da faixa etária (AMÊNDOLA et al., 2008).

A inserção social da mulher participando progressivamente no mercado de trabalho caracteriza mudança da sociedade atual, e por isso, somam-se às suas atividades de cuidar as atividades laborais fora de casa e domésticas próprias de mãe, esposa e, muitas vezes, avó, gerando um acúmulo de trabalho em casa e uma sobrecarga nos diversos domínios da vida da cuidadora, como: social, físico, emocional, espiritual, enfim, contribuindo para o autodescuido da própria saúde (MORAES e SILVA, 2009). Essa sobrecarga de papéis dificulta a prática do cuidado com o idoso, pois precisam dividir o tempo entre todas as suas atividades, gerando um estresse físico e psicológico, não permitindo que se cuidem e se valorizem enquanto ser humano.

Dados relacionados com o grau de escolaridade revelaram médias maiores de sobrecarga para os que estudaram de um a quatro anos e aqueles que estudaram mais de 12 anos, não caracterizando, portanto, uma associação linear negativa entre essas variáveis. Em um estudo sobre cuidadores de idosos demenciados a escolaridade do cuidador, também, não evidenciou forte associação relacionada à sobrecarga (CASSIS et al., 2007).

A maior sobrecarga foi, também, encontrada em cuidadores que são cônjuges. Estudos evidenciam que o cônjuge, ao assumir sozinho os cuidados do idoso no domicílio e convivendo diariamente com o mesmo, frequentemente manifesta desconforto e sentimento de solidão, quando não tem apoio de outros membros da família (LUZARDO et al., 2006). A necessidade de dividir com outras pessoas da família o desgaste provocado por eventos negativos vivenciados diariamente indica o desejo de suavizar o impacto provocado pela carga das tarefas, do cuidador. Dessa forma, evidencia-se a importância do apoio de outros membros da família ao cuidador, mesmo que ocorra em momentos de visitas. Em contrapartida, Rose et al. (2006) realizaram um estudo sobre cuidadores de pessoas mentalmente prejudicadas e mostraram que a carga do cuidar não foi aliviada pela presença da família extensa, porque esse suporte não está sempre presente, e os 
membros da família discordam sobre o que é a doença, como ela deve ser tratada e como o cuidador deve cuidar.

O fato de viver com o idoso e o tempo de cuidado durante o dia em horas e quantos dias da semana o cuidador assume a tarefa do cuidado estão estreitamente interligados. Nesta pesquisa, revelaram-se intensas e ininterruptas horas de cuidado, com médias de 12,3 horas/dia e 4,95 dias durante a semana. Entretanto, tais médias foram ainda inferiores aquelas encontradas no estudo de Gratão et al. (2010), com média de 15,6horas/dia, embora referente a cuidadores de idosos demenciados, o que exige maior demanda. Divergente ao estudo de Tooth et al. (2005), em que se revelou média de 4,6 horas/dia de cuidado com idosos após AVE. Os cuidadores que despendem maior tempo com os pacientes apresentam maior depressão e ansiedade, coincidindo com o fato de residir com o idoso (CASSIS et al., 2007).

Muitas vezes, o sentimento de esgotamento ou exaustão dos cuidadores associado ao elenco de sintomatologia caracterizada no indivíduo que sofre de sobrecarga é resultante da grande dedicação e esforço na atividade de cuidar, na qual o cuidador desconsidera suas próprias necessidades, constituindo-se um problema psicossocial (ZARIT, 1980).

De acordo com o diagnóstico da sobrecarga, levando-se os pontos de corte referenciados neste trabalho, evidenciou-se que 72 (57,6\%) apresentaram de leve a moderada sobrecarga. Luzardo et al. (2006), os quais descreveram a sobrecarga de 36 cuidadores de idosos com doença de Alzheimer em Porto Alegre (RS), encontraram que $20(55,6 \%)$ dos cuidadores apresentaram moderada sobrecarga. Não foram identificados na literatura outros estudos nacionais que revelassem dados para comparar os valores associados às categorias de sobrecarga com as características dos cuidadores.

As mesmas características do cuidador avaliadas para sobrecarga foram avaliadas pelo SRQ. Encontraram-se diferenças estatisticamente significantes ao se relacionar a desconforto emocional com o sexo e nível educacional, em que as mulheres e os cuidadores que estudaram de um a quatro anos apresentaram maiores médias, 6,3 e 7,0, respectivamente. O estudo de Scazufca et al. (2002) encontrou forte associação entre cuidadoras do sexo feminino e médias de SRQ 
$(p=0,013)$. Garrido e Menezes (2004) revelaram média de $S R Q$, para os cuidadores de idosos demenciados, de 6/7. Os dados desta presente pesquisa indicam que 0 desconforto emocional dos cuidadores está fortemente associado à sobrecarga, e que sobrecarga está apontada como fator de risco para o desconforto emocional.

Em geral, os cuidadores apresentam taxas mais altas de depressão e outros sintomas psiquiátricos e podem ter mais problemas de saúde que pessoas, com a mesma idade, que não são cuidadores (Zarit, 1987). Além disso, os cuidadores participam menos de atividades sociais, têm mais problemas no trabalho, e apresentam mais conflitos familiares, frequentemente tendo como foco a forma como eles cuidam do membro da família. Algumas pessoas chegam a apresentar o que tem sido chamado de erosão do self, pela forma como submergem no papel de cuidadores.

Chama atenção o fato de os cuidadores não familiares terem apresentado maiores média de sobrecarga, entretanto apresentaram menores médias para SRQ. De acordo com Mari e Willians (1986), o SRQ avalia desconforto emocional, como tristeza, dores de estômago, insônia, ansiedade, entre outros, o que, muitas vezes, está mais fortemente associado à ligação de parentesco do cuidador com o idoso. Aqueles que têm laços de parentesco vivenciam os sintomas de desconforto emocional mais frequentemente, se comparados aos cuidadores formais contratados.

Da mesma forma que a sobrecarga, o desconforto emocional foi potencialmente associado ao tempo gasto diariamente, provendo o cuidado, em consonância com outras pesquisas nacionais (SCAZUFCA et al., 2002, GARRIDO e MENEZES, 2004).

\subsection{Determinantes de sobrecarga e desconforto emocional relacionados às características dos idosos que vivem na comunidade de Ribeirão Preto, SP.}

$\mathrm{Na}$ análise das características do idoso relacionadas à sobrecarga do cuidador, verificou-se que os cuidadores que auxiliam idosos com idade de 65 a 69 
anos são mais sobrecarregados do que os que cuidavam de idosos mais velhos, porém os dados não foram estatisticamente significantes. Alguns autores relatam algumas divergências sobre o decréscimo de níveis de sobrecarga, como o estudo de Amêndola et al. (2008) que encontraram sobrecarga mais acentuada em cuidadores de idosos mais velhos, eles justificam o fato de que o idoso mais velho, normalmente, demanda condições específicas para o seu cuidado devido à diminuição de algumas capacidades ao longo dos anos. Em contrapartida Cassis et al. (2007) retratam algumas divergências sobre o decréscimo de níveis de sobrecarga com o passar do tempo, possivelmente, explicado por um processo adaptativo. Com o passar dos anos da atividade de cuidar, no processo de adaptação, o cuidador relata mais confiança com as experiências vividas, diminuindo os sentimentos de sobrecarga.

$\mathrm{Na}$ presente pesquisa, não houve diferenças significantes de médias de sobrecargas entre cuidadores de idosos do sexo feminino e masculino, bem como diferenças sobre o estado conjugal do idoso, escolaridade e renda. Em outro estudo, sobre cuidadores de idosos com depressão, as características sociodemográficas dos idosos (sexo, idade, nível educacional e renda), também, não foram associadas à sobrecarga (Scazufca et al., 2002).

A comparação da capacidade cognitiva do idoso, com a sobrecarga do cuidador, resultou em variáveis inversamente proporcionais, quanto menor a capacidade cognitiva do idoso, maior o nível de sobrecarga, porém as diferenças não foram estatisticamente significantes. Como já descrito na revisão da literatura desta pesquisa, o deficit cognitivo pode ocorrer em decorrência de vários fatores, como consequência do uso prolongado de alguns medicamentos, depressão, demência, entre outros. Pesquisadores argumentam que o encargo de cuidar de idosos com deficit cognitivo devido à demência gera alterações das condições físicas e psicológicas desses cuidadores e que os mesmos são doentes em potencial e que sua capacidade funcional está em constante risco ao dispensar cuidados aos idosos (GARRIDO e MENEZES, 2004, LUZARDO et al., 2006; AMINZADEH et al., 2006; GORT et al., 2007).

Figueiredo e Sousa (2008) que estudaram a percepção do estado de saúde e sobrecarga em 99 cuidadores familiares de idosos dependentes com e sem 
demência, dividiram em duas subamostras: 52 cuidavam de um idoso com demência e 47 de um idoso não demenciado. Os principais resultados indicaram que a sobrecarga é elevada em ambos os subgrupos de cuidadores familiares, ambas as subamostras perceberam o seu estado de saúde debilitado, contudo os cuidadores familiares de idosos sem demência perceberam a sua saúde mental como significativamente melhor e que os cuidadores que têm uma percepção mais desfavorável do seu estado de saúde são aqueles que se sentem mais sobrecarregados no seu papel.

O fator capacidade funcional do idoso foi o único que se revelou estatisticamente significante à sobrecarga do cuidador, com médias inversamente proporcionais, ou seja, quanto menor a média da MIF, maior a média da sobrecarga. Tais dados revelam que, quanto maior a dependência do idoso, maiores as chances de sobrecarga do cuidador, semelhantes a outros estudos, como os de Scazufca et al.,( 2002), Garrido e Menezes (2004), Gort et al. (2007), Cassis et al. (2007), Fernandes e Garcia (2009).

De acordo com o diagnóstico da sobrecarga, considerando-se os pontos de corte referenciados neste trabalho, dentre os cuidadores diagnosticados por sobrecarga intensa estão incluídos os que cuidam de idosos mais velhos, com idade média de 91 anos e com menor escolaridade e idosos com menores médias de MEEM. Idosos com menores médias da MIF global, motora e cognitiva são auxiliados por cuidadores classificados com moderada sobrecarga. Não foi identificado nenhum estudo nacional que comparou os escores de sobrecarga do cuidador com características dos idosos. Sendo assim, considera-se que estes achados são fundamentais para o planejamento do cuidado do idoso e apoio aos cuidadores.

A avaliação do desconforto emocional relacionadas com as características dos idosos revelou que os dados para maiores médias de sobrecarga se repetem para maiores médias de desconforto emocional. Luzardo et al. (2006) relatam ser comum encontrar familiares cuidadores que apresentem depressão como resposta à exposição prolongada a uma situação de desgaste físico e emocional, potencialmente geradora de estresse. Lund et al. (2005), por meio de uma reflexão sobre cuidadores e idosos com incapacidades cognitivas, relataram 
que é comum encontrar sentimentos de depressão e isolamento por parte dos cuidadores, principalmente, pelo fato de estar com o idoso o tempo todo ininterruptamente.

\subsection{Determinantes de sobrecarga e de desconforto emocional relacionados à demanda dos cuidados e a necessidades de suporte informal dos cuidadores de idosos que vivem na comunidade de Ribeirão Preto, SP.}

No contexto familiar, a pessoa que assume o papel de cuidador está sujeita à produção de demandas de cuidados que afetam sua dimensão física, mental e social.

O grau de dependência dos idosos foi avaliado pela MIF, que correspondeu à avaliação para as atividades de vida como alimentação, higiene pessoal, banho, controle de fezes e urina, transferências, resolução de problemas, memórias entre outros. Ao relacionar a dependência do idoso com as médias de sobrecarga, foi revelada maior média de sobrecarga relacionada aos idosos totalmente dependentes, principalmente para atividades como alimentação, o uso do vaso sanitário, resolução de problemas e memória. De acordo com Luzardo et al.(2006), para o cuidador, lidar ininterruptamente com o banho, a vestimenta, a higiene do idoso, a alimentação e o manejo dos distúrbios de comportamento pode acarretar altos níveis de sobrecarga, uma vez que tais atividades foram consideradas tarefas mais desgastantes no cotidiano.

Alvarez (2001) utilizou uma categorização que incluiu os cuidados de higiene; o cuidar ininterruptamente; cuidados como a alimentação e com as eliminações; cuidado com ambiente e da infra-estrutura; cuidados com o transporte do idoso e com a questão financeira. Dessas tarefas, observou-se que, apesar da compreensão do familiar cuidador a respeito da importância da higiene, do conforto e da alimentação para o idoso, a dificuldade em realizar tal tarefa está tão presente no seu cotidiano que o estresse resultante da execução do cuidado é inevitável. 
Os cuidadores desta presente pesquisa foram questionados sobre 0 suporte informal recebido no auxílio de algumas ABVDs do idoso. As respostas dos cuidadores foram correlacionadas com as médias de sobrecarga. Encontraram-se maiores médias de sobrecarga principalmente para aqueles cuidadores que não receberam ajuda na higienização oral, na atividade de alimentação e no retorno às consultas médicas. Quanto ao desconforto emocional, maiores médias foram encontradas para cuidadores que não recebem ajuda para atividade de sono/repouso e também para alimentação.

No estudo de López et al. (2005), 54,1\% dos cuidadores relataram não receber ajuda na atividade de cuidados básicos. Marques et al. (2006), ao estudarem as alterações no relacionamento familiar do idoso, após acidente vascular cerebral, verificaram que a ausência de colaboração para o cuidado pode trazer conflitos entre os membros da família.

De acordo com Gratão et al. (2010), o suporte social pode ser caracterizado como ajuda real ou percebida que o indivíduo obtém nos relacionamentos familiares ou em grupos e como importante meio para prevenção e tratamento de problemas emocionais e físicos, relacionados ao cuidar. Pode-se, então, dizer que aqueles cuidadores que não têm apoio formal, ou informal, tendem a desenvolverem mais problemas físicos e psíquicos, em comparação com aqueles que se sentem apoiados e respeitados.

A família necessita contar com rede de suporte social, constituída por um trabalho de equipe interdisciplinar; conforme proposta instituída na Política Nacional do Idoso (Brasil, 1994) e a Constituição Brasileira (1988). Apesar de os idosos terem vários filhos para o suporte, o município de Ribeirão Preto ainda conta com escassa rede de suporte social para famílias de idosos que necessitam de cuidados. O Estado tem um papel preponderante na promoção, proteção e recuperação da saúde do idoso nos três níveis de gestão do SUS, cabendo, também, o suporte à família (GORDILHO et al., 2000).

O suporte social formal envolve o cuidado domiciliar, implementado pela equipe interdisciplinar, tendo vários serviços de apoio para a prestação do cuidado. Os informais, constituídos pelos familiares, amigos e vizinhanças, são fundamentais para compor o processo. O sistema familiar funciona como núcleo de referência e 
influencia o curso de vida dos idosos, seja na saúde ou na doença (RODRIGUES et al., 2000). Entretanto, é essencial que haja complementação entre os suportes formais e informais para promover melhor qualidade de vida ao idoso.

Algumas instituições têm desenvolvido estratégias para dar suporte aos idosos e a seus cuidadores informais. A exemplo, a implementação de Centros de Referência para atendimento especializado de pessoas com doença de Alzheimer, os quais se destaca o Ambulatório de Neurologia Comportamental (ANCP) do Hospital das Clínicas da Faculdade de Medicina de Ribeirão Preto, USP. O ANCP propõe um trabalho à instituição com maior participação da equipe multidisciplinar para a atenção integral ao idoso com demência e sua família. O objetivo é de que a equipe utilize instrumentos padronizados para identificar o diagnóstico clínico, funcional, social e cognitivo do idoso, bem como ter rede de suporte formal e informal planejada, a fim de elaborar intervenções em conjunto, na instituição, com serviços internos e externos (visitas familiares) e com participação da família (BRESSAN, 2005).

Outro programa é o de orientação para cuidadores de idosos no domicílio, realizado pelo Grupo de Atenção à Saúde do Idoso (GRASI), do Hospital de Clínicas da Universidade Estadual de Campinas, que se baseou nos relatos de dificuldades enfrentadas por familiares de idosos, apresentados aos geriatras e psicólogos do serviço. Ao final das atividades, as participantes relataram que o programa possibilitou o melhor enfrentamento das dificuldades, a compreensão das distintas alterações presentes na velhice, e o desenvolvimento de procedimentos que facilitam a relação com o idoso no dia a dia (DIOGO et al., 2003).

O Centro de Saúde-Escola da Faculdade de Medicina de Botucatu UNESP, também, elaborou um programa de apoio aos cuidadores, o qual tem por objetivos gerais preservar a qualidade de vida dos mesmos e proporcionar melhores condições de atendimento aos idosos. Na primeira reunião de cada grupo (com 10 a 20 participantes), são aplicadas escalas de avaliação do impacto físico e emocional sobre os cuidadores, sendo as mesmas reaplicadas ao final do programa, pretendendo-se verificar possíveis mudanças. Os dados obtidos indicam mudanças favoráveis na expressão de sentimentos, estabelecimento de limites e retomada de atividades de lazer (CERQUEIRA e OLIVEIRA, 2002). 
Outro exemplo é o Projeto de Extensão "Assistência Interdisciplinar ao Idoso em Atenção Primária - PAINP", criado em setembro de 2005, na cidade de Londrina, por docentes da UEL (Universidade Estadual de Londrina) de medicina, enfermagem, serviço social, odontologia e fisioterapia, que desenvolveu um programa de assistência interdisciplinar ao idoso em atenção básica e objetiva. Definiu-se como prioridade o atendimento a idosos com alto grau de dependência. Mensalmente os casos de maior complexidade eram discutidos em reuniões com participação de todos, o que garantia a capacitação, devido à discussão interdisciplinar na busca das soluções dos problemas. O grupo de cuidadores com reuniões mensais desenvolvia temas de interesse comum por meio da troca de experiências entre cuidadores e a equipe (DELLAROZA, 2005).

O Hospital Universitário da Universidade Federal do Maranhão elaborou o projeto "Cuidando do Cuidador" cujo objetivo foi propiciar a tais profissionais a oportunidade de usufruir ações de saúde. No primeiro semestre de 2006, em caráter eventual, foram feitos atendimentos ambulatoriais a 396 cuidadores nas diversas especialidades médicas. Para os autores do projeto, cuidar destes indivíduos é reconhecer que cada colaborador é peça fundamental para a excelência do atendimento ao idoso dependente (SILVA, 2006).

Tais iniciativas valorizam o trabalho dos cuidadores e visam a qualidade de vida dos mesmos, porém muito ainda precisa ser feito, principalmente envolvendo os profissionais da enfermagem no apoio aos cuidadores.

A tarefa de cuidar de um idoso exige do cuidador dedicação, praticamente exclusiva, principalmente, caso em que o idoso seja portador de doenças incapacitantes. Muitas vezes, isso faz com que o cuidador deixe suas atividades, em detrimento dos cuidados dispensados, sendo que muitos abandonam seus empregos e ocupações, deixam de viver suas próprias vidas, e poucos contam com a ajuda de outros para dividir a tarefa desse cuidar.

O enfermeiro precisa atuar no cuidado ao idoso e apoio ao cuidador, principalmente, em situações de dependência cognitiva e funcional, como posicionamento no leito, banho, alimentação, troca de roupa de cama, entre outras necessidades. $O$ cuidador, com a família devem ser preparados para os sentimentos 
de culpa, frustração, raiva, tristeza, depressão e outros sentimentos que acompanham essa responsabilidade, com auxílio de profissionais da saúde.

A sociedade, composta pelos atores sociais, organizações governamentais e não-governamentais precisam se unir para um efetivo engajamento social, com vistas a melhorar a condição de vida dos cuidadores de idosos, na intenção de prevenir, ou mesmo diminuir a sobrecarga vivenciada pelos mesmos. O Plano de Ação Governamental dá as diretrizes da atenção, porém, serviços de saúde estaduais, municipais, universidades, ONGs e outras redes devem se organizar para elaborarem propostas de intervenção formal e informal aos cuidadores familiares de idosos.

Dessa forma, faz-se valer o acordado com a Política Nacional do Idoso (Brasil, 1994), em que o atendimento ao idoso deve ser feito por intermédio de suas próprias famílias, em detrimento do atendimento asilar. E a Política Nacional de Saúde do Idoso (Brasil, 1999) reconhece a importância da parceria entre os profissionais da saúde, e as pessoas que cuidam dos idosos, por meio da atenção integral, apontando que essa deverá possibilitar a sistematização da atenção no próprio domicílio, privilegiando-se tarefas relacionadas à promoção da saúde, à prevenção de incapacidades e à manutenção da capacidade funcional do idoso dependente e do seu cuidador, evitando-se, assim, hospitalizações, internações em asilos e outras formas de segregação e isolamento.

Atenção integral e integrada à saúde da pessoa idosa, de acordo com o Estatuto do idoso (Brasil, 2003), deverá ser estruturada nos moldes de uma linha de cuidados, baseado nos direitos dos idosos, necessidades, preferências e habilidades, aumentando e facilitando o acesso a todos os níveis de atenção; providos de condições essenciais - infra-estrutura física adequada, insumos e pessoal qualificado para a boa qualidade técnica.

Instrumentos gerenciais baseados em levantamento de dados sobre a capacidade funcional (inventários funcionais) e sócio-familiares da pessoa idosa é um desafio a ser planejado pelos gestores municipais e estaduais do SUS, para que haja a participação de profissionais de saúde e usuários na construção de planos locais de ações para enfrentamento das dificuldades inerentes à complexidade de saúde da pessoa idosa. 
A prática de cuidados às pessoas idosas e seus cuidadores exige abordagem global, interdisciplinar e multidimensional, que leve em conta a grande interação entre os fatores físicos, psicológicos e sociais que influenciam a saúde dos mesmos e a importância do ambiente no qual está inserido. Ainda, conforme Estatuto do Idoso (Brasil, 2003), a abordagem, também precisa ser flexível e adaptável às necessidades do idoso. A identificação e o reconhecimento da rede de suporte social informal e de suas necessidades também se fazem com o intuito de prevenir e detectar precocemente a sobrecarga das pessoas que cuidam. As intervenções devem ser feitas e orientadas com vistas à promoção da autonomia e independência da pessoa idosa, estimulando-a para o autocuidado. Grupos de autoajuda entre as pessoas que cuidam devem ser estimulados, porém esta iniciativa ainda é insuficiente diante do aumento de idosos no país.

Uma abordagem preventiva e uma intervenção precoce são sempre preferíveis às intervenções curativas tardias. Uma importante abordagem preventiva pode ser realizada através da aplicação de instrumentos de avaliação adequados. Assim, será possível detectar precocemente distúrbios cognitivos, visuais, de mobilidade, de audição, de depressão e do comprometimento funcional do idoso. Ademais, é necessária também a vigilância de todos os membros da equipe de saúde na prevenção e/ou intervenção precoce da sobrecarga dos cuidadores de idosos.

A política para a atenção ao idoso e ao cuidador está posta na sociedade brasileira, porém, é necessário sua efetividade diante dos dados demográficos e dos indicadores de saúde. O cuidador ao assumir tarefas de cuidado pode desenvolver a sobrecarga e também acaba sendo uma pessoa que necessita de cuidado; dessa forma os profissionais de saúde devem iniciar esse trabalho na atenção básica, elaborando planos de atenção integral à família, isto é, a atenção tanto ao idoso quanto ao seu cuidador. 
7. Canclusães 


\section{CONCLUSÕES}

Pôde-se identificar as principais características sociodemográficas dos idosos (Tabela 3), em que dos 574 idosos estudados, $67,8 \%$ era do sexo feminino, com média de 76,6 anos de idade, representados por $54,7 \%$ com baixa escolaridade e por renda individual mensal de $R \$ 942,20$, revelando bom nível econômico. Mediante a avaliação da capacidade funcional e cognitiva dos idosos, apenas 15,7\% dos mesmos foram identificados como dependentes e $21,6 \%$ com deficit cognitivo, representando, no geral, uma população independente e autônoma para as atividades de vida.

Observaram-se as características dos 124 cuidadores estudados (Tabela 12) e relacionou-as com a sobrecarga e desconforto emocional dos mesmos. Desta população de cuidadores, $85,6 \%$ eram do sexo feminino, com média de 56,5 anos de idade, sendo que $90,3 \%$ eram familiares, filhas e esposas, principalmente. Revelou-se que os cuidadores utilizaram, em média, 12,4 horas para prover o cuidado diariamente. $\mathrm{O}$ tempo de cuidado diário revelou-se ininterrupto, em que os cuidadores prestam o auxílio sem pausa para descanso e lazer.

O estudo contribuiu para o conhecimento sobre sintomas de sobrecarga e desconforto emocional experienciados pelos cuidadores de idosos que vivem na comunidade, revelando que $72(57,6 \%)$ dos cuidadores apresentaram de leve a moderada sobrecarga.

Quanto às características dos cuidadores, que foram estatisticamente significantes para a existência da sobrecarga, foram relacionadas ao sexo e às horas diárias de cuidado. O cuidador do sexo feminino obteve maiores escores de sobrecarga, e foi caracterizada por ter idade adulta, fase em que a mulher tem vários papéis sociais: mãe, esposa, dona de casa, dentre outros. Muitas vezes, tem outras atribuições sociais, como o trabalho fora do lar, além de assumir o cuidado de seus pais, já idosos.

Associados aos fatores dos idosos, a incapacidade cognitiva trouxe implicações na vida do cuidador, contribuindo para altos níveis de sobrecarga e desconforto emocional. Essa situação traz uma série de alterações domésticas, 
associadas ao cuidado com o corpo, com os distúrbios de comportamento, além do cuidado com os medicamentos do idoso. A dificuldade para o autocuidado, isto é, tornar-se dependente física e emocionalmente, é permeada por várias situações no meio familiar.

Evidenciou-se, ainda, que a atividade de cuidar quando associado ao comprometimento das atividades da vida diária do idoso, acarretou sobrecarga do cuidador, revelando que a dependência do mesmo foi um importante preditor de sobrecarga no cuidador. E que, ainda, o cuidador mesmo recebendo ajuda de outros para auxílio dos cuidados não amenizou sintomas de sobrecarga e desconforto emocional. Percebeu-se que ter conhecimento sobre a atividade de cuidar não é suficiente para melhorar a situação de desgaste físico e emocional do cuidador.

Na maioria das vezes, o cuidador surge para prestar cuidados ao idoso quando este já apresenta um grau mais elevado de incapacidade para o autocuidado. Muitas vezes os cuidadores tornam-se responsáveis pelos cuidados, sem qualquer treinamento prévio, sendo impelidos a aprender com a prática. Nesse sentido, os cuidadores, com freqüência, carecem de informações e orientações sobre os cuidados específicos com o idoso, os quais deveriam ser supridos pelos profissionais de saúde. Evidenciada a sobrecarga, muitas vezes acompanhada de sintomas psicossomáticos, é reforçada a importância de um trabalho específico de prevenção, orientação e até o tratamento dos cuidadores informais.

Os instrumentos utilizados revelaram-se fidedignos para a população avaliada, porém, atenção maior deve ser dada à leitura e interpretação das questões da escala de sobrecarga, quando aplicada a cuidadores com baixo grau de escolaridade. A avaliação do desconforto emocional foi aplicada para complementação da avaliação da sobrecarga, uma vez que se avaliam sinais e sintomas que se relacionam à ansiedade e depressão. Por fim encontrou-se forte correlação entre os resultados das duas escalas, e os dados revelaram que a sobrecarga foi considerada fator de risco para desconforto emocional.

A utilização de instrumentos de avaliação da capacidade funcional que abordem as AIVDs e AAVDs faz-se importante, uma vez que as pesquisas realizadas nessa área enfocam, na maioria das vezes, apenas a avaliação das ABVDs. Assim, será possível obter resultados que beneficiem não só o idoso 


\section{Conclusães}

estimulando a prevenção de incapacidades, como também os cuidadores através da prevenção da sobrecarga destes.

As variáveis referentes ao cuidador, como ser do sexo feminino, com média de $12 \mathrm{~h}$ diárias de cuidados prestados diariamente e correlacionadas com aquelas referentes ao idoso, como a dependência funcional, são fatores que devem despertar a atenção dos profissionais de saúde para a possibilidade de sobrecarga no cuidador. Assim cabe aos profissionais de saúde utilizarem protocolos de avaliação, com base nos fatores de risco, para diagnosticar e prevenir esse problema.

Nesse contexto, sugerem-se mais estudos que abordem este tema, assim como o desenvolvimento e implementação de políticas públicas voltadas aos idosos e seus cuidadores que residem na comunidade. O sistema de referência e contra referência do Sistema Único de Saúde deve estar voltado para essa prática. Para tanto, o treinamento da equipe de saúde, alinhados a aplicação de instrumentos de avaliação, validados para a população idosa brasileira, trará não só resultados positivos para os cuidadores como também para os idosos. Assim, o cuidador poderá exercer sua prática de cuidado de forma mais eficiente e sem sobrecarga e desconfortos.

A maior expectativa de vida deve trazer benefícios para o ser humano, porém a família deve ser considerada prioritária para a prestação desse ato de cuidar. 
8. Referencias 


\section{REFERÊNCIAS}

ACTON, G. J.; KANG, J. Interventions to reduce the burden of caregiving for na adult with dementia: a meta analysis. Research in Nursing \& Health, v. 24, p. 349-360, 2001.

AGUGLIA, E. et al. Stress in the caregivers of Alzheimer's patients: an experimental investigation in Italy. American Journal of Alzheimer's Disease and Other Dementias, Thousand Oaks, v. 19, n. 4, p. 248-252, 2004.

AISEN, O. S.; MARIN, D. B.; DAVIS, K. L. Doenças de Alzheimer: perguntas e respostas. 2. ed. Espanha: Atlas Medical Publishing, 2001.

ALMEIDA, O. P. Mini-exame do estado mental e o diagnóstico de demência no Brasil. Arquivos de Neuropsiquiatria, São Paulo, v. 56, p. 605-612, 1998.

ALVAREZ, A. M. Tendo que cuidar: a vivência do idoso e de sua família cuidadora no processo de cuidar e ser cuidado em contexto domiciliar. Florianópolis: UFSC/Programa de Pós-graduação em Enfermagem, 2001. 200p.

AMÊNDOLA, F.; OLIVEIRA, M. A. C.; ALVARENGA, M. R. M. A. Qualidade de vida dos cuidadores de pacientes dependentes no programa de saúde da família. Texto e Contexto Enfermagem, Santa Catarina, v.17, n. 2, p. 266-272, 2008.

AMINZADEH, F.; BYSZEWSKI, A.; DALZIEL, W. B. A prospective study of caregiver burden in an Outpatient Comprehensive Geriatric Assessment Program. Clinical Gerontologists, Philadelphia, v. 29, n. 4, p. 47-60, 2006.

ANGELO, M.; BOUSSO, R. S. Fundamentos da assistência à família em saúde: manual de enfermagem. 2001. Disponível em: <http:www.idssaude.org.br/ enfermagem>. Acesso em: 22 set. 2008.

ARGIMON, I. L.; STEIN, L. M. Habilidades cognitivas em indivíduos muito idosos: um estudo longitudinal. Cadernos de Saúde Pública, Rio de Janeiro, v. 21, n. 1, p. 6472, 2005.

BANDEIRA, M.; CALVAZARA, M. G. P.; VARELLA, A. B. Escala de sobrecarga dos familiares de pacientes psiquiátricos: adaptação transcultural para o Brasil (FBISBR). Jornal Brasileiro de Psiquiatria, Rio de Janeiro, v. 54, n. 3, p. 206-214, 2005. 
BÉDARD, M.; MOLLOY, W.; SQUIRE, L.; DUBOIS, B. A.; LEVER, J. A.; O'DONNELL, M. The Zarit Burden Interview: a new short version and screening version. The Gerontologist, Cary, v. 41, n. 5, p. 652-657, 2001.

BERQUÓ, E. Algumas considerações demográficas sobre o envelhecimento da população do Brasil. SEMINÁRIO INTERNACIONAL - ENVELHECIMENTO POPULACIONAL. UMA AGENDA PARA O FINAL DO SÉCULO, 1., Local. Anais... Brasília: MPAS, 1996. p.1-3.

BERTOLUCCI, P. H. F.; BRUCKI, S. M. D.; CAMPCCI, S. R.; JULIANO, Y. O mini exame do estado mental em uma população geral: impacto da escolaridade. Arquivos de Neuropsiquiatria, São Paulo, v. 52, p.1-7, 1994.

BRASIL. Lei no 8.842, de 4 de janeiro de 1994. Dispõe sobre a Política Nacional do Idoso, cria o Conselho Nacional do Idoso e dá outras providências. Disponível em: <http://www.pge.sp.gov.br/centrodeestudos/bibliotecavirtual>. Acesso em: 27 out. 2008.

BRASIL. Ministério da Saúde. Secretaria de Assistência à Saúde. Portaria $n^{\circ} 1395$, de 9 de dezembro de 1999. Aprova a Política Nacional de Saúde do Idoso e dá outras providências. Diário Oficial da União, Brasília, 13 dez.1999. Seção 1, p. 2024.

BRASIL. Lei no 702. Dispõe de mecanismos para organização e implementação de redes estaduais de assistência à saúde do idoso. Diário Oficial da União, Brasília, 16 abr. 2002. Seção 1, p. 45-50.

BRASIL. Lei no 10.741 , de 10 de outubro de 2003. Dispõe sobre o Estatuto do Idoso e dá outras providências. Disponível em: <http://www.senado.gov.br>. Acesso em: 27 out. 2008.

BRESSAN, L. A. O desempenho funcional do idoso com demência. 2005. $118 f$. Tese (Doutorado) - Faculdade de Medicina de Ribeirão Preto, Universidade de São Paulo, Ribeirão Preto, 2005.

BRITO, F. A transição demográfica no contexto internacional. Belo Horizonte: CEDEPLAR/ UFMG, 2007. (Texto para discussão, v. 317).

BRITO-MARQUES, P. R.; CABRAL-FILHO, J. E. Influence of age and schooing on the performance in a modified mini-mental state examination version. Arquivos de Neuropsiquiatria, São Paulo, v. 63, n. 3-A, p. 583-587, 2005. 
BRODATY, H.; GREEN, A. Who cares for the care: the often forgotten patient. Australian Family Physician, South Melbourne, v. 31, n. 9, p. 833-836, 2002.

BRUCKI, S.M.D.; NITRINI, R.; CARAMELLI, P.; BERTOLUCCI, P.H.F; OKAMOTO, I.H. Sugestões para o uso do mini-exame do estado mental no Brasil. Arquivos de Neuropsiquiatria, São Paulo, v. 61, n. 3B, p. 777-781, 2003.

BUFFUM, M. D.; BROD, M. Humor and well-being in spouse caregivers of patientes with Alzheimer's disease. Applied Nursing Research, Maryland Heights, v.11, n.1, p.12-18, 1998.

CALDAS, C. P. O idoso em processo de demência: o impacto na família. In: MINAYO, M. C. S.; COIMBRA Jr, C. E. A. (Orgs.). Antropologia, saúde e envelhecimento. Rio de Janeiro: FIOCRUZ, 2002. p. 51-71.

CALDEIRAS, A. P. S.; RIBEIRO, R. C. H. M. O enfrentamento do cuidador do idoso com Alzheimer. Arquivos de Ciências da Saúde, São José do Rio Preto, v. 11, n. 2, p. 2 - 6, 2004.

CANINEU, P. R.; SILVA, M.; DAMASCENO, B. P. Uma introdução ao estudo das demências em hospitais psiquiátricos. In: NERI, A. L.; YASSUDA, M. S. (Orgs). Velhice bem sucedida: aspectos afetivos e cognitivos. Campinas: Papirus, 2004. (Coleção Vivaidade).

CANÇADO, F. A. X.; HORTA, M. L. Envelhecimento cerebral. In: FREITAS, E. V. et al. Tratado de geriatria e gerontologia. 2. ed. Rio de Janeiro: Guanabara Koogan, 2002. cap. 13, p.112-127.

CANZOBRE, S. L.; SANCHEZ, M. D. Cuidados del cuidador del paciente com demência. Guias Clinicas, v.1, n.51, 2001. Disponível em: <www.fisterra.com>. Acesso em: 09 set. 2010.

CARAMELLI, P.; BARBOSA, T. Como diagnosticar as quatro causas mais freqüentes de demência? Revista Brasileira de Psiquiatria, São Paulo, v. 24 p.710, 2002. Suplemento 1.

CARVALHO, J. Para onde iremos: algumas tendências populacionais no século XXI. In: ASSOCIAÇÃO BRASILEIRA DE ESTUDOS POPULACIONAIS. Revista Brasileira de Estudos de População, São Paulo, v.18, n.1/2, p.7-13, 2001. 
CASSIS, S. V. A.; KARNAKIS, T.; MORAES, T. A.; CURIATI, J. A. E.; QUADRANTE, A. C. R.; MAGALDI, R. M. Correlação entre o estresse do cuidador e as características clínicas do paciente portador de demência. Revista da Associação Médica Brasileira, São Paulo, v. 53, n. 6, p. 497-501, 2007.

CERQUEIRA, A. T. A. R.; OLIVEIRA, N. I. L. Programa de apoio a cuidadores: uma ação terapêutica e preventiva na atenção à saúde dos idosos. Psicologia USP, São Paulo, v.13, n.1, p.133-150, 2002.

CHAIMOWICZ, F. Envelhecimento populacional e transição epidemiológica no Brasil. In: TAVARES, A. Compêndio de neuropsiquiatria geriátrica. Rio de Janeiro: Guanabara Koogan, 2005. p. 67-77.

CHWALISZ, K.; KISLER, V. Perceived stress: a better measure of caregiver burden. Measurement and Evaluation in Counseling and Development, Thousand Oaks, v. 28, p. 88-98, 1995.

CORREIA, A. C. O. Doença de Alheimer. In: CORREIA, A. C. O. Envelhecimento, Depressão e doença de Alzheimer. Belo Horizonte: Health, 1996. cap.8, p.135-86.

DATASUS. Censos demográficos e contagem populacional para os anos intercensitários, estimativas preliminares dos totais populacionais, estratificadas por idade e sexo pelo MS/SE/Datasus. 2006. Disponível em: < http://www.datasus.gov.br>. Acesso em: 10 out. 2008.

DELLAROZA, S. G. Projeto de assistência interdisciplinar ao idoso em atenção primária - PAINP, registrado na PROEX/UEL sob o número 004.001.134.000. In: SEURS - SEMINÁRIO DE EXTENSÃO UNIVERSITÁRIA DA REGIÃO SUL, 23., Florianópolis/SC. Anais... Florianópolis, 2005.

DIOGO, M. J. D.; CEOLIM, M. F.; CINTRA, F. A. Orientações para idosas que cuidam de idosos no domicílio: relato de experiência. Revista da Escola de Enfermagem da USP, São Paulo, v. 39, n.1, p. 97-102, 2005.

FERNANDES, M. G. M.; GARCIA, T. R. Determinantes da tensão do cuidador familiar de idosos dependentes. Revista Brasileira de Enfermagem, Brasília, v. 62, n. 1, p. 57-63, 2009.

FIALHO, P. P. A.; KOENIG, A. M.; SANTOS, H. C. G.; BEATO, R. G.; CARVALHO, V. A.; MACHADO, T. H.; CARAMELLI, Iniciais. Dementia caregiver burden in 
Brazilian sample: association to neuropsychiatric symptoms. Dementia \& Neuropsychologia, São Paulo, v. 3, n. 2, p.132-135, 2009.

FIGUEIREDO, D.; SOUSA, L. Percepção do estado de saúde e sobrecarga em cuidadores familiares de idosos dependentes com e sem demência. Saúde dos idosos, v. 26, n.1, 2008.

FOLSTEIN, M. F.; FOLSTEIN, S. E.; McHUGH, P. R. Mini-mental state: a pratical method for grading the cognitive state of patients for the clinicians. Journal of Psychiatry Research, Oxford, v. 12, p. 189-198, 1975.

FORLENZA, O. V. O tratamento da Doença de Alzheimer. Revista de Psiquiatria Clínica, São Paulo, v. 32, n. 3, p.137-148, 2005.

FUJIWARA, Y.; WATANABE, S.; KUMAGAI, S.; YOSHIDA, Y.; TAKABAYASHI, K.; MORITA, M.; HASEGAWA, A.; HOSHI, T.; YOKODE, M.; KITA, T.; SHINKAI, S. Prevalence and characteristics on older community residents with mild cognitive decline. Geriatrics \& Gerontology, Tokio, v. 2, n. 2, p. 57-67, 2002.

FRIES, J. F. Aging, natural death, and the compression of morbidity. Bull. WHO, Boston, v. 80, n. 3, p. 245, 2002.

GARRIDO, R.; ALMEIDA, O. P. Distúrbios de comportamento em pacientes com demência: impacto sobre a vida do cuidador. Arquivos de Neuropsiquiatria, São Paulo, v. 57, n. 2B, p.427-34, 1999.

GARRIDO, R.; MENEZES, P. R. O Brasil está envelhecendo: boas e más notícias por uma perspectiva epidemiológica. Revista Brasileira de Psiquiatria, Porto Alegre, v. 24, p. 3-6, 2004. Suplemento I.

GIACOMIM, K. C.; UCHOA, E.; FIRMO, J. O. A.; LIMA-COSTA, M. F. Projeto Bambuí: um estudo de base populacional da prevalência e dos fatores associados à necessidade de cuidador entre idosos. Cadernos de Saúde Pública, Rio de Janeiro, v. 21, n. 1, p. 80-91, jan-fev. 2005.

GIACOMIM, K. C.; PEIXOTO, S. V.; UCHOA, E.; LIMA-COSTA, M. F. Estudo de base populacional dos fatores associados à incapacidade funcional entre idosos na Região metropolitana de Belo Horizonte, Minas gerais, Brasil. Cadernos de Saúde Pública, Rio de Janeiro, v. 24, n. 6, p. 1260-1270, jun. 2008. 
GIVEN, C. W.; GIVEN, B.; STOMMEL, M.; COLLINS, C.; KING, S.; FRANKLIN S. The Caregiver Reaction Assessment (CRA) for caregivers to persons with chronic physical and mental impairments. Research in Nursing \& Health, Hoboken, v. 15, n. 4, p. 271-83, 1992.

GORDILHO, A.; SERGIO, J.; SILVESTRE, J. et al. Desafios a serem enfrentados no terceiro milênio pelo setor saúde na atenção ao idoso. Rio de Janeiro: UnATI, 2000.

GÓRT, A. M.; MINGOT, M.; GOMEZ, X. et al. Use of Zarit Scale for assessing caregiver burden and collapse in caregiving at home in dementias. International Journal of Geriatrics Psychiatry, West Sussex, v. 22, p. 957-962, 2007.

GRANGER, C. V.; HAMILTON, B. B.; KEITH, R. A.; ZIELEZNY, M.; SHERWIN, F. S. Advances in functional assessment for rehabilitation. In rehabilitation. Rockville, MD: Aspen, p. xi-xi,1-81, 1986. Topics in geriatric

GRATÃO, A. C. M. Demanda de cuidadores familiares com idosos demenciados. 2006. 89f. Dissertação (Mestrado) - Escola de Enfermagem de Ribeirão Preto, Universidade de São Paulo, 2006.

GRATÃO, A. C. M.; VALE, F. A. C.; CRUZ, M. R.; HAAS, V. J.; LANGE, C.; TALMELLI, L. F. S.; RODRIGUES, R. A. P. Family Caregivers Demands from Elderly Individuals with Dementia. Revista da Escola de Enfermagem da USP, São Paulo, v. 4, p.873-880, 2010.

HARDING, T. W.; ARANGO, M. V.; BALTAZAR, J. Mental disorders in primary health care: A study of their frequency and diagnosis in four developing countries. Psychological Medicina, Cambridge, v.10, p. 231-241, 1980.

HÉBERT, R.; BRAVO, G.; PRÉVILLE, M. Reliability, validity and reference values of the Zarit Burden Interview for assessing informal caregivers of community-dwelling older persons with dementia. Canadian Journal of Aging, Cambridge, v.19, p. 494507, 2000.

HERRERA, J. R. E.; CARAMELLI, P.; NITRINI, R. Estudo epidemiológico populacional de demência na cidade de Catanduva, estado de São Paulo, Brasil. Revista de Psiquiatria Clínica, São Paulo, v. 25, p. 70-73, 1998.

HSUEH, I. P.; LIN, J. H.; JENG, J. S.; HSIEH, C. L. Comparison of the psychometric characteristics of the functional independence measure, 5 item Bathel index, and 10 
item Barthel index in patients with stroke. Journal of Neurology and Neurosurgery and Psychiatry, London, v.73, p. 188-190, 2002.

IIDA, N.; KOHASHI, N. An assessment of the care burden and the quality of life on At-Home Caregivers: employing the Care Strain Index and the Questionnaire for QOL revised. Japanese Journal of Psychosomatic Medicine, v. 41, n.1, p.12-19, 2001.

INSTITUTO BRASILEIRO DE GEOGRAFIA E ESTATÍSTICA. Censo demográfico de 2000: resultado do universo. Disponível em: <http://www.ibge.gov.br/home/ estatistica/população/censo2000/tabelabrasil111.shtm> . Acesso em: 10 out 2008.

INSTITUTO BRASILEIRO DE GEOGRAFIA E ESTATÍSTICA. Síntese de indicadores sociais. 2006. Disponível em: <http://www.ibge.gov.br/home/estatistica/ condicaodevida/indicadoresminimos/sinteseindicsociais2006/default.shtm>. Acesso em: 10 out. 2008.

INSTITUTO BRASILEIRO DE GEOGRAFIA E ESTATÍSTICA. Síntese de indicadores sociais. 2008. Disponível em: <http://www.ibge.gov.br/home/estatistica/ condicaodevida/indicadoresminimos/sinteseindicsociais2008/default.shtm>. Acesso em: 12 nov. 2008.

KALACHE, A.; VERAS, R. P.; RAMOS, L. R. Envelhecimento da população mundial: um desafio novo. Revista de Saúde Pública, São Paulo, v. 21, n. 3, p. 200-10, 1987.

KARSCH, U. M. Idosos dependentes: famílias e cuidadores. Cadernos de Saúde Pública, Rio de Janeiro, v. 19, n. 3, p. 861-866, 2003.

KUSU, N.; BESER, N.; ZENEIR, M.; SAHINER, T.; NESRIN, E.; AHMET, E.; BINALI, Ç.; ÇAGDAS, E. Effects of a comprehensive educational program on quality of life and emotional issues of dementia patient caregivers. Geriatric Nursing, Columbia, v. 26, n. 6, p. 378-86, 2005.

LAUTER, H.; DAME S. Depressive disorders and dementia: the clinical view. Acta Psychiatrica Scandinavica, Aalborg, v. 366, p. 40-46, 1991.

LEBRÃO, M. L.; DUARTE, Y. A. O. O projeto SABE no município de São Paulo: uma abordagem inicial. Brasília: Organização Pan-Americana da Saúde, 2003. 
LESSA, I. Epidemiologia das doenças crônicas não transmissíveis versus terceira idade. In: LESSA, I. O adulto brasileiro e as doenças da modernidade. São Paulo: Hucitec/Abrasco, 1998. cap. 12, p.203-222.

LOPES, M. A.; BOTTINO, C. M. C. Prevalência de demência em diversas regiões do mundo - análise dos estudos epidemiológicos de 1994 a 2000. Arquivos de Neuropsiquiatria, São Paulo, v. 60, p. 61-9, 2002.

LOPES, M. A. Estudo Epidemiológico de Prevalência de Demência em Ribeirão Preto, SP. 2006. 140 f. Tese (Doutorado em Psiquiatria) - Faculdade de Medicina da Universidade de São Paulo de Ribeirão Preto, São Paulo, 2006.

LIU, K. P. Y.; CHAN, C. C. H.; CHU, M. M. L.; NG, T. Y. L.; CHU, L. W.; HUI, F. S. L.; YUEN, H.K.; FISHER, A. G.; Activities of daily living performance in dementia. Acta Psychiatrica Scandinavica, Aalborg, v. 116, p.91-95, 2007.

LOPÉZ, J.; LOPÉZ-ARRIETA, J.; CRESPO, M. Factors associated with the positive impact of caring for elderly and dependent relatives. Archives of Gerontology and Geriatrics, v. 41, p. 81-94, 2005.

LYKETSOS, C. G.; STEINBERG, M.; TSCHANZ, J. T.; NORTON, M. C.; STEFFENS, D. C.; BREITNER, J. C. Mental and behavioral disturbances in dementia: findings from the Cache Country Study on Memory in Aging. The American Journal Psychiatry, Arlington, v. 157, p. 708-714, 2000.

LUND, M. Caregiver, take care. Geriatric Nursing, Columbia, v. 26, n. 3, p.152-143, 2005.

LUZARDO, A. R.; WALDMAN, B. F. Atenção ao familiar do idoso com doença de Alzheimer. Acta Scientiarum. Health Science, Maringá, v. 26, n.1, p.135-145, 2004.

LUZARDO, A. R.; GORINI, M. I. P. C.; SILVA, A. P. S. S. Características de idosos com doença de Alzheimer e seus cuidadores: uma série de casos em um serviço de neurogeriatria. Texto e Contexto de Enfermagem, Florianópolis, v.15, n.4, out-dez, p.587-594, 2006.

MARI, J. J.; WILLIAMS, P. A validity study of a psychiatric screening questionnaire (SRQ-20) in primary care in the city of São Paulo. Brasilian Journal of Psychiatry, São Paulo, v.148, p. 23-26, 1986. 
MARQUES, S.; RODRIGUES, R. A. P.; KUSUMOTA, L. O idoso após acidente vascular cerebral: alterações no relacionamento familiar. Revista Latino-Americana de Enfermagem, Ribeirão Preto, v.14, n.3, p.364-371, 2006.

MASLACH, C.; SCHAUFELI, W. B.; LEITER, M. P. Job burnout. Annual Review Psychology, Palo Alto, v. 52, p. 397-422, 2001.

MASLOW, K. Alzheimer's disease facts and figures. Alzheimer's Association/ Alzheimer's \& Dementia, Rockville, v. 4, p.110-133, 2008.

MATSUDA, O. Caregivers: reliability and Validity of the subjective burden scale in family caregivers of elderly relatives with dementia. International Psychogeriatrics, Melbourne, v.11, n. 2, p. 159-1 70, 1999.

MATSUDO, S. M. Avaliação do idoso: física e funcional. Londrina: Midiograf, 2000.

MENDES, P. M. T. Cuidadores: heróis anônimos do cotidiano. In: LUZARDO, A. R.; WALDMAN, B. F. Atenção ao familiar do idoso com doença de Alzheimer. Acta Scientiarum. Health Sciences, Maringá, v. 26, n. 1, p. 142, 2004.

MINISTÉRIO DA PREVIDÊNCIA E ASSISTÊNCIA SOCIAL. SECRETARIA DE ASSISTENNCIA SOCIAL. INSTITUTO DE ESTUDOS ESPECIAIS PUC-SP. Publicação do papel do cuidador domiciliar. São Paulo, 1998.

MORAES, S. R. P.; SILVA, L. S.T . An evaluation of the burden of Alzheimer patients on family caregivers. Cadernos de Saúde Pública, Rio de Janeiro, v. 25, n. 8, p.1807-1815, ago. 2009.

MTE/SPPE. Classificação Brasileira de Ocupações: CBO 2002. Brasília: MTE, 2002.

MUNRO, B. H. Statistical methods for health care research. 4th ed. Philadelphia: Lippincott, 2001.

NOVAK, M.; GUEST, C. Application of a multidimensional caregiver burden inventory. Gerontologist, Cary, v. 29, n. 6, p. 798-803, 1989.

OKAMOTO, I. H. Exame neuropsicológico no diagnóstico diferencial das demências primárias. São Paulo, 1998. Sílabos do Congresso da Academia Brasileira de Neurologia 
OKAMOTO, K.; MOMOSE, Y.; FUJINO, A.; OSAWA, Y. Life worth living for caregiving and caregiver burden among Japanese caregivers of the disabled elderly in Japan. Archives of Gerontology and Geriatrics, Amsterdam, v. 48, n. 1, p. 1013, jan./feb. 2008

OMRAN, J. R. The epidemiology transition in the Americans. Washington: PanAmerican Health Organization, 1996.

ORGANIZAÇÃO DAS NAÇÕES UNIDAS. II Assembléia Mundial do Envelhecimento. Madri: ONU, 2002.

ORGANIZAÇÃO DAS NAÇÕES UNIDAS. Population division of the department of economic and social affairs of the united nations secretariat. World Population Prospects: The 2004 Revision. 2004. Disponível em: <http://esa.un.org/ unpp>. Acesso em: 22 set. 2008.

ORGANIZAÇÃO MUNDIAL DA SAÚDE (OMS). CID 10: classificação estatística internacional de doenças e problemas relacionados à saúde. 9. ed. São Paulo: EDUSP, 2003.

ORGANIZAÇÃO PAN-AMERICANA DA SAÚDE. CARMEM: iniciativa para prevenção de doenças crônicas não-transmissíveis nas américas. Havana, Cuba, 2003.

OTA, T.; AKABOSHI, K.; NAGATA, M.; SONODA, S.; DOMEN, K.; SEKI, M.; CHINO, $\mathrm{N}$. Functional assessment of patients wit spinal cord injury: measured by the motor score and the functional independence measure. Spinal Cord, London, v. 34, p. 531-5, 1996.

PAPALÉO NETO, M. Processo de envelhecimento e longevidade. In: PAPALÉO NETO, M. Tratado de gerontologia. 2. ed. São Paulo: Atheneu, 2006. cap. 1, p. 39.

PAPALEO NETO, M.; KLEIN, E. L. Demência I: epidemiologia, tipos e manifestações clínicas. In: PAPALÉO NETO, M. Tratado de gerontologia. 2. ed. São Paulo: Atheneu, 2006. cap. 26, p. 323 - 38.

PEDRAZZI, E. C.; RODRIGUES, R. A. P.; SCHIAVETO, F. V. Morbidade referida e capacidade funcional de idosos. Ciências e Cuidados da Saúde, Maringá, v. 6, n. 4, p. 407-413, 2007. 
PEDRAZZI, E. C. Arranjo domiciliar e apoio dos familiares aos idosos mais velhos. Ribeirão Preto/SP, 2008, 131f. Dissertação (Mestrado) - Escola de Enfermagem de Ribeirão Preto, Universidade de São Paulo, 2008.

PEDRAZZI, E. C.; DELLA-MOTA, T. T.; VENDRÚSCULO, T. R. P.; FABRÍCIOWEHBE, S. C. C.; CRUZ, I. R.; RODRIGUES, R. A. P. Arranjo domiciliar dos idosos mais velhos. Revista Latino-Americana de Enfermagem, Ribeirão Preto, v. 18, n.1, jan-fev. 2010.

PETERSEN, R. Mild cognitive impairment. Toronto: American Academy of Neurology, 1999. CD-ROM.

PLATT, S. Measuring the burden of psychiatric illness on the family: an evaluation of some rating scales. Psychological Medicine, Cambridge, v.15, n. 2, p. 383-393, 1985.

POLLACK, N.; RHEAULT, W.; STOECKER, J. L. Reliability and validity of the FIM for persons aged 80 years and above from a multilevel continuing care retirement community. Archives Physical Medicine and Rehabilitation, Maryland, v.77, p. 1056-61, 1996.

POULSHOCK, S. W.; DEIMLING, G. T. Families caring for elders in residence: issues in the measurement of burden. Journal Gerontology, Washington, v. 39, n. 2, mar. 1984. p. 230-239.

RADIS. Mortalidade nas capitais brasileiras, 1930-1980. Dados, v. 7, p. 1-8, 1984.

RAMOS, L. R. Fatores determinantes do envelhecimento saudável em idosos residentes em centro urbano: Projeto Epidoso, São Paulo. Caderno de Saúde Pública, Rio de Janeiro, v.19, n.3, p. 793-798, 2003.

REYES, P. F.; SHI, J. Dementias: Etiologies and differential Diagnoses. Barrow Quarterly, Phoenix, v. 22, n. 1, p. 4-8, 2006.

RIBEIRO, P. C. C.; OLIVEIRA, B. H. D.; CUPERTINO, A. P. F. B.; NERI, A. L.; YASSUDA, M. S. Desempenho de idosos na bateria cognitiva CERAD: relações com varáveis sociodemográficas e saúde percebida. Psicologia: Reflexão e Crítica, Porto Alegre, v.23, n.1, p.102-105, 2010. 
RIBERTO, M.; MIYAZAKI, M. H.; JUCÁ, S. S. H.; SAKAMOTO, H.; PINTO, P. P. N.; BATTISTELLA, L. R. Validação da versão brasileira da medida de independência funcional. Acta Fisiátrica, São Paulo, v. 11, n. 2, p.72-76, 2004.

ROBINSON, B. C. Validation of a caregiver strain index. Journal of Gerontology, Washington, v. 38, n. 3, p. 344-8, 1983.

RODRIGUES, R. A. P.; MARQUES, S.; FABRICIO, S. C. C. Envelhecimento, saúde e doença. Arquivos de Geriatria e Gerontologia, Rio de Janeiro, v. 4, p. 4-15, 2000.

RODRIGUES, S. L. A.; WATANABE, H. A. W.; DERNTL, A. M. A saúde de idosos que cuidam de idosos. Revista da Escola de Enfermagem da USP, São Paulo, v. 40, n. 4, p. 493-500, 2006.

ROSE, L. E.; MALLINSON, R. K.; GERSON, L. D. Mastery, Burden, and areas of concern among family caregivers of mentally ill persons. Archives of Psychiatric Nursing, Maryland, v. 20, n. 1, p. 41-51, 2006.

ROSA, T. E. C.; BENICIO, M. H. A.; LATORRE, M. R. D. O.; RAMOS, L. R. Fatores determinantes da capacidade funcional entre idosos. Revista de Saúde Pública, São Paulo, v. 37, n.1, p. 40-48, 2003.

ROURKE, N. O.; TUOKKO, H. A. Caregivers burden and depressive symptomatology: The association between constructs over time. Clinical Gerontologist, Philadelphia, v. 27, n. 4, p. 41-53, 2004.

SCAZUFCA, M. Brazilian version of the Burden Interview Scale for the assessment of care in carers of people with mental illnesses. Revista Brasileira de Psiquiatria, São Paulo, v. 24, n. 1, p.12-17, 2002.

SCAZUFCA, M.; MENEZES, P. R.; ALMEIDA, O. P. Caregivers burden in na elderly population with depression in São Paulo, Brazil. Social Psychiatry and Psychiatric Epidemiology, Nova York, v.37, p. 416-422, 2002.

SCHIAVETO, F., V. Avaliação do risco de quedas em idosos na comunidade. Ribeirão Preto/SP, 2008, 117f. Dissertação (Mestrado) - Escola de Enfermagem de Ribeirão Preto, Universidade de São Paulo, 2008. 
SCHULZ, R.; BEACH, S. R. Caregiving as a risk factor for mortality: the Caregiver Health Effects Study. Journal of the American Medical Association, Chicago, v. 282, p. 2215-2219, 1999.

SEQUEIRA, C. A. C. Adaptação e validação da Escala de Sobrecarga do Cuidador de Zarit. Revista Referência, Coimbra, série II, n.12, mar., p.9-16, 2010.

SILVA, E. B. N.; NERI, A. L. Questões geradas pela convivência com idosos: indicações para programa de suporte familiar. In: Neri AL. (Org). Qualidade de vida e idade madura. 3. ed. São Paulo: Papirus, 2000. p. 213-236.

SILVA G. A. Humanizando. Portal Universidade Federal do Maranhão, v. 2, n. 4, out./2006. Disponível em: <http://www.huufma.br>. Acesso em: 22 agosto 2009.

SOARES, C. B.; MUNARI, D. B. Considerações acerca da sobrecarga em familiares de pessoas com transtornos mentais. Ciencia, Cuidado e Saúde, Maringá, v. 6, n. 3, p. 357-362, jul./set. 2007.

SOLOMON, P.; DRAINE, J.; MANNIONY, E.; MEISEL, M. Effectiveness of two models of brief family education: retention of gains by family members of adults with serious mental illness. American Journal of Orthopsychiatry, Malden, v. 67, p.17786, 1997.

SPARKS, M. Assesment and management of Alheimer's disease. Advanced Practice Nursing, Seattle v. 1, n. 2, 2001.

SPOSITO, G.; DIOGO, M. J. D.; CINTRA, F. A.; NERI, A. L.; GUARIENTO, M. E.; SOUSA, M. L. Relações entre o bem-estar subjetivo e a funcionalidade em idosos em seguimento ambulatorial. Revista Brasileira de Fisioterapia, São Carlos, v. 14, n. 1, p. 81-89, 2010.

STEEN, G.; SONN, U.; HANSON, A. B.; STEEN, B. Cognitive Function and Functional Ability. A cross-sectional and Longitudinal Study at Ages 85 and 95 in Non-demented Population. Aging, Nova York, v. 13, p. 68-77, 2001. Suplemento 2.

TALMELLI, L. F. S.; GRATÃO, A. C. M.; KUSUMOTA, L.; RODRIGUES, R. A. P. Nível de independência funcional e deficit cognitivo em idosos com Doença de Alzheimer. Revista da Escola de Enfermagem da USP, São Paulo, v. 4, p. 933939, 2010. 
TAUB, A.; ANDREOLI, S. B.; BERTOLUCCI, P. H. Dementia caregiver burden: realibility of the Barzilian version of the Zarit caregiver burden interview. Cadernos de Saúde Pública, Rio de Janeiro, v. 20, n. 2, p.372-376, mar.-abr. 2004.

TESSLER, R. C.; GAMACHE, G. M. The Family Burden Interview Schedule - Short Form (FBIS/SF). In: SEDERER, L.; DICKEY, B. (Eds.). Outcome assessment in clinical practice. Baltimore: Williams \& Williams, 1996. p.110-112.

THOMPSON, W. S. Population. American Journal of Sociology, Chicago, v. 34, p. 959-975, 1929.

TOOTH, L.; MCKENNA,K.; BARNETTI, A.; PRESCOTT, C.; MURPHY, S. Caregivers burden, time spent caring and health status in the first 12 months following stroke. Brain Injury, Virginia, v.19, n.12, p.963-974, nov. 2005.

VERAS, R. P. País jovem com cabelos brancos: a saúde do idoso no Brasil. Rio de Janeiro: Relume Dumará, 1994.

VERAS, R. P.; LOURENÇO, R.; MARTINS, C. S. F.; SANCHES, M. A. S.; CHAVES, $P$. H. Novos paradigmas do modelo assistencial no setor saúde: conseqüências da explosão populacional dos idosos no Brasil. 2002. 64 f. Disponível em: <http://www.abramge.com.br/download/premio.pdf>. Acesso em: 15 set. 2002.

WANG, L.; LARSON, E. B.; BOWEN, J. D.; VAN BELL, G. Performance-based physical function and future dementia in older people. Archives of Internal Medicine, Chicago, v. 166, n.10, p. 1115-20, 2006.

WORLD HEALTH ORGANIZATION. 1984. Disponível em: <http://www.who.int>. Acesso em: 28 out. 2008.

WORLD HEALTH ORGANIZATION. Envelhecimento ativo: uma política de saúde. Brasília: Organização Pan-Americana da Saúde, 2005. 60 p.

ZARIT, S. H.; REEVER, K. E.; BACH-PETERSON, J: Relatives of the impaired elderly: correlates of feelings of burden. Gerontologist, v. 20, n. 6, p. 649-655, 1980.

ZARIT, S. H.; ZARIT, J. M. The memory and behavior problems checklist: 1987R and the burden interview (technical report). Pennsylvania State: Universiy University Park (PA), 1987. 
140

Apêndices e Anexas 


\section{APÊNDICES E ANEXOS}

\section{APÊNDICE A}

Colher as informações direto com o(a) idoso(a)e/ ou familiar

\section{SEÇÃO A: INFORMAÇÕES PESSOAIS}

A1) Idade (anos completos)

Mês e ano de nascimento

I

A2) Sexo
(1) Masculino
(2) Feminino

A3) Qual é a cor da sua pele?
(1) Branca
(4) Preta
(2) Parda
(5) Indígena
(3) Amarela
(99) NS/NR

AIDADE

AMANO

ASEXO

$A C O R$

$A L O C A L$

A4) Local de nascimento (Ver documento se necessário)
(1) Urbano
(2) Rural
(99) NS/NR

Cidade:

Estado:

País:

A5) Com quem o sr(a) mora:

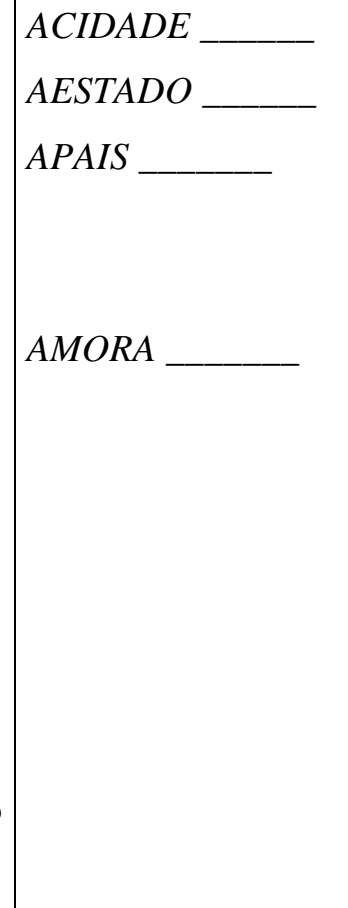

(1)sozinho

(2) somente com o cônjuge

(3) cônjuge e filho(s)

(4) cônjuge, filhos, genro ou nora

(5) somente com o filho(s)

(6) arranjos trigeracionais (idoso, filhos e netos)

(7) arranjos intrageracionais (mora somente com outros idosos e o cônjuge) 
(8) arranjos intrageracionais (somente com outros idosos)

(9) somente com os netos(sem filhos)

(10) não familiares

(99) NS/NR

A6) Há quanto tempo está morando na cidade ou região de Ribeirão Preto (em ATEMPO anos completos)

A7) Mora sempre neste endereço ou existe mais de um local para residir: $A L O C A L$ A8) Qual seu estado conjugal? AESTCIV

(1) Solteiro (a) .

(2) Casado (a)

(3) Divorciado (a)/desquitado(a)

(4) Separado (a)

(5) Viúvo(a)

(6) Outro

(99) NS/NR

A9) Quantos filhos próprios teve? A10) Quantos filhos adotivos teve? (99) NS/NR

AFILHOP AFILHOAD

A11) Quantos filhos próprios e adotivos estão vivos? (99) NS/NR A12) Qual é a sua religião?

(00) Nenhuma

(01) Católica

(02) Protestante ou Evangélica

(03) Espírita

(04) Judaica

(05) Outra (especifique)

(99) NS/NR

AFILHVIV

ARELIG

A13) SE POSSUI RELIGIÃO, qual a importância da religião na sua vida?

AIMPREL

(1) Importante

(2) Regular

(3) Nada importante

(99) NS/NR 
SEÇÃO B: PERFIL SOCIAL

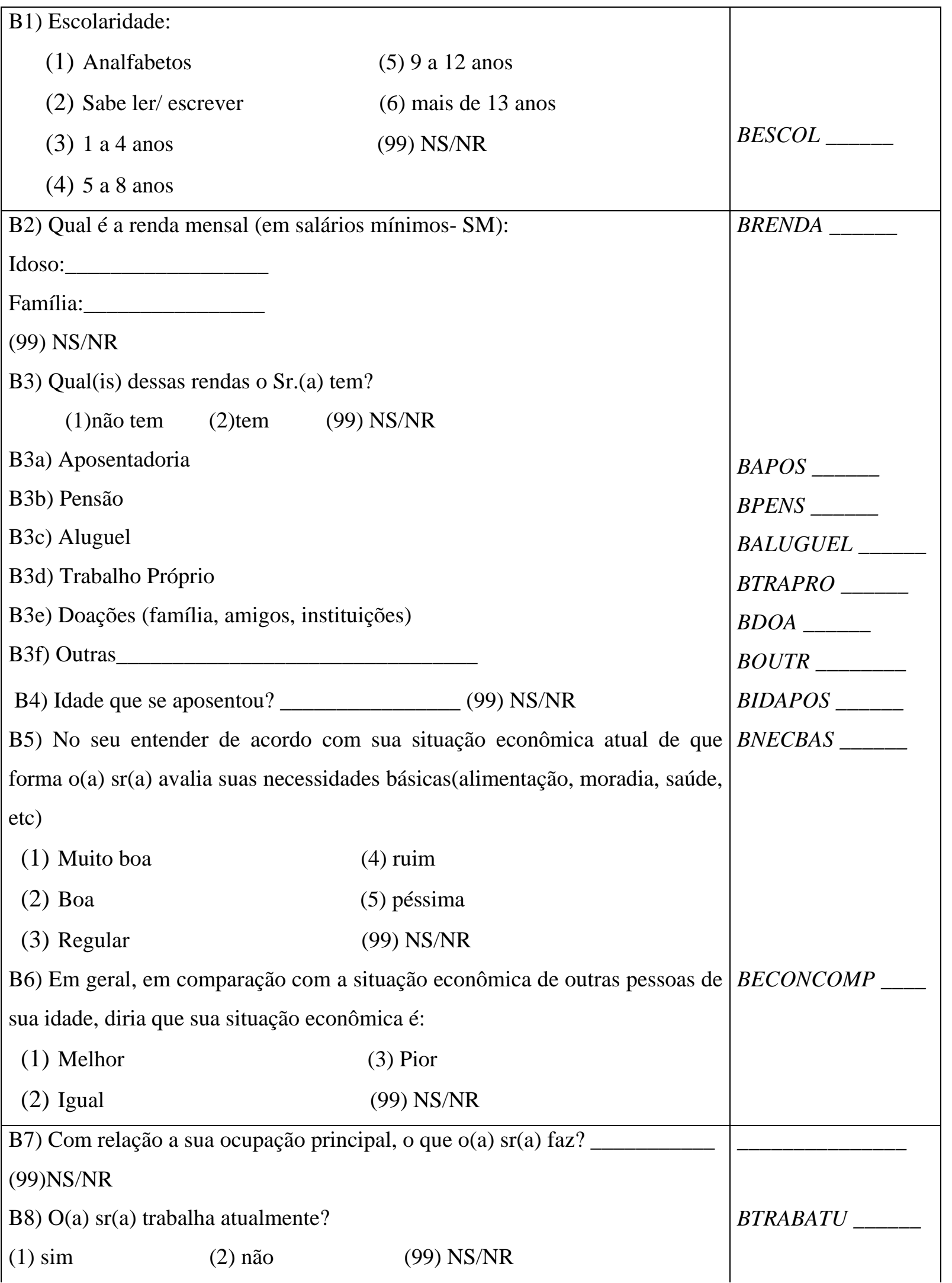


B9) Descreva o tipo de trabalho:

B10) No momento necessita (ou necessitaria) trabalhar por razões econômicas?
(1) Sim
(3)Talvez
(2) Não
(99) NS/NR

B11) A casa onde mora é:

$B C A S A$
(1) Própria-quitada
(5) Asilo
(2) Própria-paga prestação
(6) Casa de repouso
(3) Paga aluguel
(7) Outro Tipo
(4) Cedida- sem aluguel
(99) NS/NR

B12) Compartilha seu espaço de dormir com outra pessoa no mesmo quarto?
(1) Não
(5) Amigo
(2) $\operatorname{Esposo(a)}$
(6) Particular/Contratado
(3) Um familiar
(99) NS/NR
(4) 2 ou mais familiares

B13) Por que necessita dormir com acompanhante?

(99) NS/NR

\section{SEÇÃO C: AVALIAÇÃO COGNITIVA}

C1) Como o (a) Sr(a) avalia sua memória atualmente?
(1) Excelente
(2) Muito Boa
(3) Boa
(4) Regular
(5) Péssima
(99) NS/NR

C2) Comparando com um ano atrás, o (a) $\operatorname{Sr}($ a) diria que agora sua memória está...
(1) Melhor.
(2) Igual
(3) Pior
(99) NS/NR

CAVAMEM

CMEMPOS 
C3) ORIENTAÇÃO TEMPORAL - Anotar se acertou ( 1 ponto) , errou CORITEM (zero), ou não sabe (zero).)

\begin{tabular}{|l|l|l|l|}
\hline Ano & ( )acertou & ( )errou & ( )Não sabe \\
\hline Semestre & ( )acertou & ( )errou & ( )Não sabe \\
\hline Mês & ( )acertou & ( )errou & ( )Não sabe \\
\hline Dia & ( )acertou & ( )errou & ( )Não sabe \\
\hline Dia da semana & ( )acertou & ( )errou & ( )Não sabe \\
\hline
\end{tabular}

C4) ORIENTAÇÃO ESPACIAL - Anotar se acertou ( 1 ponto) , errou (zero), ou não sabe (zero).)

\begin{tabular}{|l|l|l|l|}
\hline Nome da rua & ( )acertou & ( )errou & ( )Não sabe \\
\hline Número da casa & ( )acertou & ( )errou & ( )Não sabe \\
\hline Bairro & ( )acertou & ( )errou & ( )Não sabe \\
\hline Cidade & ( )acertou & ( )errou & ( )Não sabe \\
\hline Estado & ( )acertou & ( )errou & ( )Não sabe \\
\hline
\end{tabular}

C5) REGISTRO - Leia os nomes dos objetos devagar e de forma clara somente uma vez e anote > Se o total for diferente de três repita todos os objetos até que o entrevistado aprenda em no máximo 5 repetições. Anote o número de repetições que fez e nunca corrija a primeira parte. Anote um ponto para cada objeto lembrado e zero para os que não foram.

Vou lhe dizer três palavras e, quando terminar, pedirei que as repita, em qualquer ordem. Guarde-os que mais tarde voltarei a perguntar. O (a) sr(a) tem alguma dúvida?

Lembrou $=1 \quad$ Não lembrou $=0$

\begin{tabular}{|l|l|l|}
\hline Árvore & ( )conseguiu & ( )não conseguiu \\
\hline Mesa & ( )conseguiu & ( )não conseguiu \\
\hline Cachorro & ( )conseguiu & ( )não conseguiu \\
\hline
\end{tabular}

Número de repetições:

C6) ATENÇÃO E CÀLCULO - Anotar se acertou ( 1 ponto) , errou (zero), ou não sabe (zero).

Vou dizer alguns números e gostaria que realizasse os seguintes cálculos

\begin{tabular}{|l|l|l|l|}
\hline $100-7=93$ & ( )acertou & ( )errou & ( )Não sabe \\
\hline $93-7=86$ & ( )acertou & ( )errou & ( )Não sabe \\
\hline
\end{tabular}




\begin{tabular}{|l|l|l|l|}
\hline $86-7=79$ & ( )acertou & ( )errou & ( )Não sabe \\
\hline $79-7=72$ & ( )acertou & ( )errou & ( )Não sabe \\
\hline $72-7=65$ & ( )acertou & ( )errou & ( )Não sabe \\
\hline
\end{tabular}

C7) MEMÓRIA DE EVOCAÇÃO DAS PALAVRAS - Marcar 1 ponto para cada cálculo ou letra correta, em qualquer ordem

Há alguns minutos, li uma série de 3 palavras e o(a) Sr(a)as repetiu. Digame agora de quais se lembra.

\begin{tabular}{|l|l|l|l|}
\hline Árvore & ( )acertou & ( )errou & ( )Não sabe \\
\hline Mesa & ( )acertou & ( )errou & ( )Não sabe \\
\hline Cachorro & ( )acertou & ( )errou & ( )Não sabe \\
\hline
\end{tabular}

C8) LINGUAGEM - Anotar se acertou ( 1 ponto), errou (zero), ou não sabe (zero).

Aponte a caneta e o relógio e peça para nomeá-los...(permita $10 \mathrm{seg}$. para cada objeto)

\begin{tabular}{|l|l|l|l|}
\hline Caneta & ( )acertou & ( )errou & ( )Não sabe \\
\hline Relógio & ( )acertou & ( )errou & ( )Não sabe \\
\hline
\end{tabular}

C9) Repita a frase que vou lhe dizer - (Pronuncie em voz alta, bem articulada CREPFRA e lentamente). A resposta correta vale 1 ponto.

NEM AQUI, NEM ALI, NEM LÁ

\begin{tabular}{|l|l|}
\hline Conseguiu ( ) & Não conseguiu ( ) \\
\hline
\end{tabular}

C10) Dê ao idoso(a) uma folha de papel, na qual esteja escrito em letras grandes: FECHE OS OLHOS, diga-lhe:

Leia este papel e faça o que está escrito. (permita $10 \mathrm{seg}$ ).

\begin{tabular}{|l|l|}
\hline Fechou os olhos ( ) (1 ponto) & Não fechou os olhos （ ） (zero)
\end{tabular}

C11) Diga ao idoso(a):

Vou lhe dar um papel, e quando eu o entregar, pegue-o com a mão direita, dobre-o na metade com as duas mãos e coloque no chão. Anotar se acertou ( 1 ponto), errou (zero), ou não sabe (zero).)

\begin{tabular}{|l|l|l|l|l|}
\hline Pegue o papel com a mão & ( )acertou & ( )errou & ( )Não sabe \\
\hline
\end{tabular}




\begin{tabular}{|l|l|l|l|}
\hline direita & & & \\
\hline Dobre esse papel ao meio & ( )acertou & ( )errou & ( )Não sabe \\
\hline Ponha-o no chão & ( )acertou & ( )errou & ( )Não sabe \\
\hline
\end{tabular}

C12) Diga ao idoso(a):

$\mathrm{O}$ (a) $\mathrm{Sr}(\mathrm{a})$ poderia escrever uma frase completa de sua escolha?

Contar 1 ponto se a frase tem sujeito,verbo e predicado, sem levar em conta erros de ortografia e sintaxe, se ele(a) não fizer corretamente, pergunte-lhe: “Isto é uma frase?” e permita-lhe de corrigir se tiver consciência de seu erro (máx. 30 seg)

Pontuação

C13) Diga ao idoso(a):

Por favor, copie este desenho:

Mostre o modelo e peça para

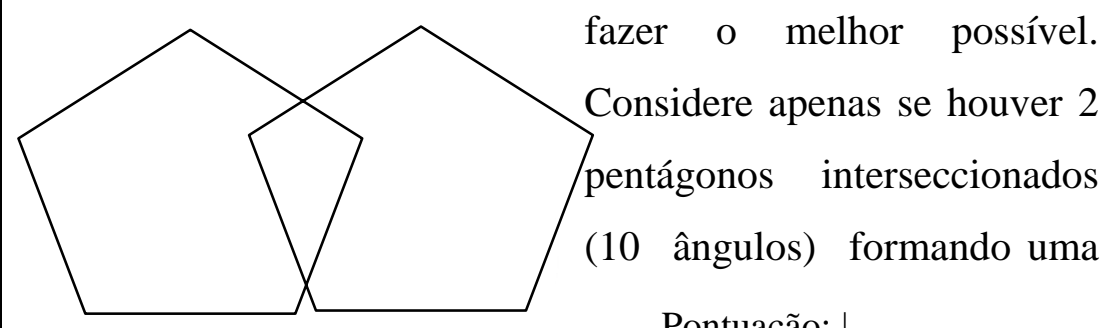
Pontuação: |

OBS: SOME AS RESPOSTAS

CORRETAS ANOTADAS NAS PERGUNTAS C3 A C13 E ANOTE O TOTAL. A PONTUAÇÃO MÁXIMA É DE 30. SE A SOMA FOR IGUAL A 12 OU MENOS, VERIFIQUE SE ALGUÉM QUE MORA NA MESMA RESIDÊNCIA PODE AJUDAR NAS RESPOSTAS. 


\section{ANEXO B - MEDIDA DE INDEPENDÊNCIA FUNCIONAL - MIF}

RIBERTO et al. Validação da Versão Brasileira da Medida de Independência Funcional. Acta Fisiatr 2004; 11(2): 72-76.

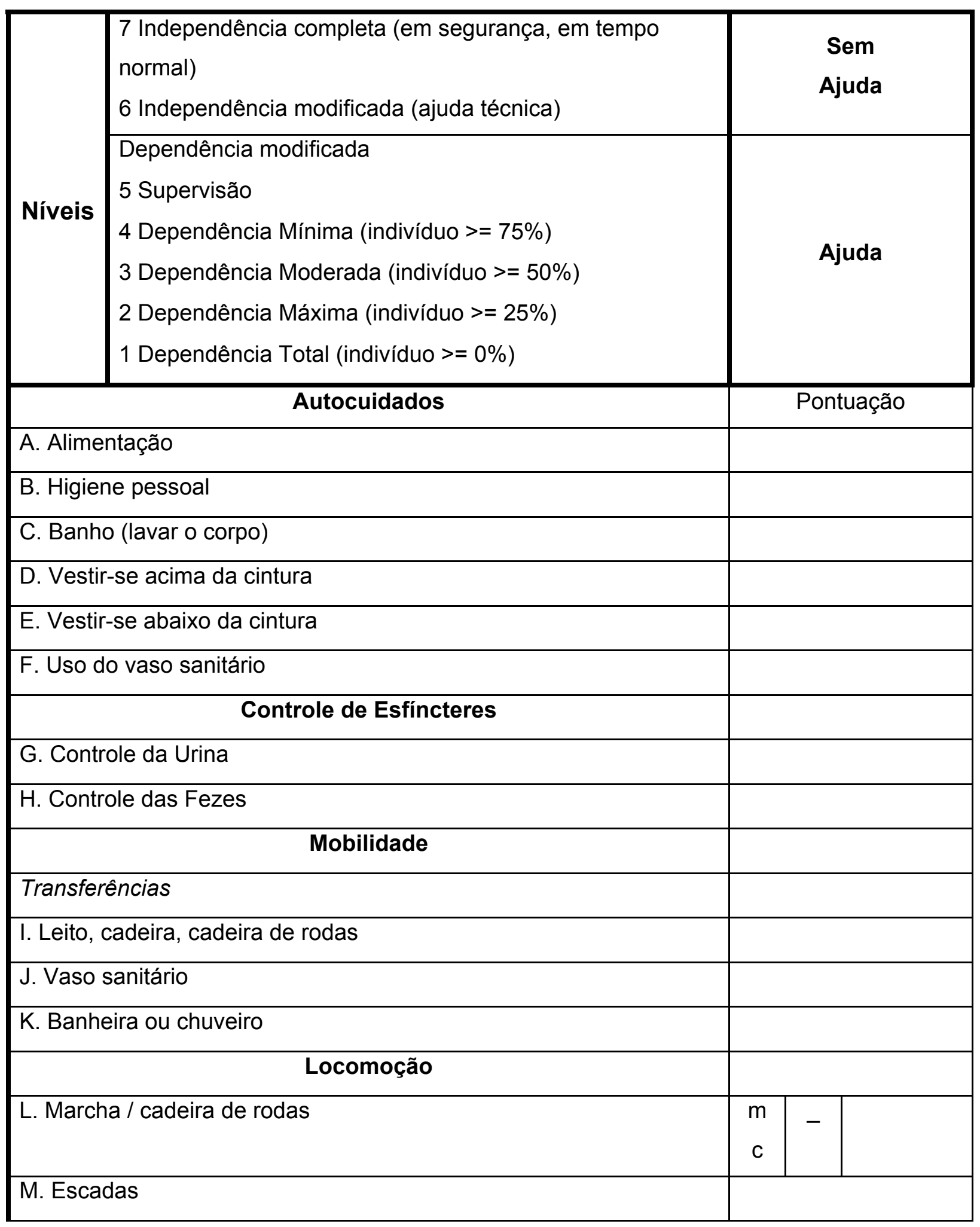




\begin{tabular}{|l|l|l|l|}
\hline \multicolumn{2}{|c|}{ Comunicação } & \multicolumn{2}{|l|}{} \\
\hline N. Compreensão & $\mathrm{a}$ & - & \\
& $\mathrm{v}$ & & \\
\hline O. Expressão & $\mathrm{v}$ & - & \\
\hline \multicolumn{1}{|c|}{ Cognição Social } & $\mathrm{n}$ & & \\
\hline P. Interação Social Total & & \\
\hline Q. Resolução de problemas & & \\
\hline R. Memória & & \\
\hline testado, marque 1 & \\
\hline Nota: Não deixe nenhum item em branco; se não for possível de ser & & \\
\hline
\end{tabular}

m=marcha; c=cadeira de rodas; $\mathrm{a}=$ =uditiva; $\mathrm{v}=$ =visual; $\mathrm{v}$ '=verbal; $\mathrm{n}=$ =não verbal Traduzido e adaptado por Riberto et al. 2001 
APÊNDICE B

INSTRUMENTO DE AVALIAÇÃO - CUIDADOR

\section{O.1 - CARACTERÍSTICAS DO CUIDADOR}

Nome:

Grau de parentesco:

Idade:

Sexo:

O.2) Estado conjugal:

1 - Nunca se casou ou morou c/ companheiro.

2 - Mora com esposo(a) ou companheiro(a)

3 - Sep.(a), desquitado(a) ou divorc(a)

4 - Viúvo(a)

$99-\mathrm{NS} / \mathrm{NR}$

O.3) Vive com o idoso: 1 - Sim 2 - Não

O.4) Escolaridade (em anos):

1- Analfabeto 2 - Sabe ler/escrever informal $\quad 3$ - 1 a $4 \quad 4$ - 5 a 8

5 - 9 a $12 \quad 6-13$ ou mais

$99-\mathrm{NS} / \mathrm{NR}$

O.5) É o cuidador principal ? 1- Sim

2- Não

OESTCIV

Para as questões 0.6 e O.7:

0 - não 1 - pouco e insuficiente 2 - pouco, mas suficiente

3 - bem $\quad 4$ - muito bem $\quad 99-$ NS/NR

\begin{tabular}{|l|l}
\hline O.6) CONSIDERA-SE INFORMADO EM RELAÇÃO À DOENÇA DO(A) & OINFORM
\end{tabular} PACIENTE?

O.7) CONSIDERA-SE INFORMADO EM RELAÇÃO A COMO CUIDAR DO (A)

OINFCUID PACIENTE?

O.8) TEVE CURSO INSTITUIÇÃO (FORMAL) PARA CUIDAR ?

0 - Não $\quad 1$ - Sim $\quad 99-$ NS/NR

O.9a)Qual:

O.10) TEVE ALGUM OUTRO TIPO DE TREINAMENTO?

0 - Não $\quad$ 1- Sim 99 - NS/NR

O.10a)Qual :

O.11) TEMPO DEDICADO, LEVANDO EM CONSIDERAÇÃO O ÚLTIMO MÊS.:

O.11a) Quantos dias da semana são dedicados para cuidar do idoso durante

ODIASEM a semana ( $2^{\mathrm{a}}$ feira a $6^{\mathrm{a}}$ feira): 


\begin{tabular}{|l|l|}
$\begin{array}{l}\text { O.11b) Quantos dias são dedicadas ao idoso, no fim de semana (Sábado e } \\
\text { Domingo): }\end{array}$ & ODIASFIM__ \\
\hline $\begin{array}{l}\text { O.11c) Quantas horas por dia são dedicadas ao idoso durante a semana (2 } \\
\text { f. a } 6^{\text {a }} \text { f.): }\end{array}$ & OHORSEM__ \\
$\begin{array}{l}\text { O.11d) Quantas horas por dia são dedicadas ao idoso, no fim de semana } \\
\text { (Sáb e Dom): }\end{array}$ & OHORFIM \\
\hline
\end{tabular}

\section{OI - APOIO AO CUIDADOR}

OI.11) Outro

OI.2) CONTA COM A AJUDA DE ALGUÉM PARA CUIDAR DO PACIENTE?

0 - não $\quad 1$ - às vezes $\quad 2$ - sempre/quase sempre 99 - NS/NR

OI..2a) Higiene Corporal :

OI.2b) Higiene Oral:

OI .2c) Eliminações:

OI .2d) Cuidados c/ a Pele:

OI .2e) Alimentação:

OI .2f) Medicação:

OI .2g) Sono e Repouso:

OAJHIGO

OI .2h) Atividade Física:

OAJELIM

OAJCUIPE

OAJALIM

OI .2i) Lazer:

OAJMEDIC

OI .2j) Serviço de Fisioterapia:

OAJSONO

OAJATFIS

OI .2k) Retornos às Consultas:

OAJLAZER

OAJFISIO

OI .2l) Outro:

OAJCONSU

OI .3) RECEBE OU RECORRE À AJUDA DE ENTIDADES ASSISTENCIAIS?

1 - sim 2 - não 99 - NS/NR

OI .3a) Igreja:

OI .3b) Grupo(Ong) de Apoio da Comunidade:

OI .3c) Grupo de Apoio (Instituição de Saúde):

OI .3d) Clubes (SESI/SESC/SENAC/SENAI):

OI .3e) Serviço de assistência social (pref./ estado):

OIGREJA

OCOMUNID

OGRUPSD

OCLUBE

OSERASSI

OI .3f) Outro Especificar: 


\section{ANEXO C}

\section{P. AVALIAÇÃO DO CUIDADOR - BURDEN INTERVIEW}

\section{Para as questões P.1 a P.21, as respostas são:}

0 -nunca 1 -raramente 2 -algumas vezes 3 -frequentemente 4 -sempre OBS: $\mathrm{S} *$ refere-se a quem é cuidado (usar o nome)

P.1 O Sr/Sra sente que S* pede mais ajuda do que ele(a) necessita?

P.2 O Sr/Sra sente que por causa do tempo que o Sr/Sra gasta com S, o Sr/Sra não tem tempo suficiente para si mesmo?

P.3 O Sr/Sra se sente estressado(a) entre cuidar de $\mathrm{S}$ e suas outras responsabilidades com a família e o trabalho?

P.4 O Sr/Sra se sente envergonhado(a) com o comportamento de S?

P.5 O Sr/Sra se sente irritado quando S está por perto?

P.6 O Sr/Sra sente que S afeta negativamente seus relacionamentos com outros membros da família ou amigos?

P.7 O Sr/Sra sente receio pelo futuro de S?

P.8. O Sr/Sra sente que S depende do Sr/Sra?

P.9 O Sr/Sra se sente tenso(a) quando S está por perto?

P.10 O Sr/Sra sente que a sua saúde foi afetada por causa do seu envolvimento com S?

P.11 O Sr/Sra sente que o Sr/Sra não tem tanta privacidade como gostaria, por causa de S?

P.12 O Sr/Sra sente que a sua vida social tem sido prejudicada porque o $\mathrm{Sr} / \mathrm{Sra}$ está cuidando de S?

P.13 O Sr/Sra não se sente à vontade de ter visitas em casa, por causa de S?

P.14 O Sr/Sra sente que S espera que o $\mathrm{Sr} / \mathrm{Sra}$ cuide dele(a), como se o $\mathrm{Sr} / \mathrm{Sra}$ fosse a única pessoa de quem ele(a) pode depender?

P.15 O Sr/Sra sente que não tem dinheiro suficiente para cuidar de S, somandose as suas outras despesas?

P.16 O Sr/Sra sente que será incapaz de cuidar de S por muito mais tempo?

P.17 O Sr/Sra sente que perdeu o controle da sua vida desde a doença de S?

P.18 O Sr/Sra gostaria de simplesmente deixar que outra pessoa cuidasse de S?

P.19 O Sr/Sra se sente em dúvida sobre o que fazer por S?

P.20 O Sr/Sra sente que deveria estar fazendo mais por $\mathrm{S}$ ?

P.21 O Sr/Sra sente que poderia cuidar melhor de S? K.4f) Outro

PAJUDA

PTEMPO

PESTRES

PENV

PIRRIT

PAFETA

PRECEIO

PDEP

PTENSO

PSAUDE

PPRIVAC

PSOCIAL

PVVISITA

PCUIDE

PDINH

PINCAPAZ

PPERDAC

POCUIDA

PDUVID

PFAZM

PCUIDAM 
especificar:

Para a questão $P .22$ a respostas são:

0 -nem um pouco 1 -um pouco 2 -moderadamente 3 -muito 4 -extremamente

P.22 De uma maneira geral, quanto o Sr/Sra se sente sobrecarregado(a) por cuidar de $\mathrm{S}$ ?

PSOBREC

Burden Interview (Zarit \& Zarit, 1987; tradução para o português: Márcia Scazufca, 2002) 


\section{ANEXO D}

Q. AVALIAÇÃO DO CUIDADOR - SELF REPORTING QUESTIONAIRE (SRQ)

Para as questões Q.1 a Q.20, as respostas são:

0 - não $1-\operatorname{sim}$

Q.1 Tem dores de cabeça frequentes?

Q.2 Tem falta de apetite?

Q.3 Dorme mal?

Q.4 Assusta-se com facilidade?

Q.5 Tem tremores nas mãos?

Q.6 Sente-se nervoso(a), tenso(a) ou preocupado(a)?

Q.7 Tem má digestão?

Q.8 Tem dificuldade de pensar com clareza?

Q.9 Tem se sentido triste ultimamente?

Q.10 Tem chorado mais do que de costume?

Q.11 Encontra dificuldades para realizar com satisfação suas atividades diárias?

Q.12 Tem dificuldades para tomar decisões?

Q.13 Tem dificuldades no serviço (seu trabalho é penoso, lhe causa sofrimento?

Q.14 É incapaz de desempenhar um papel útil em sua vida?

Q.15 Tem perdido o interesse pelas coisas?

Q.16 Você se sente uma pessoa inútil, sem préstimo?

Q.17 Tem tido a ideia de acabar com a vida?

Q.18 Sente-se cansado(a) o tempo todo?

Q.19 Tem sensações desagradáveis no estômago?

Q.20 Você se cansa com facilidade?

QDORES
QFAPET
QDORMEM
QASSUSTA
QTREM
QNERV
QMAD
QDIFIC
QTRIST
QCHORA
QDIFAVD
QDIFD
QDIFS
QPAPEL
QPERDIN
QSIN
QIVIDA
QCANS
QSENDES
QCANSAF _

Self Reporting Questionaire (SRQ-20) (HARDIN; ARANGO; BALTAZAR, 1980; tradução para o português: MARI E WILLIANS, 1986 
ANEXO E

CERTIFICADO DE APLICAÇÃO DA MIF

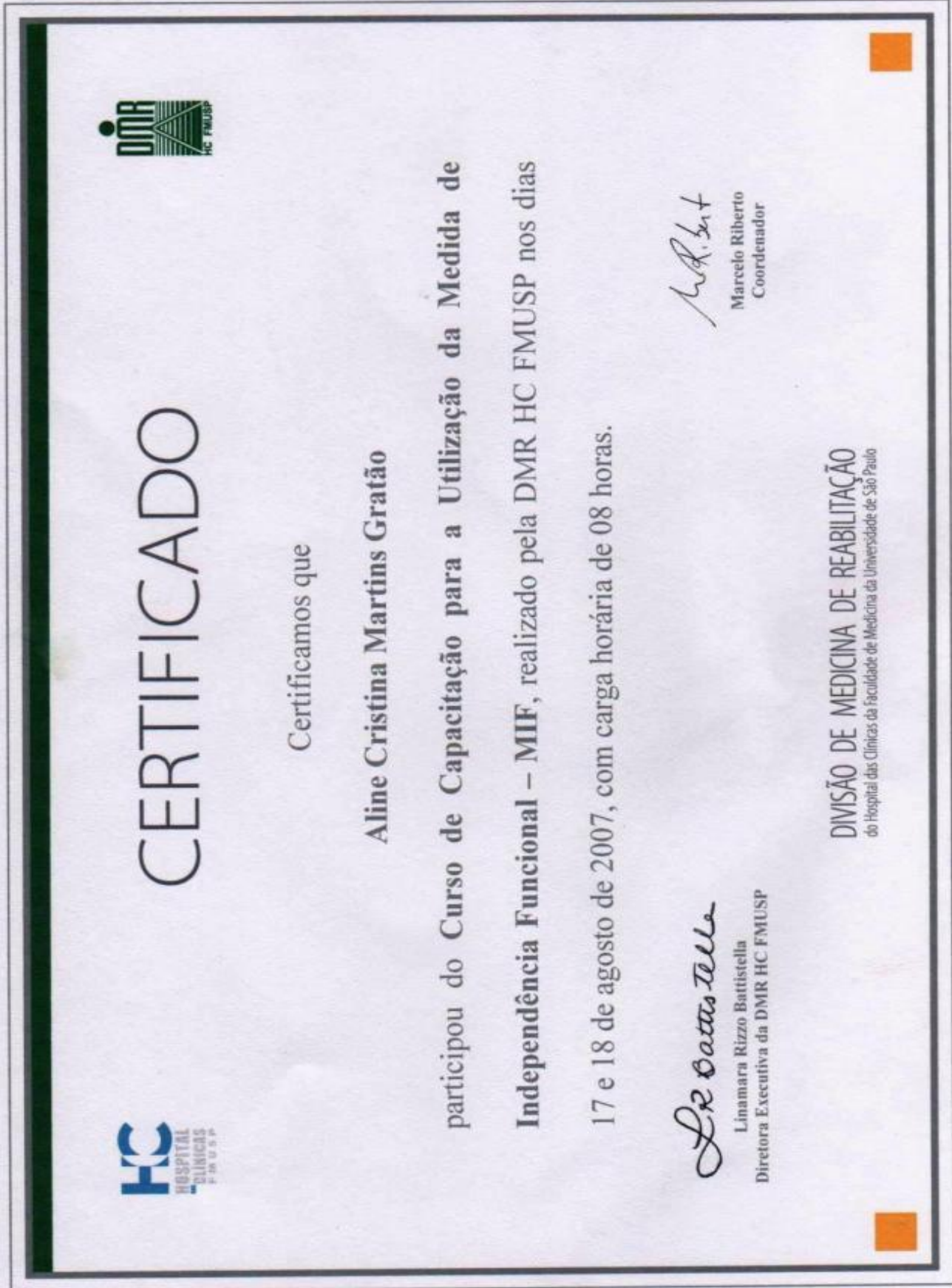




\section{ANEXO F \\ APROVAÇÃO COMITÊ ÉTICA}

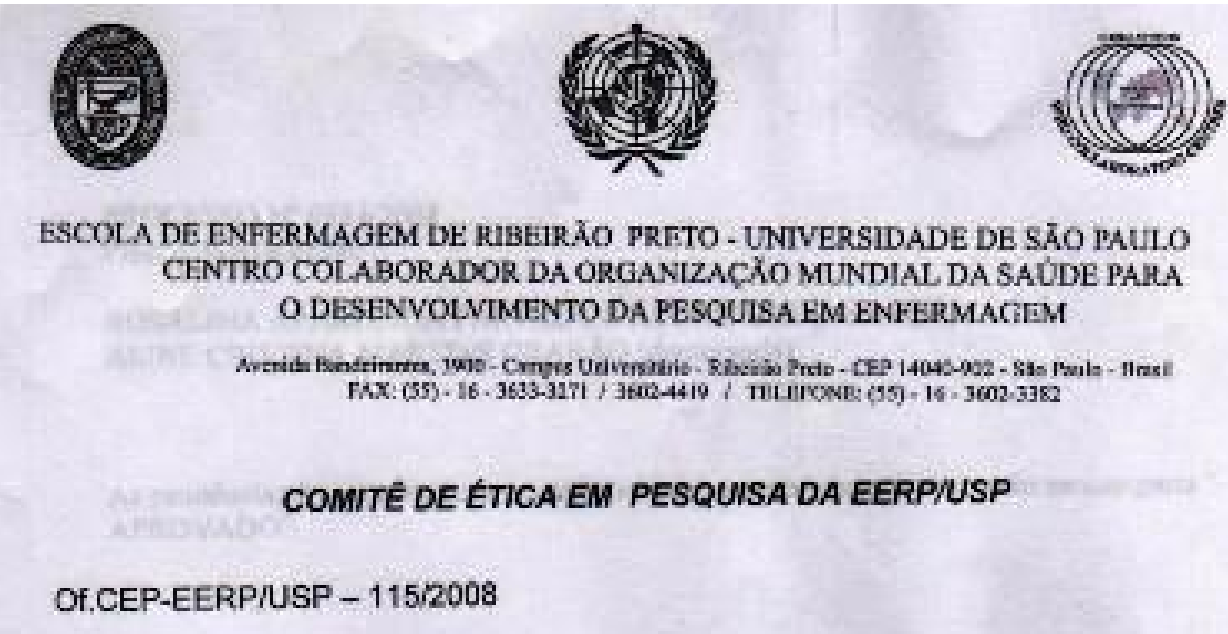

Ribeirăo Preto, 08 de maio de 2008

Prezada Senhora,

Comunicamos que o projeto de pesquisa, abaixo especificado. foi analisado e considerado APROVADO AD REFERENDUM pelo Comite de Ética em Pesquisa da Escola de Enfermagem de Ribeirâo Preto da Universidade de Sáo Paulo, em 08 de maio de 2008.

Protocolo:

$n^{\circ} 0884 / 2008$

Projeto:

AVALUACĀO DA SOBRECARGA EM CUIDADORES FAMILIARES DE IDOSOS COM DÉFICIT COGNITIVO.

Pesquisadores: Rcsalina Aparecida Partezani Rodrigues Aline Cristina Martins Gratēo

Em atendimento à Resoluçăo 196/96, deverá ser encaminhado ao CEP o relatório final da pesquisa e a publicaçalo de seus resultados, para acompanhamento, bem como comunicada qualquer intercorráncia ou a sua interrupçăo.

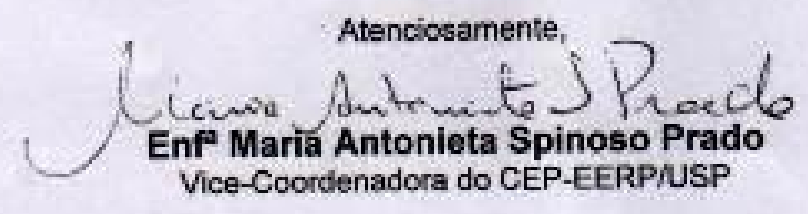

llma. Sra.

Prof' Dr" Rosalina Aparecida Partezani Rodrigues

Departamento de Enfermagem Geral e Especializada

Escola de Enfermagem de Ribeiráo Preto - USP 


\section{APÊNDICE C}

Data: Thu, 07 Sep 2006 05:48:16 -0300

De:scazufca@usp.br

Prezada Aline,

Parabens pelo seu mestrado. Acho muito importante que voce continue nesta linha de pesquisa. No Brasil ainda temos pouca informacao sobre as necessidades dos cuidadores. Com certeza voce pode usar a Burden Interviwe, nao tem problema nenhum. Seria interessante tambem fazer uma avaliacao de transtorno mental comum, usando uma escala que se chama SRQ. Assim voce pode ter uma medida no nivel de sintomas de ansiedade e depressão na sua amostra. E importante para se planejar inetervencoes.

No moneto estou trabalhando em Bristol, com bolsa de Pos doutorado do CNPq. Ainda nao aprendi a colocar acento nas palavras,desculpe!

Qualquer duvida por favor entre em contato.

Abs,

Marcia Scazufca

Citando Aline Cristina Martins Gratao <alinegratao@eerp.usp.br>:

> Cara Márcia!

> Venho por meio deste e-mail parabenizá-la, primeiramente, pelo importante

$>$ trabalho com cuidador de idoso. Eu defendi minha dissertação de mestrado

> pela Escola de Enfermagem de Ribeirão Preto/USP sob orientação da Prof. Dra

Rosalina Ap.Partezani Rodrigues em agosto/2006 e meu trabalho foi

$>$ relacionado a demanda do cuidado com idoso demenciado. Tenho intenção de

$>$ continuar nesta linha para o doutorado. Gostaria de saber sua opinião a

$>$ respeito de estar utilizando esta escala "burden interview" que vc validou

$>$ para o Brasil para avaliar a sobrecarga em cuidadores familiares de idosos

> demenciados na comunidade de Ribeirão Preto como projeto de doutorado.

$>$ Gostaria tbém de ter sua autorização.

>> Atenciosamente.

$>$

$>$ Aline Cristina Martins Gratão

> Escola de Enfermagem de Ribeirão Preto (http://www.eerp.usp.br) 


\section{APÊNDICE D}

Data: Mon, 11 Sep 2006 22:00:44 -0300

De:"Jair Mari" <jamari@attglobal.net>

Para: "Aline Cristina Martins Gratao" < alinegratao@eerp.usp.br>

Assunto: Re: autorização para utilização SRQ-20 rial. Jair Mari.

----- Original Message -----

From: "Aline Cristina Martins Gratao" < alineg

Legal Aline. Vou providenciar o envio do materatao@eerp.usp.br>

To: "Jair Mari" <jamari@attglobal.net>

Sent: Monday, September 11, 2006 12:22 PM

Subject: Re: autorização para utilização SRQ-20

CARO DR.JAIR;

OBRIGADA PELO RETORNO. GOSTARIA SIM DE RECEBER O MATERIAL, MEU

ENDEREÇO: RUA ADERCIA MACHADO GONTIJO, 125, APTO 12. BAIRRO:

RESIDENCIAL FLÓRIDA, CEP:14028-310. MAIS UMA VEZ OBRIGADA.

\section{ATENCIOSAMENTE}

On Mon, 11 Sep 2006 06:50:11 -0300, Jair Mari wrote

Aline,

Não muito prpblema em aplicar o SRQ. Se voce me enviar seu endereço posso enviar o material. Jair Mari.

----- Original Message -----

From: "Aline Cristina Martins Gratao" < alinegratao@eerp.usp.br>

To: <jamari@attglobal.net>; <rosalina@eerp.usp.br>

Sent: Thursday, September 07, 2006 5:23 PM

Subject: autorização para utilização SRQ-20

Prezado Dr. Jair;

Venho por meio deste e-mail solicitar autorização para aplicar instrumento

SRQ-20. Defendi minha dissertação de mestrado, cujo tema foi demanda do cuidador familiar com idoso demenciado, em agosto de 2006 pela Escola de Enfermagem de Ribeirão Preto/USP sob orientação da prof ${ }^{a}$ Dra Rosalina Ap. Partezani Rodrigues. Estou tentando o doutorado este ano na mesma linha de pesquisa, gostaria de avaliar cuidadores familiares de idosos demenciados na comunidade de Ribeirão Preto aplicando 2 instrumentos: Burden Interview Scale (já obtive autorização da Dra Marcia Scazufca) e o SRQ-20.

Atenciosamente.

Aline Cristina Martins Gratão.

Escola de Enfermagem de Ribeirão Preto (http://www.eerp.usp.br) 


\section{APÊNDICE E \\ TERMO DE CONSENTIMENTO LIVRE E ESCLARECIDO PARA IDOSO}

Título da Pesquisa: Avaliação da sobrecarga em cuidadores familiares de idosos na comunidade.

Pesquisador Responsável: Aline Cristina Martins Gratão. Enfermeira e aluna de doutorado pelo Departamento de Enfermagem Geral e Especializada - Escola de Enfermagem de Ribeirão Preto, Universidade de São Paulo.

Promotor da Pesquisa: Escola de Enfermagem de Ribeirão Preto - USP

Prezado(a) Senhor(a)

Vimos pedir sua colaboração em um estudo cujo objetivo é o de avaliar a memória e a capacidade funcional dos idosos na comunidade, caracterizar, descrever e avaliar a sobrecarga e o desconforto emocional de seus cuidadores familiares.

Solicitamos ao (a) Sr (a) autorização para realização de uma entrevista de aproximadamente 25 minutos, por um (a) entrevistador (a) devidamente identificado com avental branco e crachá da Escola de Enfermagem de Ribeirão Preto - USP. O Sr (a) deverá responder a um questionário, que além de ser composto por perguntas, ainda terá testes, cálculos e desenhos.

O (a) senhor (a) terá liberdade para se recusar a participar da pesquisa, podendo, inclusive, retirar-se da mesma em qualquer etapa e isso não trará nenhum prejuízo ao seu cuidado. Ainda, estará livre para deixar de responder às perguntas que possam lhe causar algum incômodo ou constrangimento.

Os nomes dos participantes da pesquisa não serão divulgados e não se espera causar desconfortos ou riscos para os entrevistados.

Essa pesquisa também não trará despesas, gastos ou danos para os entrevistados e, caso haja, serão ressarcidos.

Esperamos merecer sua confiança, colocamo-nos à disposição para qualquer informação adicional no telefone 3602-3416.

Atenciosamente,

\section{Aline Cristina Martins Gratão}

(pesquisadora)
Rosalina Ap. Partezani Rodrigues

(orientadora)

$\mathrm{Eu}$, declaro estar ciente das informações recebidas e concordo em participar desta pesquisa.

Ribeirão Preto, de de 20 


\section{APÊNDICE F \\ TERMO DE CONSENTIMENTO LIVRE E ESCLARECIDO PARA FAMILIARES/CUIDADORES}

Título da Pesquisa: Avaliação da sobrecarga em cuidadores familiares de idosos na comunidade.

Pesquisador Responsável: Aline Cristina Martins Gratão. Enfermeira e aluna de doutorado pelo Departamento de Enfermagem Geral e Especializada - Escola de Enfermagem de Ribeirão Preto, Universidade de São Paulo.

Promotor da Pesquisa: Escola de Enfermagem de Ribeirão Preto - USP

Prezado (a) Senhor (a)

Vimos pedir sua colaboração em um estudo cujo objetivo é o de avaliar a memória e a capacidade funcional dos idosos na comunidade, caracterizar, descrever e avaliar a sobrecarga e o desconforto emocional de seus cuidadores familiares.

Solicitamos ao (a) Sr (a) autorização para realização de uma entrevista de aproximadamente 25 minutos, por um (a) entrevistador (a) devidamente identificado com avental branco e crachá da Escola de Enfermagem de Ribeirão Preto - USP. O Sr (a) deverá responder a um questionário, que além de ser composto por perguntas, ainda terá testes, cálculos e desenhos.

O (a) senhor (a) terá liberdade para se recusar a participar da pesquisa, podendo, inclusive, retirar-se da mesma em qualquer etapa e isso não trará nenhum prejuízo ao seu cuidado. Ainda, estará livre para deixar de responder às perguntas que possam lhe causar algum incômodo ou constrangimento.

Os nomes dos participantes da pesquisa não serão divulgados e não se espera causar desconfortos ou riscos para os entrevistados.

Essa pesquisa também não trará despesas, gastos ou danos para os entrevistados e, caso haja, serão ressarcidos.

Esperamos merecer sua confiança, colocamo-nos à disposição para qualquer informação adicional no telefone 3602-3416.

Atenciosamente,

Aline Cristina Martins Gratão

(pesquisadora)

$\mathrm{Eu}$,

informações recebidas e concordo em participar desta pesquisa.
Rosalina Ap. Partezani Rodrigues

(orientadora)

declaro estar ciente das

Ribeirão Preto, de de 20 